\title{
THE INTERNAIIONAL
}

REVIEW OF RESEARCH IN

OPEN AND DISTANCE LEARNING

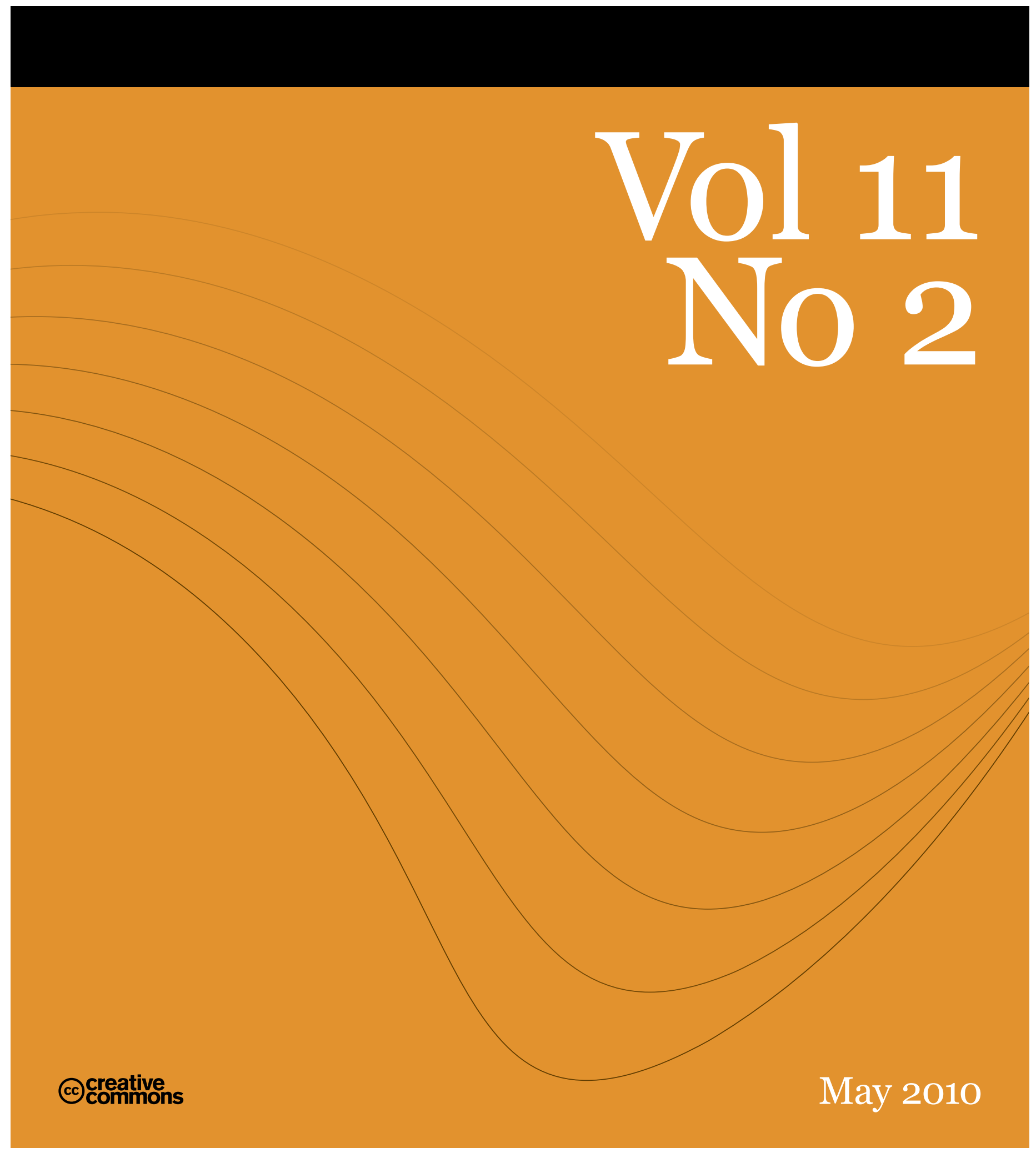




\section{Editorial}

\section{Terry Anderson}

Editor, IRRODL

We are pleased to present another extensive issue of IRRODL, which features five research articles, one field note, two book reviews, two technical reports, and two transcripts from recent CIDER sessions. In this editorial, I briefly review the contents of the issue, with a hope that you are induced to read, bookmark, recommend, and forward the links and the RSS feeds to your colleagues and your networks.

The first research article by Patrick Parrish and Jennifer Linder-VanBerschot is entitled "Cultural Dimensions of Learning: Addressing the Challenges of Multicultural Instruction" and focuses on the important role of culture in the design and delivery of distance programming. As an international journal, we are acutely aware of the mediating effect of culture on journal publication, but its importance to education, with high stakes and often high costs, can not be overlooked nor minimized.

The second article focuses on an equally critical component of distance education programming cost effectiveness. In "Unbundling Faculty Roles in Online Distance Education Programs," authors Jan Tucker and Patricia Neely help us sort out the true costs of program development and delivery under different models of faculty responsibility and employment.

The third research article, "Process-Based Assessment for Professional Learning in Higher Education: Perspectives on the Student-Teacher Relationship" by Peter Bergström, reports on a mixed methods doctoral dissertation study of the complex relationships between students and teachers in a professional nursing program.

Paul Gorsky, Avner Caspi, Avishai Antonovsky, Ina Blau, and Asmahan Mansu next bring us, once again, to the fascinating study of interactions, as revealed in the transcripts of computer conferences produced by distance education students. In this study, "The Relationship between Academic Discipline and Dialogic Behavior in Open University Course Forums," the researchers examine differences in dialogic behaviour between postings by 
students in the humanities and in the sciences. They use the popular community of inquiry model to analyze teaching, cognitive, and social presence differences.

Distance education has, by definition, always involved shifting geographic spaces, but it can also involve shifting time as in shorter, longer, or self-paced courses. In the final research study, "Length of Online Course and Student Satisfaction, Perceived Learning, and Academic Performance," researchers Janet Ferguson and Amy DeFelice provide the results of a quasi-experimental comparison between shorter and longer courses - with interesting results!

The Field Notes section contains an interesting account of the challenges and affordances of distance education in an African context. In "The Challenges of Implementing Distance Education in Uganda: A Case Study," authors Gudula Naiga Basaza, Natalie B. Milman, and Clayton R. Wright detail the many challenges faced by Ugandan educators but, as importantly, suggest three strategic directions to meet these challenges.

In the Book Notes section, Nataly Tcherepashenet's review of Learning Cultures in Online Education by Robin Goodfellow and Marie-Noëlle Lamy (2009) returns to the critical theme of culture in distance education. Ramesh Sharma's review of Perspectives on Distance Education: Open Schooling in the 21st Century by Dominique Abrioux, former Athabasca University president, and F. Ferreira overviews the increasingly critical contribution of distance education in providing access, flexibility, and opportunity for school-aged learners.

Dr Jon Baggaley and his students in the Master of Distance Education program at Athabasca University provide two technical reports for this issue. The first is an excellent report by Tanya Elias, "Universal Instructional Design Principles for Moodle," which evaluates the capacity of a typical Moodle-based course to meet the inclusivity guidelines of universal design. The second report, "Thirty Years of Distance Education: Personal Reflections" by Terralyn McKee, examines distance education systems through the lens of the five generations of distance education technology proposed by James Taylor.

Finally, the slides and web conference transcripts of two CIDER sessions are included. The first presentation by Geoffrey Roulet, "Message Interactions in Online Asynchronous Discussions: The Problem of Being Too Nice," looks at the extent (or lack) of critical dialogue in web conferences. In the second recording, I present an overview of three generations of distance education pedagogy, which moves us from defining distance education generations by the technology used to deliver it and brings us back to a pedagogical orientation. 
I am sure you will agree that there is a great deal to learn from in this extensive and wideranging issue. We hope you will enjoy, learn from, and share these insights.

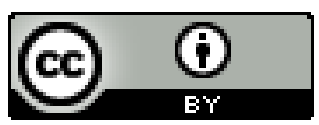




\title{
Cultural Dimensions of Learning: Addressing the Challenges of Multicultural Instruction
}

\author{
Patrick Parrish \\ The COMET Program, USA \\ Jennifer A. Linder-VanBerschot \\ University of New Mexico, USA
}

\begin{abstract}
The growing multicultural nature of education and training environments makes it critical that instructors and instructional designers, especially those working in online learning environments, develop skills to deliver culturally sensitive and culturally adaptive instruction. This article explores research into cultural differences to identify those dimensions of culture that are most likely to impact instructional situations. It presents these in the cultural dimensions of learning framework (CDLF), which describes a set of eight cultural parameters regarding social relationships, epistemological beliefs, and temporal perceptions, and illustrates their spectrums of variability as they might be exhibited in instructional situations. The article also explores the literature on instructional design and culture for guidelines on addressing the cross-cultural challenges faced by instructional providers. It suggests that these challenges can be overcome through increased awareness, culturally sensitive communication, modified instructional design processes, and efforts to accommodate the most critical cultural differences. Finally, it describes the use of the CDLF questionnaire as a tool to illuminate the range of preferences existing among learners and to discover the potential range of strategies and tactics that might be useful for a given set of learners.
\end{abstract}

Keywords: Distance education; online learning; pedagogy; multicultural education

\section{Why Multicultural Education and Training is a Growing Concern}

Numerous factors are converging that make teaching and learning in cross-cultural and multicultural contexts more commonplace. Expanding world trade and globalization of industry, finance, and many professions are creating a world in which cross-cultural interactions occur more frequently than at any time in the past (Friedman, 2007). As well, increasing specialization within many professions has led to a widely dispersed audience for targeted education and 
training. Professionals wishing to stay current or students wanting to develop specialized skills that match the needs of a rapidly changing world demand access to proper educational opportunities, even if this requires international travel or distance learning approaches (Berge, 2007). Simpler and cheaper telecommunications, in particular, fuel a growing willingness to teach and learn across cultures. Advances in Internet technologies and applications make open and distance learning a fully viable alternative to traditional education, creating a natural environment for the development of effective virtual learning communities.

But contrary to the growing flatness that Friedman (2007) reports, cultural diversity remains apparent among learners, perhaps owing to deeply rooted cultural values and modes of thinking that are difficult to separate from learning processes (Nisbett, 2003). A growing appreciation of cultural diversity is demonstrated by more than its acknowledgement and tolerance, but also by a desire to preserve that diversity as a valuable asset for addressing the many challenges faced by the global community now and in the future. Additionally, one can recognize a strong desire to preserve diversity in response to the threat of loss of cultural identity in the face of globalization and because of the benefits of community cohesiveness through unique cultural expression (Mason, 2007).

The growing need for educational access leads students rightly to demand culturally adaptive learning experiences that allow full development of the individual (Visser, 2007). As noted by Pincas (2001), students entering into professional education in a multicultural context not aligned with their own culture can experience significant conflict. This conflict arises not only in regards to incompatible teaching and learning styles, but also because the growing "professional self" struggles to maintain both a connection to the local culture in which the student eventually intends to work and a connection to the learning environment. Accordingly, instructional providers, including instructors and instructional designers, especially those working in online environments and struggling to maintain sufficient presence and student engagement, should develop skills to deliver culturally sensitive and culturally adaptive instruction (Gunawardena \& LaPointe, 2007). This article provides a summary and consolidation of useful existing literature to aid in developing these skills. Although culture has begun to be addressed in the field of Instructional System Design (ISD), it is still too often overlooked or undervalued (Henderson, 1996; Rogers, Graham, \& Mayes, 2007; Thomas, Mitchell, \& Joseph, 2002; Young, 2007). If education and instructional design are inherently social processes (Schwier, Campbell, \& Kenny, 2004), then instructional providers can no longer take a neutral position in developing their courses and materials. For instruction to do the most good for students, instructional providers must be cognizant of the cultures of their learners and how those cultures manifest themselves in learning preferences (Nisbett, 2003).

Cultural sensitivity is not just one-way, however. Instructional providers should be acutely aware of their own culture because their world views cannot be separated from the training that they develop (Thomas, Mitchell, \& Joseph, 2002). They should become cognizant of how their own cultural perspectives are represented in the design decisions they make. Furthermore, instructional providers should examine the assumptions they hold about how learners will and should respond, keeping an open mind for potentially unexpected responses. Moreover, they must 
balance the need to help students adapt to specific professional, academic, and mainstream cultures (which instructors, by proxy, represent) and the need to embrace the culture in which the student is embedded (Henderson, 1996). This is no small challenge.

\section{Sources of Thinking and Behavior}

The sources of influence on thinking and behavior can be seen as existing at several levels, including human nature, culture, and personality (Hofstede \& Hofstede, 2005). When people demonstrate differences or similarities, it is easy to confuse these levels because their influences combine, making them difficult to distinguish. The resulting uncertainty can lead to false assumptions and difficulties in interactions with others. This is just as true in education and training as it is in other life situations.

Hofstede and Hofstede (2005) present these levels as a pyramid, with human nature as the base all people share, and personality as the peak, being unique to the individual. Culture forms an expansive middle portion of the pyramid, reflecting its multiple layers of group interactions (e.g., from national to local community). The authors have chosen to represent these influences differently in Figure 1 to highlight an increased complexity and to emphasize the nature of these constructs as mutually influencing sources of thought and behavior.

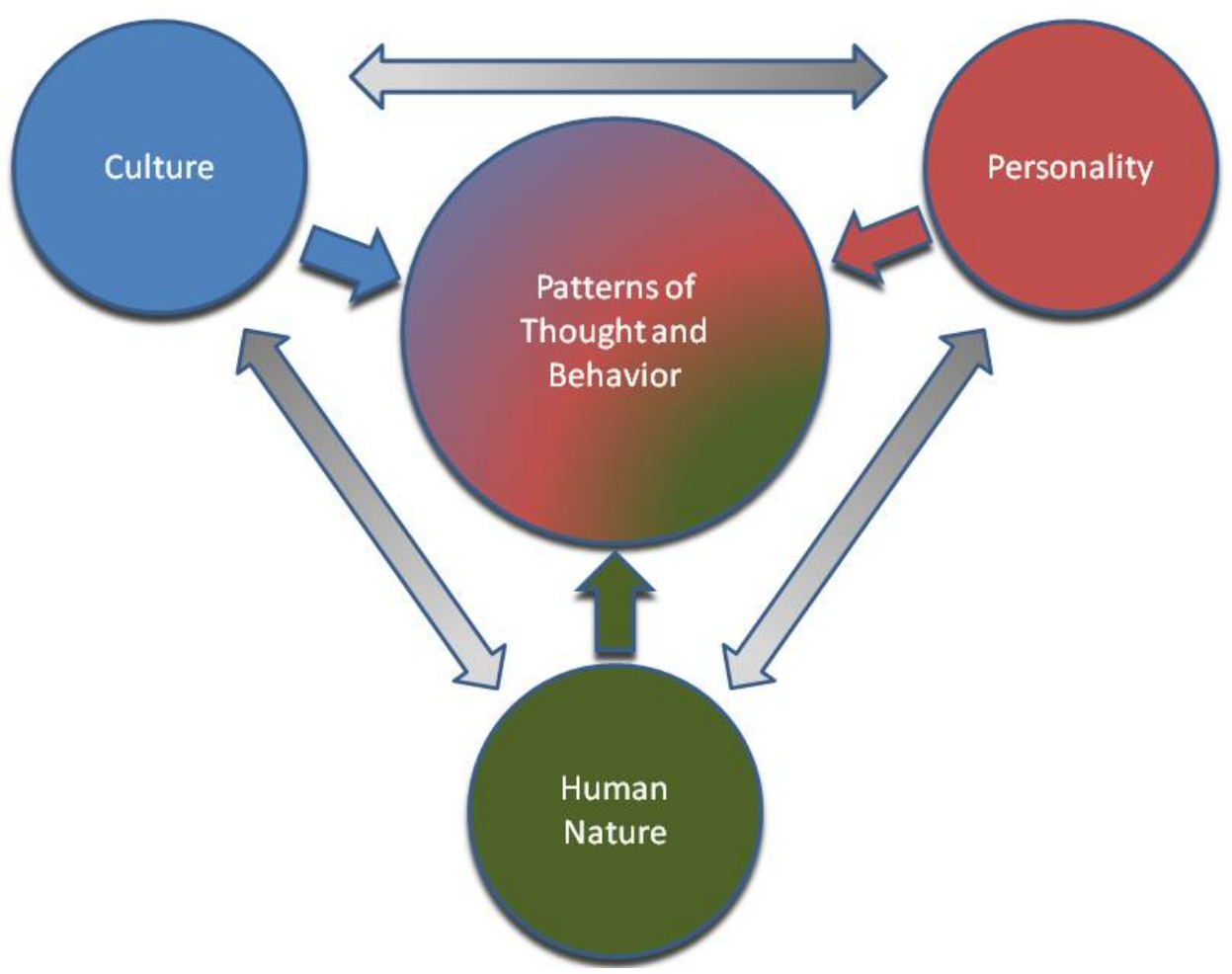

Figure 1. Sources of thought and behavior and their interactions. 
Human nature comprises the assumed commonalities all humans share because they are members of the same species - Homo sapiens. People inherit these ways of thinking and behaving because they result from our genetic makeup and the constraints this places on how they respond to the world. These constraints come in the form of sensory capabilities and other physiological traits, as well as predispositions toward socialization, for example. Of course, the human genetic stream diverges and re-converges over time, so the concept of "species" itself is imperfect. But one can, in practice, see commonalities across the human species. Culture includes those ways of thinking and behaving that are taught by social groups, including family, friends, community, and work colleagues, developed through direct interaction but also through exposure to media (Hofstede \& Hofstede, 2005). Among many other things, culture includes,

... how people express themselves (including shows of emotion), the way they think, how they move, how problems are solved, how their cities are planned and laid out, how transportation systems function and are organized, as well as how economic and government systems are put together and function. (Hall, 1981, pp. 16-17)

Cultural preferences are strongly embedded because humans are highly social creatures with strong needs to fit within our groups. There are many layers of culture, from work and family cultures to community and regional cultures up to national and even international cultures based on shared heritage and language. Culture is learned but is also constrained by human nature.

Unlike human nature, which is inherited, and culture, which is learned, personality is both learned and inherited. Individuals within cultures vary in ways that are as dramatic as the variations across cultures, and one can map similar personality variations across different cultures. This suggests that personality is in part a reflection of the natural variability within human nature and cuts across cultures. But, also, there is no one-to-one correspondence of personalities across cultures due to the blend of cultural and natural influences on personality. Some discernable personalities and even some emotions may be culturally unique (Kitayama \& Markus, 1994).

Together, culture and human nature have a monumental influence on individual personalities, yet people are also willful and creative in their responses to the world, frequently stretching or transcending their natural and cultural inclinations. And even though they are products of their cultures, some individuals ultimately have a profound influence on their cultures; consider the ongoing influence that individuals like Confucius or Plato have had on civilizations over thousands of years. Through processes of natural selection, individuals and cultures may even be seen as influencing human nature over time. In this way, even human nature is in a sense "learned."

Of course, one doesn't have to postulate a person as influential as Confucius to demonstrate the nature of culture as changing through the influence of individuals and groups. Deep-rooted as culture may be, a description of any culture is merely a snapshot of a continually evolving matrix of beliefs, values, and behaviors developed through the creative interactions of its constituents as 
well as through interactions and clashes with other cultures. In addition, while culture is reflected in arts and technologies, it is also influenced by them. The fact that culture is created by the accumulation of historical experience is well acknowledged in education literature through its embrace of cultural-historical activity theory (Cole, 1996).

However, the inevitability of cultural evolution does not suggest that how practitioners carry out cross-cultural interactions in instruction is unimportant. (One might ask, "Why work to preserve culture that will change anyway?”) On the contrary, in this article we argue that respect for preservation of culture is an important value for instructors and instructional designers to hold because they are clearly in the position of social agents having substantial influence on their learners (Schwier, Campbell, \& Kenny, 2004). In other words, prioritizing culture in education and training goes beyond wanting to be effective in promoting knowledge acquisition. It is also an ethical concern.

Fundamentally, when we teach, we are teaching culture. Knowledge, skills, and attitudes are all manifestations of culture and are not somehow immune to it. Moreover, when we teach, we are passing along not only what we know, but how we come to know it as well as the basis for accepting it as useful knowledge, and the values these represent. Teaching and learning are not only embedded in culture, they are cultural transmission in action - the means to culture. In multicultural settings, in particular, this leads to the conundrum posed in the first section that educators must take responsibility to both acculturate students and in the process avoid cultural bias that could impede instructional goals. Potential approaches to this challenge are posed in the upcoming sections.

\section{A Framework for Cultural Differences}

The cultural dimensions of learning framework (CDLF) (Table 1), adapted from the work of Hofstede and Hofstede (2005), Nisbett (2003), Levine (1997), Hall (1983), and Lewis (2006), is useful for understanding the spectrum of cultural differences that impact the teaching and learning enterprise. Where individuals fall along these dimensions impacts both how instructional providers approach their roles and how students view their own roles and expected behaviors. The dimensions do not describe either/or conditions but spectrums along which both cultures and individuals vary. Accordingly, no end of the spectrum should be unrecognizable to the reader, regardless of cultural background. Because humans share a common nature, each person is capable of the entire range of thoughts and behaviors that can arise along each of the dimensions. Research shows that cultural differences can be usefully described along these dimensions but that within any culture individuals will differ in how strongly they display these tendencies.

This framework differs in scope from the framework offered by Reeves (1992), as cited by Henderson, (1996), which begins from the perspective of pedagogical differences; however, the frameworks reach many of the same conclusions. The CDLF touches upon nearly all the dimensions described by Reeves but includes several new dimensions due to its broader starting point and the benefit of new research performed in the intervening years. It also describes these cultural dimensions in more detail. Even so, the CDLF does not pretend to address all potential 
cultural dimensions that might be useful to consider. For example, gender roles and differences in non-verbal communications are treated only indirectly. Cultural complexity and the fundamental role of education and training in the transmission of culture make a comprehensive framework impractical to describe in a single article.

In presenting their model of cultural dimensions, Hofstede and Hofstede (2005) discuss the difference between values and practices as layers of culture. In their terms, cultural values are acquired early in life and are the deepest and most enduring aspects of culture. Cultural practices, on the other hand, are the superficial rituals and norms that are more easily observed. While practices may be reflections of cultural values, they are more subject to change. The most superficial practices are not inevitable outcomes of values; they are often mere trappings that can change without challenging underlying values. In this framework, the eight cultural dimensions represent values. Consequently, the manifested learning behaviors described are more than superficial practices. Instead, they are direct reflections of values, and challenging them may conflict with those underlying values. More research specifically focused on cultural aspects of learning environments is required before this claim can be asserted with full confidence, although compelling research already exists for many of the aspects (e.g., Nisbett, 2003).

The descriptions of eight key cultural dimensions in the CDLF are offered so that culturally based learning differences can be recognized when they manifest themselves. It is not suggested that each of the dimensions needs to be considered and addressed in every instructional design project. However, those involved in a large multicultural instructional undertaking for the first time may find it useful to study the framework to prepare for the potential differences they might encounter among learners. Parrish and Linder-VanBerschot (2009a) offer a survey on culturally based learning preferences, derived from the CDLF, which can also aid in the analysis phase of projects or in the early phases of a course.

Another important use of the CDLF is as a tool for instructional providers to understand better their own cultural biases and to account for them in their practice. Recognizing that one's beliefs and behaviors fall along a spectrum of differences can help increase flexibility in instructional approaches and create stronger empathy for learners. However, because the framework, even with its numerous dimensions, does not begin to capture the cultural diversity that actually exists, unanticipated differences are likely. Note that while no attempt is made here to classify cultures according to these dimensions, the works cited provide substantial demonstration of how specific national and regional cultures vary. This article instead stresses the spectrums of variability rather than the generalized differences between cultures. 
Table 1

The Cultural Dimensions of Learning Framework

\section{Social Relationships}

\section{Cultural dimension Equality and authority}

How is inequality handled? How is status demonstrated and respect given? What interactions are appropriate for those of unequal status?

(Hofstede \& Hofstede, 2005;

Lewis, 2006)

\section{Individualism and collectivism}

Which prevails, the interests of the individual or the interest of the group? To what degree are interpersonal relationships valued?

(Hofstede \& Hofstede, 2005; Nisbett, 2003)

\section{Nurture and challenge}

Which is the more important set of goals, cooperation and security or recognition and advancement? Which achieves better learning outcomes, supportive acts or challenging acts?

(Hofstede \& Hofstede, 2005)

How this dimension is manifested in learning situations More equality More authority

Teachers treated as equals to be engaged and even challenged

Students take responsibility for learning activities

Teachers are solely responsible for what happens in instruction

Dialogue and discussion are critical learning

The teacher is the primary communicator activities

\section{More individualistic}

Expectation that students speak up

Learning how to learn (cognitive skill) is primary (individual growth)

Expression of student's point of view is valuable component of learning

Hard work is motivated by individual gain

\section{More nurturing}

Average is used as the norm

All students are praised

Collaboration is cultivated

Failure is a growth opportunity

More modesty

Seek good relationships and security

\section{More collectivist}

Students speak up in limited situations

Learning how to do (content knowledge) is primary (social growth)

Student expected to accommodate teacher's point of view

Hard work is motivated by the greater good

\section{More challenging}

Best student is used as the norm

Only excellence is praised

Competition is cultivated

Failure is a highly discouraged, and can be considered disastrous

More assertiveness

Seek challenge and recognition 


\section{Epistemological Beliefs}

\section{Cultural dimension Stability seeking and uncertainty acceptance} How is uncertainty dealt with? Is it avoided or accepted? Is structure assumed more important than flexibility? What is the status of knowledge - established or in a process of development? (Hofstede \& Hofstede, 2005; Nisbett, 2003)

\section{Logic argumentation and being reasonable}

How are arguments developed? Which is more important, logical consistency or practical outcomes? How is disagreement managed?

(Nisbett, 2003)

\section{Causality and complex systems (Analysis and holism)} How is causality assigned typically? Is it assigned to a single, most likely source, or is it assigned to the broader context? (Nisbett, 2003)
How this dimension is manifested in learning situations

\begin{tabular}{|c|c|}
\hline More stability seeking & More uncertainty acceptance \\
\hline Structured learning activities & $\begin{array}{l}\text { Learning activities more open-ended (discussions, } \\
\text { projects) }\end{array}$ \\
\hline Focus on getting right answers & Focus on process and justified opinions \\
\hline Ambiguity to be avoided & Ambiguity is a natural condition \\
\hline Teachers expected to have the answers & Teachers can say “I don’t know” \\
\hline Single textbooks or teacher authority & Many resources used \\
\hline $\begin{array}{l}\text { Luck is a factor in student success (e.g., guessing } \\
\text { the right things to study for the test) }\end{array}$ & $\begin{array}{l}\text { Demonstrated ability to think is the key to } \\
\text { academic success, not right answers }\end{array}$ \\
\hline More stressed & Less stressed \\
\hline
\end{tabular}

\section{More logical \\ Focus on logical argumentation to find truth \\ Insistence on single truths based on logical reasoning}

Debate/argumentation is a learning activity

Being right is most important

Willingness to challenge others when the teacher/students are presumed wrong or being

.
inconsistent

\section{More reasonable}

Focus on achieving practical and socially acceptable outcomes

Acceptance of multiple truths based on experience

Consensus building is a learning activity

Being virtuous is most important

Acceptance of contradictions for the sake of continuing, harmonious dialogue

\author{
More focus on causality \\ More goal orientation expected of learners \\ Knowledge tied to cause-effect explanations \\ Focus on stable knowledge and rules \\ Learning success or failure attributed to student \\ characteristics
}

\section{More focus on systems and situations}

More willing to work within situational constraints

Knowledge tied to explanations of systems and situations

Focus on evolving and situational knowledge

Learning success or failure attributed to the situation 


\section{Temporal Perceptions}

\section{Cultural dimension \\ Clock time and event time}

Do people conform to an external measure of time, or do they allow the event at hand to unfold on its own time? Which are more important, deadlines or relationships?

(Levine, 1997)

\section{Linear time and cyclical time}

Do people see time as a path and see goals as necessary destinations, or do they see time as a pattern of interlocking cycles into which they step in and out over the course of a life? (Hall, 1983; Lewis, 2006)

\section{How this dimension is manifested in learning situations}

\section{More clock focus}

Instructional activities start and stop promptly

Meetings outside of class time are limited to strict

schedules

Strict deadlines and consequences for missing them

Likes procedures

Learners work quietly toward planned ends

\section{More event focus}

Instructional activities are allowed to continue as long as they are useful

Boundaries between class and outside class time more fluid

Work continues toward improvements with less regard for deadlines

Willing to bypass procedures

Learners are talkative and expressive and may ignore plans

\section{More cyclical time}

One adapts to time
Time is to be managed

Learning proceeds along a linear path with clear prerequisites and milestones

Goal setting is essential to learning

Time is not to be wasted, actions should be quick and decisive if one cares about achievement

Opportunities are not to be wasted. Chances don't present themselves twice

The past is irrelevant. Future goals are what are important.

Repetition can be seen as a being in a "rut" (not progressing)

Students want to see immediate relevance
Learning is seen as practice toward slowly increasing perfection

Goals are secondary, one adapts to the situation to draw from it as much as possible

Time exists for observation and reflection, rushing is counter-productive to achievement

Because time is a series of cycles, opportunities recur. When they do, one may make wiser decisions

The past is influential since cycles repeat. One carries the past forward.

Repetition is valuable for learning

Students may be more patient to discover relevance 


\section{Cross-Cultural Challenges for Instruction}

People make false assumptions when they attribute ways of thinking and behavior to the wrong source of influence (human nature, culture, or personality). They may wrongly assume that a particular behavior is a manifestation of personality, perhaps making a value judgment about that individual, when the behavior is actually driven more from the cultural level. Conversely, they may over-generalize conclusions about a particular culture from a few individuals when actually their behaviors are strongly personality driven. Perhaps the most common false assumption is when people take their own cultural ways of thinking and behaving as representative of human nature and therefore the "right" way to think or behave. For example, instructional providers may assume that they need to teach those from other cultures to adopt new learning behaviors to think and learn properly. The CDLF may aid in avoiding such false assumptions.

Humans are highly adaptable, and the situational influences on thought and behavior are significant (Lemke, 1997). So observing how a person behaves in one situation is not necessarily indicative of how they will behave in another. In addition, people are able to compensate for their cultural conditioning when they find themselves participating in another culture by adopting the behaviors they begin to see as appropriate to that culture. These cases can also lead to additional false assumptions that are more difficult to avoid.

The unique challenge for instructional providers is to understand which learning behaviors are based on deeply entrenched cultural values that should not be challenged and which behaviors are more superficial practices that can be challenged for the sake of promoting learning. In addition, other challenges include (a) accepting that research-based instructional strategies are also culturebased and may be at times inappropriate, (b) knowing which instructional activities will be most effective for a particular group of students, and (c) deciding how instructional strategies should be adapted in cross-cultural and multicultural situations. The existing literature that will aid in addressing these challenges is growing but still limited.

\section{Addressing the Challenges of Multicultural Education and Training}

Many of the challenges to practicing education and training in multicultural contexts have been put forth in the preceding pages with few direct recommendations for changing practice. The challenges, restated more succinctly, are these:

1. Understanding and appreciating the cultural differences of students in order to make the appropriate instructional decisions that will enhance their learning;

2. Becoming aware of one's own cultural preferences for what they are and not assuming they represent the "right" way to think;

3. Determining which student behaviors represent cultural values and are therefore less prone to modification to accommodate the instructional situation;

4. Accepting the dual responsibility of educators to acculturate and respect individual student cultural backgrounds; and 
5. Accepting that research-based instructional strategies are also culture-based and therefore may be at times inappropriate or in need of adaptation.

The CDLF can be used to help address the first three challenges. Challenges 4 and 5 require additional effort toward a reflective practice that the CDLF also indirectly encourages and, hopefully, stimulates. This section summarizes several additional ideas and perspectives that can lead to effective multiculturally sensitive practice.

\section{Awareness}

Instructional providers must become more knowledgeable about the cultural differences existing among the learners they serve. With an unpredictable learner population in most settings, perhaps especially in open and distance learning settings, instructional providers can no longer make overarching judgments about the demographics of their learners before having the opportunity to interact with them (Lea \& Goodfellow, 2003). Therefore, instructors and IDs should carefully consider the learner population during the analysis phase of any instructional design or planning effort (Edmunson, 2007; Young, 2008).

Unfortunately, culture is often overlooked because the analysis phase of instructional design is one of the most commonly skipped phases. Thomas, Mitchell, and Joseph (2002) remind us that, "culture is so much a part of the construction of knowledge that it must underpin not only the analysis phase but all phases of the design process" (p. 41). Thus it is essential that instructional providers continue to familiarize themselves with the learners' cultures throughout the implementation phase and even through the evaluation stage. They might consider including a cultural expert as part of the design team or asking a representative participant to help plan a course, training event, or product before implementation occurs (Thomas, Mitchell, \& Joseph, 2002; Young, 2008).

Of course, educators must also become more aware of the cultural biases embedded in their own teaching and instructional designs, including the selection of instructional activities, their presentation styles (including both verbal and non-verbal communications), and their expectations of students. Ignorance of these biases could prevent them from seeing opportunities for more effective avenues of interaction with learners. The CDLF presented in the previous section is meant to increase both kinds of awareness. Reviewing the framework while considering current and past students, as well as one's own practice, can help create a higher degree of awareness and sensitivity to cultural differences when they emerge.

To aid in using the framework, the authors have developed a questionnaire based on the CDLF that can illuminate the range of preferences existing among learners (Parrish \& LinderVanbershot, 2009a). The questionnaire is not intended to be used to make final judgments about individuals but to point to the potential range of strategies and tactics that might be useful for a given set of learners. It can be used in at least two ways. First, instructional providers may complete the survey themselves to identify their personal learning (and teaching) preferences. This will help them become aware of their biases as they design and deliver instruction. The 
second use is to have learners complete the survey before instruction or instructional development begins. Students can self-analyze or, if there is time, results can be analyzed as a group (using the CDLF questionnaire analysis form, Parrish \& Linder-Vanbershot, 2009b), which has the additional benefit of encouraging understanding between learners. The results can also guide instructional providers in adapting instruction to meet the learning preferences of learners. (Note that the CDLF questionnaire has not yet been used in a research context. It is offered here as a tool for practice.)

\section{Communication}

To aid in increasing awareness, instructional providers should clearly communicate the cultural bases of their approaches to instruction and should provide opportunities for students to voice their own cultural proclivities. Creating opportunities for discussion about learning preferences should be a first step in determining the direction an instructional event should take. Gunawardena, Wilson, and Nolla (2003) suggest that dialogue and communication, leading to negotiation of the instructional details, are the central factors in creating a culturally relevant design. Of course, for those who develop self-pace materials or never actually meet their learner audiences, communication may be limited to the interactions that occur during a learner analysis phase. But even in these instances of remoteness, communication can be extended by providing opportunities for feedback via surveys and evaluation tools.

The CDLF questionnaire results also can be a tool to stimulate class discussion about learning preferences; it can create a venue for an instructor to justify the instructional strategies employed in a course, or it can offer a structure for negotiation for those course activities that remain negotiable.

\section{Process}

Several authors have suggested amendments and alternatives to traditional instructional systems design (ISD) models to better incorporate consideration of cultural diversity. Thomas, Mitchell, and Joseph (2002) suggest adding a "third dimension" to the traditional ADDIE process (analysis, design, development, implementation, and evaluation) that includes pervasive (a) questioning of design intentions throughout to ensure designers remain culturally sensitive, (b) interaction with the intended audience to better understand their needs and preferences, and (c) introspection about beliefs and attitudes toward other cultures.

Edmundson (2007) offers the CAP (cultural adaptation process) model as an expansion of the traditional needs assessment and learner analysis phases of an instructional design process (part of the "A" of ADDIE). This model includes several levels of cultural analysis, including consideration of those factors that impact content, pedagogical, and media choices, and identification of appropriate adaptation strategies. While focused on needs assessment, CAP also implies recommendations for formative evaluation. Rogers, Graham, and Mayes (2007) also point to the need for a much expanded analysis phase for cross-cultural situations. 
Gunawardena, Wilson, and Nolla (2003) emphasize interaction and negotiation in their adaptive, meaningful, environmental-based architecture for online course design (AMOEBA). This model suggests a highly participatory role for students in course decisions, including making choices regarding language (when feasible), interface formats, communication channels, instructional activities, and instructional methods.

Finally, Young (2007; 2008) offers the culture based model (CBM), which includes consideration of culture throughout the instructional development process. The CBM is less a process-based model and more an elaborate framework for culturally sensitive instructional design activity that describes (a) questions asked to help maintain an audience focus, (b) project management recommendations, (c) design team roles, (d) the use of assessment and review, (e) prescriptions for decision making processes, (f) appropriate learner-centered learning outcomes, (g) culturally sensitive design factors that must be considered, and (h) skills required of the design team.

These process recommendations have three things in common:

- Consideration of cultural differences in each phase of the design process, with extra attention occurring during the analysis phase;

- Pervasive reflection and a willingness to modify one's first inclinations about the instructional design; and

- Interaction with students or student representatives during design (user-centered design) (Carr-Chellman, 2006).

\section{Accommodation}

Awareness, communication, and process changes will lead to increased knowledge about cultural diversity, but the need remains to use that knowledge in making design decisions to address diversity. This section describes several ways in which instruction can provide opportunities for learners to apply their culturally dependent approaches to learning, effectively allowing a pedagogical "localization." Yet, the degree to which an instructor and ID can adapt instruction, given time and budget constraints, organizational desires for consistency, and the need to acculturate students into professional and mainstream cultures, is limited. Which adaptive design choices should be made requires careful consideration.

In single cross-cultural instances, in which instruction is being designed for a culturally homogeneous set of students but from a culture different than that of the instructional provider, accommodation should include as much adaptation as possible based on the cultural analysis, without compromising the fidelity of the content and underlying necessary instructional principles (Castro, Barrera Jr., Martinez Jr., 2004; Rogers, Graham, \& Mayes, 2007). Of course, this assumes that instructional providers can transcend their cultural inclinations to identify the instructional elements that require fidelity as well as the changes that would corrupt the instructional intent and the comfortable trappings that could be sacrificed for the sake of the students. For example, will a problem-based learning activity require the same student roles as were used in a previous implementation? Will each class be predominately discussion based, or 
should there be some lecture/presentation component that provides increased guidance? To what degree should the instructor expect students to express personal views or to ask challenging questions, and to what degree is that also the duty of the instructor? Should a strict schedule be enforced, or should some flexibility be built in?

Most authors suggest that accommodation in multicultural situations be achieved by offering students alternative choices in learning activities and instructional formats (Irvine \& York, 1995; McLoughlin, 2001). Some choices may be more costly than others to include, so the use of alternatives must be based on how deeply rooted the cultural preferences are (the degree to which ignoring them will affect learning) and on how easy the alternatives are to implement (which will vary by instructional mode). The alternatives that will be most critical to learning success can be discerned during the cultural analysis of learners, which can be guided by the CAP, CBM, or AMOEBA models, as well as the CDLF offered here. The CDLF questionnaire and analysis form (Parrish \& Linder-Vanbershot, 2009a; 2009b) might be useful in determining the degree to which learners feel they are represented on each dimension, which would be a good indicator of how critical that dimension is for determining alternatives.

Knowing which types of adaptations instruction should undergo based on cultural analysis is difficult and calls for additional research. The details offered in the CDLF can be of help in stimulating design adaptations, but it offers no direct advice for design decisions. These must be derived by the instructional provider based on a deeper understanding of a particular group of learners. However, detailed case studies of adaptations are worth studying as best practices.

Henderson (1996), who espouses a "multiple cultural” approach that embraces both predominant and minority cultures, describes a module design that supports both constructivist and instructivist orientations, allowing freedom for students to follow either a prescribed path or one of their own choosing. Arya, Margaryan, and Collis (2003) describe an instructional product that offers alternatives in both content and learning activities in a blended learning course on workplace problem-solving, a skill area which the CDLF suggests should reveal a high degree of cultural differences. Edmundson (in press) describes how strategic modularization can achieve a similar effect for multinational organizations, who desire to reuse core content while supplying interchangeable cross-cultural learning objects (XCLOs) for key content and learning activities that call for cultural adaptation. Edmundson also argues for careful use of "low-context" content (Hall, 1983), content that avoids language, idioms, and references that assume a high degree of cultural context or that includes a clear description of that context, which can avoid the need for unnecessary adaptation.

One might argue that research-based educational practices transcend culture or are culture-neutral and that it is simply good practice to use what research tells us works, regardless of cultural differences. But of course research itself is culturally bound, not only by the situations in which it is performed and the availability of participants, but also by the chosen research questions, research designs, and what is considered acceptable as evidence. In fact, the existence of longheld cultural differences exhibited by foreign but successful cultures should make us question the broad validity of any research-based practices. At a minimum, one should reflect to determine the 
underlying operational principles of any particular research-based instructional strategy (Gibbons, 2009) and decide whether some of its prescribed methods and conditions can be modified to work more effectively within other cultural frameworks (Rogers, 2007).

\section{Remaining Questions and Conclusions}

The CDLF could prove useful in multiple contexts. This article presents the framework and questionnaire as tools for practice, but the CDLF might also support research, for example to determine which preferences appear to cluster together or which appear to be common among a particular group of learners. Many questions remain, the answers to which may help provide additional guidance for the utilization of the CDLF.

- Which cultural dimensions are most important to consider in adapting instruction? Which offer more forgiveness if ignored?

- Which dimensions provide the most difficulty for adaptation? Which can be accommodated via easily implemented adaptations?

- Because some of these dimensions likely suggest new considerations for educators, what are the strategies that can be used to create adaptations? At what point(s) in the ADDIE process is it most important to consider these adaptations?

- Do the extremes in some dimensions represent incompatible approaches, while others might peacefully coexist?

- What degree of variation exists among culturally homogeneous students in comparison to multicultural groups? To what degree can the framework help in either situation?

- What roles do these cultural dimensions (and others not identified here) play in the choice and application of instructional technologies?

- How might prominent instructional strategies, like problem-based learning, be adapted to fit in a multicultural context? Which cultural dimensions are impacted when applying such fundamental strategies?

- How do generational differences of both students and educators affect location along the dimensions? What role does the age of students play in determining the cultural rootedness of learning preferences?

The ability to accommodate culturally based learning differences is becoming an increasingly critical skill in this time of rapid globalization and technology-influenced cross-cultural interactions. This paper contributes to the literature on cultural considerations of teaching and learning by exploring the basis of culture and the dimensions that most directly impact the teaching and learning enterprise. The CDLF provides a rich tool for analyzing the differences in learning preferences, which, when combined with process-oriented strategies for culturally sensitive adaptation, can help instructional providers become more effective in cross- and multicultural situations.

It has been suggested that being involved in multicultural exchanges can make one more sensitive to communication patterns because the old, reliable patterns are no longer effective. For example, 
one may become a better listener and a more careful communicator because first assumptions are more suspect. One becomes more conscious of the unspoken intentions, and perhaps unintended messages, embedded in communications. This increased awareness may improve overall communication skills within and across cultures (Hall, 1981).

Arya, Margaryan, and Collis (2003) ponder whether cultural accommodation in instruction "suggests stereotyping which can lead to new dilemmas" (p. 41). Future research must respond to this question because the resulting compartmentalization could lead to results counter to the goals of instruction, which include opening students' minds to change and new ideas. Thomas (2003) reminds us that instructional providers need to be aware of both the intended and unintended consequences of their instructional designs and that all consequences should be researched and discussed. In the end, research into the multicultural education and training challenges may lead to greater wisdom for all instructional situations. 


\section{References}

Arya, K., Margaryan, A., \& Collis, B. (2003). Culturally sensitive problem solving activities for multi-national corporations. TechTrends, 47(6), 40-49.

Berge, Z. L. (2007). Training in the corporate sector. In M. G. Moore (Ed.), Handbook of distance education $\left(2^{\text {nd }}\right.$ ed.). Mahwah, NJ: Lawrence Erlbaum Associates.

Carr-Chellman, A. A. (2006). User design. Mahwah, NJ: Lawrence Erlbaum Associates.

Castro, F. G., Barrera Jr., M., \& Martinez Jr., C. R. (2004). The cultural adaptation of prevention interventions: Resolving tensions between fidelity and fit. Prevention Science, 5(1), 4145.

Cole, M. (1996). Cultural psychology: A once and future discipline. Cambridge, MA: Harvard University Press.

Edmundson, A. (2007). The cultural adaptation process (cap) model: Designing e-learning for another culture. In A. Edmundson (Ed.), Globalized e-learning cultural challenges (pp. 267-290). Hershey, PA: Idea Group, Inc.

Edmundson, A. (in press). Cross cultural learning objects. In A. Edmunson (Ed.), Cases on globalized and culturally appropriate e-learning: Challenges and solutions. Hershey, PA: IGI Global.

Gibbons, A. S. (2009). The value of the operational principle in instructional design. Educational Technology, 49(1), 3-9.

Gunawardena, C. N., Wilson, P. L., \& Nolla, A. C. (2003). Culture and online education. In M. G. Moore \& W. G. Anderson (Eds.), Handbook of distance education (pp. 753-775). Mahwah, NJ: Lawrence Erlbaum Associates.

Gunawardena, C. N., \& LaPointe, D. (2007). Cultural dynamics of online learning. In M. G. Moore (Ed.), Handbook of distance learning ( $2^{\text {nd }}$ ed., pp. 593-607). Mahwah, NJ: Lawrence Erlbaum Associates.

Hall, E. T. (1981). Beyond culture. New York: Random House.

Hall, E. T. (1983). The dance of life. New York: Doubleday.

Henderson, L. (1996). Instructional design of interactive multimedia: A cultural critique. Educational Technology Research \& Development, 44(4), 85-104. 
Hofstede, G., \& Hofstede, G. J. (2005). Cultures and organizations: Software of the mind (2 ${ }^{\text {nd }}$ ed.). New York: McGraw-Hill.

Irvine, J. J., \& York, D. E. (1995). Learning styles and culturally diverse students: A literature review. In J. A. Banks (Ed.), Handbook of research on multicultural education (pp. 484497). New York: Macmillan.

Kitayama, S., \& Markus, H. R. (Eds.). (1994). Emotion and culture: Empirical studies of mutual influence. Washington, D.C.: American Psychological Association.

Lea, M., \& Goodfellow, R. (2003). Supporting academic writing in a global online environment. Paper presented at the European Association of Teachers of Academic Writing, Budapest, Hungary.

Lemke, J. L. (1997). Cognition, context, and learning: A social semiotic perspective. In D. Kirshner \& J. A. Whitson (Eds.), Situated cognition: Social, semiotic, and psychological perspectives (pp. 37-55). Mahwah, NJ: Lawrence Erlbaum Associates.

Levine, R. (1997). A geography of time. New York: Basic Books.

Lewis, R. D. (2006). When cultures collide: Leading across cultures ( $3^{\text {rd }}$ ed.). Boston: Nicholas Brealey International.

Mason, R. (2007). Internationalizing education. In M. G. Moore (Ed.), Handbook of distance education ( $2^{\text {nd }}$ ed., pp. 583-591). Mahwah, NJ: Lawrence Erlbaum Associates.

McLoughlin, C. (2001). Inclusivity and alignment: Principles of pedagogy, task and assessment design for effective cross-cultural online learning. Distance Education, 22(1), 7-29.

Nisbett, R. E. (2003). The geography of thought: How Asians and westerners think differently...And why. New York: Free Press.

Parrish, P. E., \& Linder-VanBerschot , J.A. (2009a). The cultural dimensions of learning framework questionnaire. Retrieved from http://homes.comet.ucar.edu/ pparrish/index.htm.

Parrish, P. E., \& Linder-VanBerschot, J.A. (2009b). The CDLF questionnaire analysis form. Retrieved from http://homes.comet.ucar.edu/ pparrish/index.htm.

Pincas, A. (2001). Culture, cognition, and communication in global education. Distance Education: An International Journal, 22(1), 30-51.

Rogers, C. P., Graham, C. R., \& Mayes, C. T. (2007). Cultural competence and instructional 
design: Exploration research into the delivery of online instructoin cross-culturally. Educational Technology Research \& Development, 55(2), 197-217.

Schwier, R. A., Campbell, K., \& Kenny, R. (2004). Instructional designer's observations about identity, communities of practice and change agency. Australasian Journal of Educational Technology, 20(4), 69-100.

Thomas, M., Mitchell, M., \& Joseph, R. (2002). The third dimension of ADDIE: A cultural embrace. TechTrends, 46(2), 40-45.

Thomas, M. K. (2003). Designer's dilemmas: The tripartheid responsibility of the instructional designer. TechTrends, 47(6), 34-39.

Visser, J. (2007). Learning in a global society. In M. G. Moore (Ed.), Handbook of distance education ( $2^{\text {nd }}$ ed.). Mahwah, NJ: Lawrence Erlbaum Associates.

Young, P. A. (2007). The culture based model: A framework for designers and visual id languages. In L. S. Botturi \& L. Todd (Eds.), Handbook of visual languages for instructional design (pp. 52-75). Hershey, PA: Information Science Reference.

Young, P. A. (2008). The culture based model: Constructing a model of culture. Educational Technology \& Society, 11(2), 107-118.

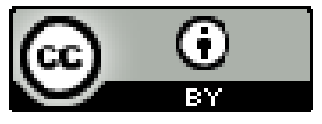




\title{
Unbundling Faculty Roles in Online Distance Education Programs
}

\author{
Patricia W. Neely and Jan P. Tucker \\ Kaplan University, USA
}

\begin{abstract}
Many colleges and universities are expanding their current online offerings and creating new programs to address growing enrollment. Institutions often utilize online education as a method to serve more students while lowering instructional costs. While online education may be more cost effective in some situations, college decision makers need to consider the full range of cost implications associated with these online offerings. The unbundling of faculty roles in online distance education programs is one cost consideration that is often overlooked. As the faculty role has become more distributed, so have the costs associated with providing instruction and instructional support. This paper reviews the hidden costs associated with the unbundling of the faculty role and presents a framework for calculating the true costs of the unbundled faculty role.
\end{abstract}

Keywords: Faculty roles; unbundling; higher education; online education; faculty costs

\section{Unbundling Faculty Roles in Online Distance Education Programs}

Online distance education programs are growing. Allen and Seaman (2008) reported a 12\% increase in students taking at least one online course from 2007 to 2008. The growth is expected to continue over the next five years with estimates placing the number of students taking online classes in 2014 at over 18.5 million students (Nagel, 2008). Universities are expanding current online offerings and creating new programs to address growing enrollment. At the same time that online enrollments are increasing, most colleges and universities are facing unprecedented pressures to cut costs. State funding for higher education is being cut dramatically and university endowments have decreased in value (Stratford, 2009). In response to the growing pressures to reduce costs, many colleges have looked to distance education, particularly online education, as the primary method for reaching more students while lowering instructional costs. Studies have shown that while online education may be more cost effective in some situations, college decision makers need to consider the full range of cost implications associated with online education. The unbundling of faculty roles in online distance education programs is one cost consideration that is often overlooked. Interviews were conducted at a major regionally accredited online university to 
determine the true cost of the development, launch, facilitation, and maintenance of a graduate business course. The data, while limited to one three-credit graduate course at one university, is presented as a means of opening the discussion of the true cost of unbundling faculty roles in online education.

\section{Problem Significance}

The unbundling of faculty roles begins with determining the core faculty responsibilities associated with the institution. For example, Franklin University has identified three principle faculty functions including leadership, instruction, and curriculum quality (Hagerott \& Ferezan, 2003). The unbundling of these roles allows the university to assess, manage, and utilize resources based on each of these functions. It also allows the faculty to focus on their areas of expertise. Faculty members with training in curriculum design are involved in developing courses, while those with experience delivering instruction are able to focus on facilitating the course. In a traditional faculty model the faculty is responsible for both the content and delivery along with other functions like supervising graduate students, advising students, conducting research, and serving on university committees. In an online classroom this would also entail being responsible for technology functions. Unbundling these roles separates the instructional from the delivery activities and redistributes them (see Figure 1).

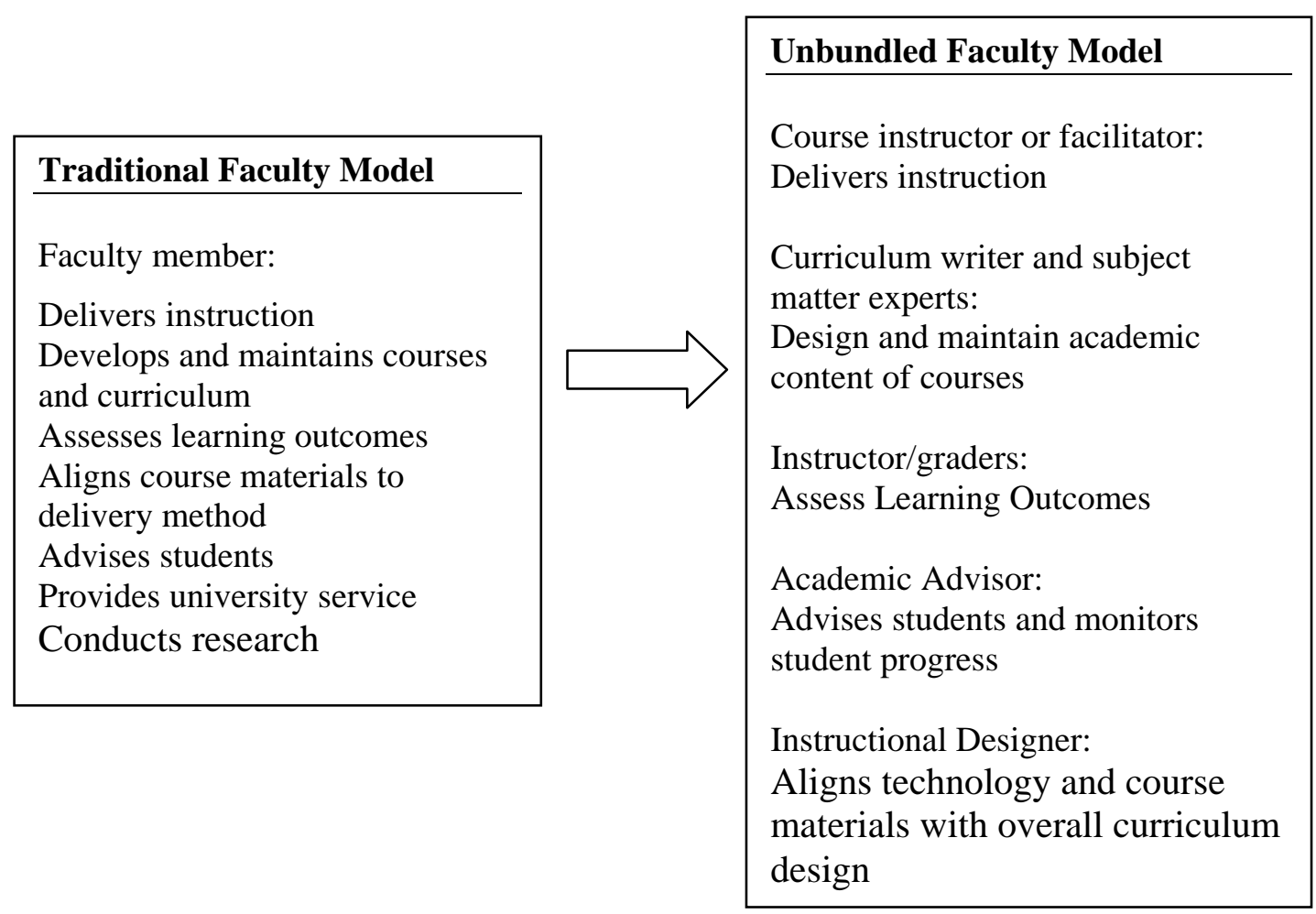

Figure 1. This figure illustrates the unbundling of a traditional faculty role. 
The unbundling process allows faculty, to some degree, to be involved in the processes in which they have the most experience and expertise. This specialization may contribute to the overall quality of the curriculum developed but it may also cause the teaching faculty to feel they are too far removed from the material developed to teach it effectively (Sammons \& Ruth, 2007). Unbundling faculty roles help administration to assign costs to specific components of the design and instruction of a course, but determining exactly how to calculate and assign these costs can be challenging. As enrollment in online classes continues to grow and universities continue to feel the pressure to adapt by expanding their course offerings in an effective and efficient manner, the problem of how to adequately budget these functions will continue to be an issue. This paper examines some of the costs that are often overlooked when allocating costs to instruction and design in an effort to increase awareness among those tasked with budgetary responsibilities in higher education institutions.

\section{Brief Literature Review}

\section{The Unbundling Concept}

The concept of unbundling is not new. The problems associated with the bundling of faculty roles, for example faculty being responsible for areas in which they were not trained such as advising students, counseling, credentialing, and course development, were first introduced in the 1970's (Trout, 1979; Wang, 1975). Research has suggested that there is often a negative correlation between faculty time spent on research and faculty time spent on teaching and that often instructors feel that one must be sacrificed for the other (Linsky \& Straus, 1975; Feldman, 1987, Fairweather, 1993). The idea is that if the instructional role is disseminated too widely, instructors will become ineffective in all roles. The theory behind the unbundling of the teaching role is that it would improve both the quality and the cost effectiveness of learning (Wechsler, 2004).

Most online faculty members today are hired specifically to work with students in a facilitator's role around the course content. The unbundling of the traditional faculty role results in the need for a number of support personnel. Faculty supervisors, trainers, instructional technologists, academic advisors, and graders are used to support the faculty member. Schuster and Finkestein (2006) indicate that information technology may be a contributing factor to the unbundling of the faculty role as higher education institutions are pressured to increase the speed at which they deliver content to keep up with student demand. Over twenty years ago, Ljosa (1988) indicated that distance education must focus on the communication between teachers and students to facilitate learning in an online environment, which supports the concept of teachers focusing on teaching.

The unbundling of faculty roles results in a number of challenges for online colleges and universities. At a time when state budgets are shrinking and pressures to contain costs have risen, the unbundled faculty role makes it increasingly difficult to calculate the actual costs of instruction for a single course (Neely, 2004). From a management perspective, an increased 
number of support personnel leads to additional activities involved with hiring, training, and supervising individuals in specialized roles.

\section{Cost of Unbundled Faculty Role}

In the traditional university structure, the department or college is a cost center, and budgets and reports on instructional activities are contained within the department. Department chairs and university administrators who take an accounting or historical approach to costing in higher education are able to attribute actual expenditures to each activity (Rumble, 2001). When costs for instructional activities are included in a department budget, allocating the costs on a per course basis becomes a matter of bookkeeping wherein direct costs are attributed to a single activity or course (Brinkman, 2001). Costing efforts in higher education are often fraught with problems due to the fact that the true costs of using the building and equipment are often not reported correctly and many costs are considered joint production costs (Winston, 1988). Finkelstein, Frances, Jewett, and Scholz (2000) indicate that duplication of efforts in higher education resources reduces costs and that course preparation is the function that allows the most duplication of faculty effort. Disaggregating the components of the faculty role may change the cost structure in higher education. Trying to determine how much change in cost and if that change is positive is challenging.

As the faculty role has become more distributed, the costs associated with providing instruction and instructional support have been dispersed to multiple cost centers across the university. Faculty salaries are tangible and easy to account for in budgets (Palloff \& Pratt, 2007). Less tangible and more difficult to identify are supervisory costs, training costs, and other support costs necessary to keep online courses functioning. Examining multiple budgets to identify and allocate costs to a specific course is a complex undertaking. To properly allocate costs, the activities of all instructional support personnel would need to be recorded and allocated to a specific course. In doing so, the costs from multiple departments would need to be gathered and calculated on a per course basis.

With the unbundled faculty model, new hierarchies are created within the university to support instructional activities. What does it cost to create a new department dedicated to curriculum development, academic advising, or instructional technology? Calculating the costs goes beyond allocating an instructional technologist's salary to each course supported. Administrative support, equipment, technology, training, and supervision must also be allocated to course activities to obtain the true instructional costs for an online course.

Recruiting, hiring, and training activities proliferate with the unbundled faculty model. The traditional faculty model tasks the department chair with recruiting, selecting, hiring, and training new faculty with support from the human resources department and faculty committees. Hiring multiple individuals in highly specified roles also requires increased support for human resource activities as increased numbers of individuals are hired for these roles and the activities are continuous. Hiring is typically based on the semester system in a traditional faculty model. Many online institutions have multiple terms throughout the year, resulting in continuous hiring 
and training of instructional support positions. Increased administrative support is required for processing the hiring paperwork, for payroll, and for monitoring faculty performance.

Multiple supervisors are needed with specialized expertise to monitor and evaluate the performance of individuals in specialty roles. Instruction, training, and supervision are ongoing in the unbundled faculty model as multiple part-time instructors are used in various capacities to facilitate learning. The instructional cost per student is a growing concern for higher education institutions as they struggle to contain costs while providing quality education in a technologically rich and competitive environment. It is important that all costs be considered when determining the yearly budget for faculty and when calculating the true capital-labor ratio in these institutions.

\section{Research Design and Method}

The researchers used a case study approach to gathering data on the costs of unbundled faculty roles. The first phase of the research involved the collection of data and general information on the unbundled faculty role and on costs in higher education. The second phase of the research included identifying the course to be studied. Once a course was selected, university documents were examined to determine course instructional support. The final phase in the research included interviewing department administrators. The research questions that guided the gathering of data included the following:

- How has the faculty role been unbundled for the identified course?

- What are the cost implications for the unbundled faculty role?

- How do university administrators capture the costs of the unbundled faculty role?

A limitation of this study is the very narrow focus of examining one course at one institution. This case study may be of limited help in drawing broad generalizations about the costs of the unbundled faculty role at another institution or across institutions. Although limited in scope, this case study acts as a starting point for the examination of the cost implications for the unbundling of faculty roles in online institutions.

\section{Developing a Framework for Calculating Unbundled Faculty Costs}

A review of each of the unbundled faculty roles identified in Figure 1 reveal that the process for identifying costs must begin by creating a framework for the costing process. The researchers determined that a modified activity based costing approach would be used. According to Horngren and Harrison (2009), activity based costing (ABC) examines costs that are the building blocks for measuring the costs of services, such as an online course. Traditional costing systems

only measure inputs, such as salaries and administrative activities; whereas, activity based costing provides a mechanism and methodology for also measuring the cost of outputs (Granof, Platt, \& Vaysman, 2000). While ABC is frequently used in business models it is not as prevalent in institutions of higher education. Higher education accounting systems typically rely on fund 
accounting, which may not provide the information administrators need to make strategic decisions within their institutions. Granof, Platt, and Vaysman (2000) found that the usefulness of allocating indirect costs based on factors by which they are most influenced, afforded by ABC, was just as applicable to universities as it was to industry. With an activity based costing methodology, individual activities are identified and the resulting costs attributed to an individual, online course at the university.

The process for identifying the costs of the unbundled faculty role began by reviewing each of the unbundled faculty roles identified in Figure 1. The costs for all roles were examined and calculated, except the academic advising role. Over the past 30 years, the academic advising function has been increasingly segregated from the role of a faculty member (Hrabowski, 2004). Specialized positions have been created within most colleges and universities to address student advising activities. For the purposes of this study, it was determined that academic advising activities were provided through the same advising centers for students in both traditional courses and in online courses. Academic advising has been segregated from the faculty instructional role at many universities using a traditional faculty model. The researchers determined that calculating the costs for academic advising would not be undertaken as part of this study because advising was centralized for students in both online and on-grounds courses.

The first step in conducting a study of the costs of the unbundled faculty role was to identify a framework for gathering costs. The unbundled roles can be separated into three types of activities. The first activity is the design and development of the online course. Rumble (2001) suggests that there is a clear division of labor between the activities associated with course development and the activities associated with the delivery of the course. Delivering the course is a second cost center. Interviews with distance education administrators at the university where this study was undertaken revealed a third center of activity, course maintenance.

Once the cost centers were identified, a second step was taken to identify the individuals and the actions taken by those individuals to support online course design and development, delivery, and maintenance. A course developer, course facilitator, and faculty member charged with course maintenance were interviewed to determine the activities associated with each unbundled faculty role.

Data obtained from the interviews as well as from research into costing in distance learning was used to develop the unbundled faculty costs worksheet presented in Table 1. The worksheet provided a starting point for gathering and calculating the costs of the activities associated with the unbundled faculty role. 
Table 1

Unbundled Faculty Costs Worksheet

\begin{tabular}{|c|c|}
\hline \multicolumn{2}{|l|}{ Course development } \\
\hline Curriculum developer (curriculum writer) & $\begin{array}{l}\$ 140 \\
\$ 2800 \text { divided by } 20 \text { deliveries of the course }\end{array}$ \\
\hline Faculty co-writer & $\begin{array}{l}\text { \$150 } \\
\$ 3000 \text { stipend divided by } 20 \text { deliveries of the } \\
\text { course }\end{array}$ \\
\hline Instructional designer costs & $\begin{array}{l}\$ 104 \\
80 \text { hours multiplied by } \$ 26 \text { per hour }(\$ 2,080) \\
\text { divided by } 20 \text { deliveries of the course }\end{array}$ \\
\hline Curriculum supervisor/department chair & $\begin{array}{l}\$ 27 \\
12 \text { hours multiplied by } \$ 45 \text { per hour divided by } \\
20 \text { deliveries of the course }\end{array}$ \\
\hline $\begin{array}{l}\text { Total course development support per each } \\
\text { delivery of the course }\end{array}$ & $\$ 431$ \\
\hline \multicolumn{2}{|l|}{ Course instruction } \\
\hline Instructor/facilitator & $\begin{array}{l}\$ 2,600 \\
\text { Per course costs for a course instructor }\end{array}$ \\
\hline Graders & $\begin{array}{l}\$ 0 \\
\text { No additional graders used }\end{array}$ \\
\hline Department chair/faculty mentor supervision & $\begin{array}{l}\$ 315 \\
7 \text { hours per course per term multiplied by } \$ 45 \text { per } \\
\text { hour }\end{array}$ \\
\hline $\begin{array}{l}\text { Total course instruction per each delivery of the } \\
\text { course }\end{array}$ & $\$ 2915$ \\
\hline \multicolumn{2}{|l|}{$\begin{array}{l}\text { Course maintenance (each term course is } \\
\text { delivered) Estimated number of hours spent on } \\
\text { course maintenance multiplied by hourly rate }\end{array}$} \\
\hline Course lead/supervisor: 3 hours @ \$38 per hour & $\$ 148$ \\
\hline $\begin{array}{l}\text { Instructional Technologist: } 7 \text { hours @ \$26 per } \\
\text { hour }\end{array}$ & $\$ 182$ \\
\hline Total course maintenance & $\$ 330$ \\
\hline $\begin{array}{l}\text { Total costs of unbundled faculty support for } \\
\text { one course }\end{array}$ & $\$ 3,676$ \\
\hline
\end{tabular}




\section{Calculating Costs of the Unbundled Faculty Role}

Online universities seem to follow three major models for curriculum development. A number of universities have developed departments devoted to curriculum development. Subject matter experts and curriculum developers with expertise in course design are hired in full-time positions to develop courses (Knowles \& Kalata, 2007). Many universities follow the traditional model of paying a stipend to current faculty for course development, while some universities use part-time curriculum developers to create courses. Other universities use some type of blended model using current faculty and outside experts to develop courses. In this study, the university that provided costing data used a blended method, which paired a current faculty member with an external curriculum writer. The faculty member created learning objectives, identified learning materials including journal articles and textbooks, and identified the assessment methodology. The external curriculum writer developed the course assignments, the discussion threads, and the scoring rubrics for assignments.

The role of an instructional designer can vary depending on the university (Tantivivat \& Allen, 2004). Some universities do not provide instructional design assistance to course developers. At other universities, the instructional designer assists with each step of course development. The university participating in this study provided instructional designer support to assist the faculty member with loading the course into the learning management system used by the university. The instructional designer ensured that the course provided ease of interaction and clarity to the student and made certain that there were no biases in the way the subject matter was presented.

During the course design process, a department chair or lead faculty member often provides assistance to the course designers. The individual in this role makes sure that the course meets university standards, ensures that the course is developed according to project deadlines, and reviews the course to ensure quality. In this study, a full-time faculty member provided support and supervision for the development of the course. The faculty member estimated the number of hours dedicated to supporting the course in this study.

Calculating the costs for individuals filling the unbundled faculty role required several different approaches to costing. The costs for individuals who worked for the university on a full-time basis were calculated by dividing the total amount of salary plus benefits by the number of hours in the yearly contract to arrive at a per hour cost. The per hour cost was then multiplied by the number of hours that the individual identified as spending in support of the course. Some individuals participating in the study were paid a flat fee for their contributions. The flat fees were easily allocated to the course activities.

\section{The Study}

For this study, data was gathered on the per class compensation for an online graduate business course. Compensation data was gathered on faculty members who had earned a terminal degree in their field (PhD, EdD, JD, or DBA) and who had three years teaching experience. The number 
of weeks per class ranged from six to ten weeks and the per class compensation ranged from a low of $\$ 1800$ per class to a high of $\$ 4,000$ per class with the average hovering around $\$ 2200$ per class. The course instructors in the specific graduate course included in this study were paid $\$ 2600$ to facilitate the class for six weeks.

Course maintenance costs were calculated as $\$ 330$ based on interview data from the department chair and an instructional technologist. Course maintenance costs are the least identifiable costs in the unbundled faculty role. Course maintenance may be as simple as updating a web link in a course or as complex as revising the assignments. Course maintenance is ongoing and is not reflected in budgets except when major course revisions are scheduled.

After calculating the cost of unbundled faculty support for one course, the researchers examined how the cost of support compared to the costs of support for one class with a traditional faculty role. The National Center for Education Statistics reported that the average salary for an assistant professor was \$55,300 (Knapp, 2009). Fringe benefits varied as a percentage of salary dependent upon the type of institution. For the purposes of this study, fringe benefits were estimated at $30 \%$ of salary (Employee Benefits Research Institute, 2009). Total compensation for an instructional faculty member was calculated at $\$ 71,890$ for the purposes of this study. The National Center for Education Statistics also reports that instructional faculty, on average, support eight courses during the academic year (Knapp, 2007). Based on data from the National Center for Education Statistics, the faculty member's total compensation was approximated at $\$ 8,986$ for a single course.

\section{Research Findings}

Our study revealed a cost of $\$ 3,676$ for the instructional support provided to a single course with the unbundled faculty model. At first glance, the unbundled faculty role seems significantly less expensive than the cost of a traditional faculty member's course support at $\$ 8,986$ per course. However, the investment on a per course basis may be skewed in favor of the unbundled faculty role due to limitations in calculating the number of hours that a faculty member devotes to activities outside of instruction, such as university service. Also, it is difficult to assign the amount of time actually devoted to course design and maintenance unless instructional support personnel are asked to keep a time log of activities by course. For the purposes of this study, time spent on administrative and university service activities by faculty was ignored.

Our study revealed that there are significant per course costs that are often underaccounted in university budgets as a result of the unbundled faculty model. The unaccounted costs in the course design phase include leadership and support provided by lead faculty and department chairs in coordinating the design, development, and implementation of new courses. Far easier to identify and quantify are the costs incurred during the instructional phase. Faculty salaries were clearly identified based on the course assignments. The missing costs in the instruction phase were activities around faculty supervision and training. Course maintenance activities were also difficult to identify and were often overlooked in calculating unbundled faculty costs. 
Most university budgets consider course development costs as sunk costs and do not allocate the costs to each delivery of the course. The costs of department chair support and instructional designer support are also rarely allocated at the course level. Course development costs for the course studied were $\$ 431$ per course delivered. These costs included the work of a curriculum writer, a faculty lead, an instructional designer, and a department chair. These costs may not be considered significant on a per course basis, but when calculated across a number of courses can represent a significant investment of financial resources for a university. With the traditional faculty model, a faculty member would be tasked with developing a new course. The faculty member may or may not receive additional compensation for course development work depending on institutional policies.

The costs for course instruction are the most recognized costs in the unbundled faculty role. Often, course costs in budgets are limited to the cost of course instruction. Again, the costs of providing supervision and training to adjunct instructors are either not reported or are underreported when considering the costs of delivering an online course. The adjunct faculty member's salary at the institution studied was higher than an average adjunct salary but significantly less than the cost of a full-time faculty member.

\section{Summary and Conclusion}

At first glance, the data seem to indicate that the costs per course of the unbundled faculty role are lower than the cost per course of hiring traditional faculty. However, this study suggests that it is difficult to identify and assign costs for instructional activities in higher education, particularly when comparing the traditional faculty model with the unbundled faculty model.

Interviews with university administrators indicate that there is an understanding that hidden costs are incurred, but ferreting out the information is difficult given the structure of budgeting and recording costs in higher education. Rumble (2001) writes, "Decision-makers want to know how much something will cost, and whether they can afford it. They need this information to set a budget, to cost change, and to decide between two or more different options” (p.2). The need to identify costs is not diminished by the fact that costing is a difficult and messy process as the researchers learned in conducting this case study.

Completion of this study indicates a need for further research in several areas. The costing worksheet that was designed as part of this study needs to be further developed so that university administrators can easily identify costs with the unbundled faculty model. Further research needs to be undertaken to identify whether an activity based costing model could be used to develop more accurate cost calculations for activities associated with the unbundled faculty role. A number of questions remain unanswered, such as the costs associated with creating new departments within the university to support instruction. Also, questions around how much it costs a university to hire, train, and supervise instructors remain unanswered.

In conclusion, there is much work to be done in developing costing models for the unbundled faculty roles. This study addresses only minimally the hidden costs of the unbundled faculty role. 
Future studies examining these costs would need to include real-time recordkeeping of hours dedicated to course development, delivery, and maintenance for not only the instructor but also for the online coordinators, the faculty schedulers, the instructional design coordinators, the course evaluators, and the quality assurance personnel. As online courses continue to proliferate and scrutiny of higher education costs increases, university administrators need to identify the cost impact of the unbundled faculty role. 


\section{References}

Allen, E., \& Seaman, J. (2008). Staying the course. Babson Survey Research Group: The Sloan Consortium.

Brinkman, P.T. (2001). The economics of higher education: Focus on cost. In M. Middaugh (Ed.), Analyzing costs in higher education: What institutional researchers need to know (pp. 5-17). San Francisco, CA: Jossey-Bass.

Employee Benefits Research Institute. (2008). FAQs about benefits - general overview. Retrieved from http://www.ebri.org/publications/benfaq/index.cfm?fa=ovfaq1.

Fairweather, J. S. (1993). Faculty rewards reconsidered: The nature of tradeoffs. Change, 25, 4447.

Feldman, K. A. (1987). Research productivity and scholarly accomplishment of college teachers as related to their instructional effectiveness: A review and exploration. Research in Higher Education, 26, 227-298.

Finkelstein, M.J., Frances C., Jewett, F.I., \& Scholz, B.W. (2000). Dollars, distance, and online education: The new economics of college teaching and learning. Phoenix, AZ: Oryx Press.

Granof, M.H., Platt, D.E, \& Vaysman, I. (2000). Using activity based costing to manage more effectively. PricewaterhouseCoopers Endowment for the Business Government.

Hagerott, J., \& Ferezan, J. (2003). Faculty roles unbundled - Franklin University. In G. Richards (Ed.), Proceedings of World Conference on E-Learning in Corporate, Government, Healthcare, and Higher Education 2003 (pp. 1306-1308). Chesapeake, VA: AACE. Retrieved from http://www.editlib.org/p/12128.

Horngren, C.T., \& Harrison, W.T. (2007). Accounting ( $7^{\text {th }}$ ed.). Upper Saddle River, NJ: Pearson Prentice Hall.

Hrabowski, F.A. III. (2004). Leadership for a new age: Higher education's role in producing minority leaders. Liberal Education, 90.

Knowles, E., \& Kalata, K. (2007). A model for enhancing online course development. Innovate, 4(2). Retrieved from http://www.innovateonline.info.

Knapp, L.G. (2008). Employees in postsecondary institutions, fall 2007, and salaries of full-time instructional faculty 200. Retrieved from National Center for Education Statistics website: http://nces.ed.gov/pubsearch/pubsinfo.asp?pubid=2009154. 
Linsky, A. S., \& Straus, M. (1975). Student evaluation, research productivity, and eminence of college faculty. Journal of Higher Education, 46, 89-102.

Ljosa, E. (1988). The boundaries of distance education. Journal of Distance Education, 3(1), 8588.

Nagel, D. (2009, October 28). Most college students to take classes online by 2014. Campus Technology Online. Retrieved from http://campustechnology.com.

Neely, P.W. (2004). A cost study of various methods of delivering a university course (Unpublished doctoral dissertation). University of Virginia, Charlottesville, VA.

Palloff, R.M., \& Pratt, K. (2007). Building online learning communities: Effective strategies for the virtual classroom. Danvers, MA: Jossey-Bass Publishing.

Rumble, G. (2001). The costs and costing of networked learning. Journal of Asynchronous Learning Networks, 5(2), 75-96. Retrieved from http://php.auburn.edu/outreach/dl/pdfs/Costs_and_Costing_of_Networked_Learning.pdf.

Sammons , M.C., \& Ruth, S. (2007, January). The invisible professor and the future of virtual faculty. International Journal of Instructional Technology and Distance Learning, 4(1), 3-13.

Schuster, J.H., \& Finkestein, M.J. (2006). The American faculty: The restructuring of academic work and careers. Baltimore: John Hopkins University Press.

Stratford, M. (2009, January 26). University set to slash budgets. The Cornell Daily Sun.

Tantivivat, E.M., \& Allen, S.D. (2004, July). Instructional designers and faculty working together to design learning objects. Paper presented at the $20^{\text {th }}$ Annual Conference on Distance Teaching and Learning, Madison, WI.

Trout, W. E. (1979). Unbundling instruction: Opportunity for community colleges. Peabody Journal of Education, 56(4), 253-259.

Wang, W. K. S. (1975). The unbundling of higher education. Duke Law Journal, 1, 53-90.

Wechsler, H. S. (2004). Overview. The NEA 2004 almanac of higher education. Washington, DC, NEA. Retrieved from http://www.nea.org/assets/img/PubAlmanac/ALM_04_01.pdf.

Winston, G.C. (1988, December 14). Economic research shows that higher education is not just another business. The Chronicle of Higher Education.

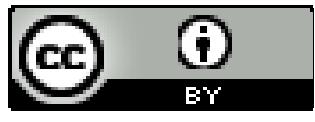




\title{
Process-Based Assessment for Professional Learning in Higher Education: Perspectives on the Student-Teacher Relationship
}

\author{
Peter Bergström \\ Umeå University, Sweden
}

\begin{abstract}
This article reports on a study that was carried out in autumn 2007 with students in a professional nurse education distance course at a Swedish university. The study aimed to develop a greater understanding of the student-teacher relationship based on research questions addressing the teachers' role, the learning process, and the assessment process in traditional approaches to teaching and learning. A didactical design was adopted, focusing on three learning outcomes in three phases. In each of the three phases, these learning outcomes were assessed by each student documenting his/her knowledge at the beginning, middle, and end of the course. Data was collected via in-depth interviews with students $(n=14)$ and through a questionnaire $(n=40)$ and was analysed using an inductive thematic analysis of the material. The results indicate a studentteacher relationship involving ambiguity and complexity in relation to the degree of teacher direction as being teacher-centred or learner-centred and also in relation to the learning process as being reproductive or productive. The interpretation of the results shows diverse aspects of the student-teacher relationship arising from students' beliefs about teaching, learning, and assessment and, in particular, process-based assessment. The locus of control involves the teachers' role, the learning process, and the assessment process, which illuminates different perspectives of power relations in the student-teacher relationship.
\end{abstract}

Keywords: Process-based assessment; power relations; learning process; assessment process; teacher direction

\section{Background to the Study}

Students can access education today without leaving their hometown and family, making it easier to increase the overall level of education of citizens in society. The use of contemporary technologies in education creates the possibility of changed roles for both students and teachers. In this evolving paradigm, new skills are necessary for managing students' learning and their achievements. The European Union has identified eight key competencies (The European 
Parliament and the Council of the European Union, 2006). The goals of the fifth key competency, learning to learn, are to make the learner aware of his/her learning process, to develop the learner's skills to solve problems in the learning situation, and to build on the learner's existing knowledge, gained from other educational experiences at work or in everyday life.

Both in face-to-face learning and distance education, there are perspectives of control in the student-teacher relationship. When entering a distance course, most students will have experienced traditional teaching and learning, which is understood as the knowledge transfer metaphor (Säljö, 2000), mediated by desk teaching. Within this tradition, the students are characterised as having a passive role in the student-teacher relationship. Garrison and Anderson (2003) argue that e-learning provides a different learning experience but that much of the existing knowledge on the student-teacher relationship rests upon classroom teaching. It is plausible to believe that this interaction between new and old experiences creates confusion regarding control. Garrison and Baynton (1987) explore the notion of control as the balance between independence, power, and support. In the student-teacher relationship, independence is simply freedom in the students' learning; power deals with the question of responsibility for one's learning; and support grows from the role of the teacher. Thus, confusion can arise for both teachers and students when control shifts between the actors. This paper reports on a study that aims to understand the student-teacher relationship in the context of process-based assessment for learning (Black \& Wiliam, 1998). The notion of process-based assessment is understood from cycles of reflections and formative assessment. The context for the study is a professional distance education course on the subject of child health care in a nurse education programme. Limited generalisations are warranted with regard to the particular context of this study and to the group of students of inquiry. The research questions addressed students' expectations and beliefs in relation to teaching and learning:

- How does the teacher's role change in relation to traditional approaches to teaching and learning?

- How does the learning process change in relation to traditional approaches to teaching and learning?

- How does the assessment process change in relation to traditional approaches to teaching and learning?

\section{Didactical Design}

In practice, there are a variety of methods to document the learning process, including reflective journals, learning journals, or process diaries. The promotion of critical thinking is a central aspect of all these methods (Harris, 2007; Langer, 2002; Thorpe, 2004). Thorpe (2004) highlights the move from a routine practice to a reflective professional practice. This movement fosters a student-centred approach and active learning in which students at different levels arrive at new insights into the practice or subject at hand. Such a shift in practice reflects a student-teacher relationship in which the teachers guide students with the support of formative feedback (Bergström \& Granberg, 2007). However, when students are not accustomed to employing these 
reflective methods, difficulties can arise, as illuminated in the study by Langer (2002), which highlights the problems that students can have in understanding the purpose of a learning journal.

The figure below illustrates the didactical design for a course of study that takes its starting point in the three phases aimed at covering and capturing the students' learning process during the semester. In the Swedish language, the term process refers to a course of events that is intended to change and develop something (SAOL, 2009).

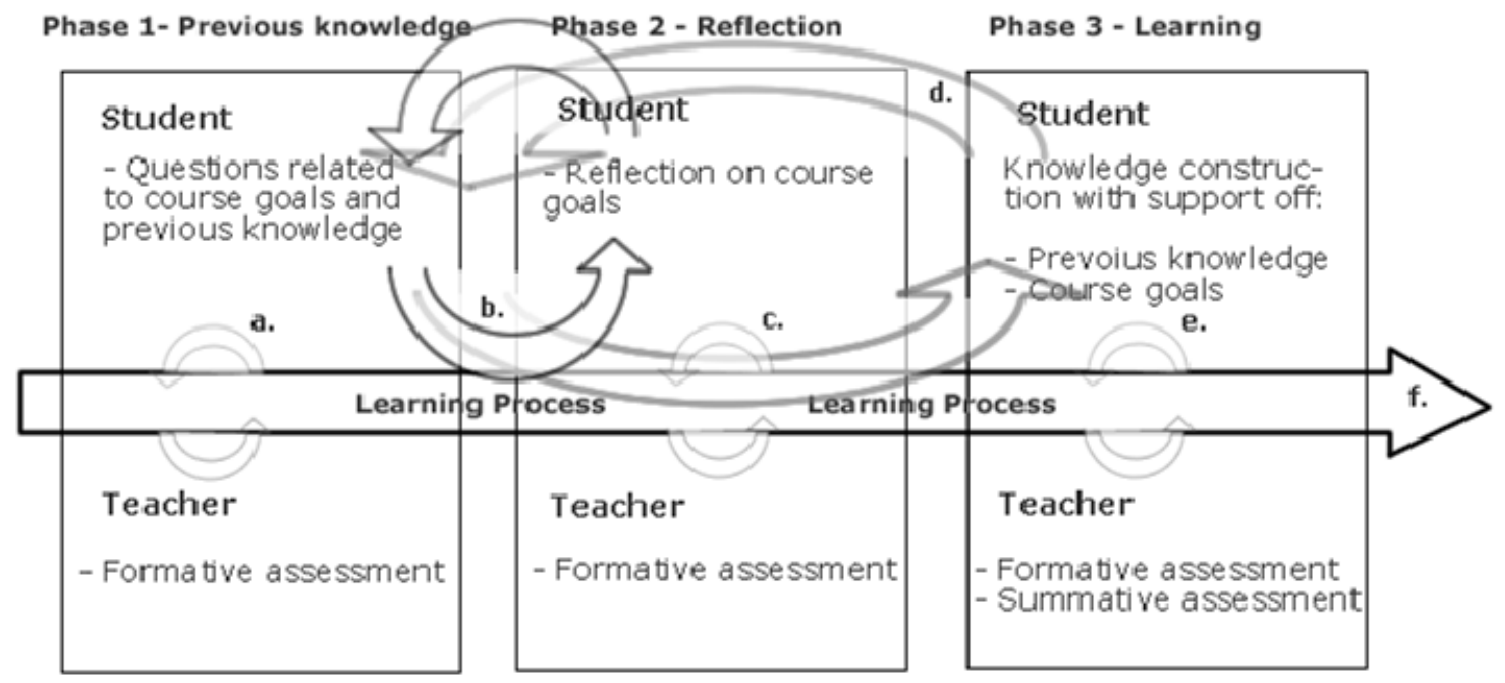

Figure 1. The figure illustrates the didactical design of process-based assessment.

Phase 1 establishes the starting point as the beginning of the course. In this phase, students describe previous knowledge from the perspective of their previous life, work, and study experiences, upon which the teacher gives feedback (a). In the middle of the course (phase 2), students reflect upon their knowledge in relation to their previous knowledge and the learning outcomes (b), which is followed up with teacher feedback (c). When students finish the course (phase 3), they summarise their learning in relation to their previous knowledge and the learning outcomes (d). The teacher provides feedback on the students' texts and makes a final judgement (e). As with reflective learning journals, students focus on the documentation of their experiences, events, and concepts, and over a period of time they gain self-awareness and insight into their learning (Thorpe, 2004), which constitutes the learning process (f). In this study, the students had the support of a learning management system (LMS) and a web-based videoconference system (Marratech). Recording of the outcomes of the process-based assessment was achieved by using document files stored in the LMS.

The teachers used a template developed in a teacher education programme. In the first phase, the students were asked to describe their previous experiences from work, school, and life, and this was followed by three open questions from the perspective of three learning outcomes; for example, "Analyse lifestyle and risk of accidents among children and youths, and carry through and evaluate necessary actions." In the second phase, the students found eight points for reflection from the perspective of the assignments in the course (e.g., the care of children), 
followed by four points of reflection upon literature, lectures, and scientific articles. In the third phase, the students took their starting point from the learning outcomes by developing three key concepts in their own words together with an analysis of their learning during the course of study. Furthermore, the teacher asked the students for future reflections in phase three.

\section{Methodology}

The study focused on a mixed group of district and child nurse students attending a child health care course in a specialist nurse program at a university in Sweden in autumn 2007. The course was a distance course at a $50 \%$ pace, with two mandatory face-to-face meetings at the start of the course and at the end of the course. Between the meetings, the students worked in study groups at a distance, supported by videoconferencing and the use of the LMS. Each week the teachers held seminars through the use of videoconferencing. Furthermore, as a course requirement, the students underwent practical nurse training at child health care centres and in school health care. As well, the students attended another course at a $50 \%$ pace, fulfilling the $100 \%$ study pace. At the start of the course, students were asked to answer a questionnaire about their previous educational backgrounds and their positive and negative experiences of being assessed. From the questionnaire a convenience selection was used in which 10 out of 42 students volunteered to participate in the research study. At the outset, students agreed to a statement of research ethics. This followed the guidelines from both the Swedish Research Council (2001) and the University and addressed the aspects of beneficence, nonmalfeasance, informed consent, and confidentiality/anonymity. Before the study began, two students dropped out. The eight students were females between 25 and 42 years of age, with 1.5 to 20 years of work experience. The informants had limited experience with distance education, particularly ICT-supported distance education.

The teachers who decided to use process-based assessment were keen and enthusiastic about starting. Neither the teachers nor the students had prior experience of process-based assessment. Accordingly, the teachers took as their starting point the work of Bergström \& Granberg (2007) by adopting a template that was modified for their particular needs. At the start of the course, the teachers introduced the students to process-based assessment during the mandatory meeting by giving a lecture for 30 minutes in which the pedagogical approach was briefly explained and the students had the opportunity to ask questions. The slides from the lecture were accessible in the LMS during the course.

Qualitative semi-structured interviews were conducted with the eight students, five weeks after the start of the course, and focused on the first phase of the process-based assessment. The interviews were conducted by phone and, when possible, face-to-face. A follow-up interview was completed with the six remaining students, three weeks after the course was completed, and was focused on the second and third phases of the process-based assessment. The student interviews were based on themes from all three phases. The two sets of interviews followed a similar structure, which aimed to capture the students' experiences in each phase from the perspective of the students' feelings, the character and nuances of process-based assessment, and the students' expectations of the teachers and of process-based assessment. The interviews were recorded 
digitally and transcribed, and notes were taken during the interviews. The recorded material from the interviews amounted to 15.5 hours.

\section{Thematic Analysis}

Thematic analysis is a process used for analysing qualitative data. This process is understood from the two perspectives of "seeing" and "seeing as" (Boyatzis, 1998). To see something means to find patterns in the data that begin with a coding procedure; whereas, to see as focuses on the interpretation of the analysis by bringing parts together. A starting point in the data was taken, and the coding procedure was derived inductively.

The qualitative process was understood from different steps of reflections and interpretations by using an inductive approach. However, Coffey and Atkinson (1996) describe clues to look for in qualitative data in support of inductive analysis of the material, including episodes, comparisons, and contrastive thinking in the statements. In line with Boyatzis' (1998) views on inductive thematic analysis, the coding procedure started by reducing the raw information into written outlines of each unit of text. The information was interpreted in terms of what the interviewee was explicitly or implicitly saying. From the units of text, the process of "seeing” started by identifying descriptive themes (Wolcott, 2001). As the purpose of my research was to understand process-based assessment, taking it a step further was necessary. This step moved from the descriptive level to a higher analytical level in order to investigate what underpinned processbased assessment. The higher level of "seeing as" involved a process of interpreting the themes in relation to other themes and to theory.

\section{Theoretical Framework}

The tools for understanding didactical design through the analysis of student interviews are based on a theoretical framework that has been developed as part of this study. In the analysis, Moore's (2007) theory on transactional distance was used to conceptualise the degree of teacher direction, while Illeris' theory (2009) was necessary for conceptualising the learning process. By combining the theoretical perspectives of Moore and Illeris it was possible to illuminate how students move between different approaches to learning. Bernstein's (2000) concepts of strong and weak classification and framing were used to interpret what underpins the context of process-based assessment, which supported an understanding of the student-teacher relationship.

The theory of transactional distance (Moore, 2007) addresses the teacher-student relationship in light of the degree of teacher direction. Transactional distance is seen as a relative concept that is especially applicable to working in online contexts. The transaction between the teacher and the student is seen to be dependent on two variables, in particular dialogue and structure (Moore, 1980). Dialogue is seen as important for bridging transactional distance (Moore, 1991; 2007), while the structure of a course frames the ways in which students are able to make their own interpretations of the what, how, and why questions with regard to tasks they are asked to accomplish. If the structure is loose, the students have greater opportunities for making their own interpretations. However, assessment of students' work is necessary and despite the dichotomy 
between summative and formative assessment it should always involve both summative and formative assessment (Taras, 2005; 2007a; 2007b). Through the application of these theories, the aspects of teaching and assessment are brought to the fore.

The major challenge in the learning process is bridging the gap between different learning experiences (Illeris, 2009). Building on Piaget's cognitive theory, Illeris (2009) classifies levels of learning from the perspectives of assimilative or accommodative learning. These concepts are not separated in practice, but emphasis is often placed on the assimilative learning perspective. Illeris (2009) explains the assimilative learning perspective as learning by addition, or, in other words, the learner adds new pieces of knowledge to what already exists. The accommodative approach or transcendent learning modifies existing schemes by a process of deconstruction and reconstruction. Space is found within the latter process to include previous experiences and knowledge acquired from other contexts, assignments, or experiences. In practice, Illeris (2009) suggests problem-based learning as one way of transferring knowledge between two different contexts. Thus, these concepts demonstrate ways of understanding the learning process, which are of significance for process-based assessment.

Bernstein's (2000) theoretical framework in relation to pedagogical practice and the concepts of classification and framing provide the basis for an understanding of different power relationships between agents in the classroom. The theory of classification and framing was applied in order to understand what underpins the student-teacher relationship as well as the messages arising from introducing process-based assessment into practice. The concept of classification provides a framework for exploring relationships between different categories and between agents, discourse, and practices. Classification is constituted from the degree of insulation between the categories. The degree of insulation helps to recognise a unique identity, approach, or voice. Thus, it is possible to differentiate between strong and weak classification based on the extent of insulation between categories. The concept of classification is between categories, while that of framing is within categories.

Framing refers to what is inside a category and is carrying its message. Framing is the locus of control and varies according to the pedagogical relationship between the teacher and the student. This locus of control relates to a number of questions about students' learning, such as who decides the frequency of reflections, which learning outcomes to focus on, how assessment is accomplished, and what to do with feedback. These questions reflect Bernstein's (2000) concepts of selection, pacing, timing, and organisation of students' learning in the student-teacher relationship. Furthermore, if framing is strong, the students have explicit instructions about how to deal with these questions; if framing is weak the students must take greater responsibility for interpreting and taking different decisions in their learning. 


\section{Results}

The results of the study are presented in the following section. In the presentation of the data, an attempt was made to show the student-teacher relationship from the perspective of the teacher's role, the learning process, and the assessment process; a table was created with this goal in mind. In order to illustrate the different perspectives, the students' voices are made evident via frequently used quotations. The students' perceptions of process-based assessment were ambiguous and comparable to other educational experiences, such as the nursing programme in general. They were positive towards reflecting and reinforcing prior learning but argued strongly for developing new pieces of knowledge through activities supported by course literature and assignments, rather then developing previous knowledge. By reading, re-reading, and listening to the interviews, my perception of this particular group of students was that it was a group that was interested, engaged, and ambitious about the subject knowledge, particularly as it pertained to their daily work as nurses. From the questionnaire it was found that the entire group of students had experienced learning according to the knowledge transfer metaphor of desk teaching as described by Säljö (2000). Desk teaching involves the students being strongly monitored by the teacher with little opportunity for making their own decisions. Most of the students had been taught through such a teaching approach in both compulsory school and upper secondary school. Furthermore, a majority of the students regarded norm-referenced marks as unfair, as exemplified by one student who remembered "my teacher could not give me a four [five was the highest mark] because all fours were already occupied." The students mentioned feedback from the teacher in their previous experiences as something positive. An example of this was expressed in the following statement: "studying at the upper secondary school I was informed what was good and what I should think about for improving.” The interviewees all had a similar experience of work, school, and higher education, and none had prior experience of process-based assessment.

The data was analysed by reading and re-reading the interviews. A first analysis resulted in three categories, or themes, which were inductively derived at a descriptive level. The descriptive themes of process-based assessment were

- the why, how, and what questions,

- the learning dimension, and

- the students' perception of the teachers' feedback.

The analysis was brought to a deeper level by applying aspects of Illeris's (2009) theory of assimilative and accommodative learning, which underpins the labels of reproductive and productive learning. The category of teacher directedness was derived by Moore (2007) as teacher-centred teaching or learner-centred teaching. The typology attempts to capture the relationship between the student and the teacher in process-based assessment. Each square in the quadrant is derived from the students' reasoning in the interviews, from answers in the questionnaire, and from the contribution of the theoretical framework presented earlier. The quadrant indicates the complexity in the intersection between students' beliefs about their learning process and the visible and tacit direction by the teacher. These intersections give rise to "fields of tension" (spänningsfält in Swedish) between the categories, which produce the content 
in the quadrant. All of the interviewees' answers can be placed in the four categories, which constituted the following intersections: teacher-centred teaching and reproductive learning, teacher-centred teaching and productive learning, learning-centred teaching and reproductive learning, and learning-centred teaching and productive learning.

Table 1

The Student-Teacher Relationship in Process-Based Assessment

\section{Student learning}

\section{Reproductive learning}

\begin{tabular}{|c|c|c|}
\hline مo & $\begin{array}{l}\text { 1. The students expect } \\
\text { strong teacher direction } \\
\text { and students’ beliefs are } \\
\text { characterised by } \\
\text { instrumentality in learning } \\
\text { and assessment }\end{array}$ & $\begin{array}{l}\text { 2. The students expect } \\
\text { strong teacher direction. } \\
\text { The students' beliefs are } \\
\text { characterised by an } \\
\text { awareness of their } \\
\text { learning and a view of } \\
\text { assessment for learning }\end{array}$ \\
\hline 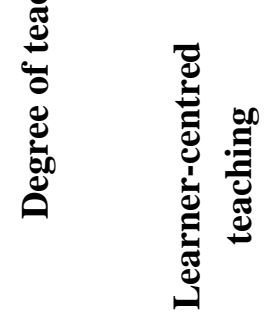 & $\begin{array}{l}\text { 3. Teacher direction is } \\
\text { weak, and students’ beliefs } \\
\text { are characterised by } \\
\text { instrumentality in learning } \\
\text { and assessment }\end{array}$ & $\begin{array}{l}\text { 4. Teacher direction is } \\
\text { weak and students' beliefs } \\
\text { are characterised by an } \\
\text { awareness of their } \\
\text { learning and a view of } \\
\text { assessment for learning }\end{array}$ \\
\hline
\end{tabular}

The typology shows the student-teacher relationship derived from the students' narratives. The students' experiences are complex because they have not taken a clear decision for any category. The names of the students are replaced by pseudonyms.

\section{Teacher-Centred Teaching and Reproductive Learning}

As reflected in the first quadrant, students argued for teacher-centred learning in which they conducted a reproductive strategy for learning. In this category, students expected teacher guidance to be authoritarian. The students waited for the teacher to give orders, which Elisabeth expressed as, "I wait for someone to tell me that now it is part two, write part two." Cecilia strongly expressed that the written instructions should be given without room for interpretation. Her view was that the written instructions should provide information on "how you shall think and how you shall write and what to focus upon.” 
In the students' narratives of their learning, a web of reflections on their thinking and actions portrayed their subjective strategies. These strategies were often derived from a starting point of asking for references to use. As Linda commented, "Yes, but you always think that assignments shall be written with references and that everything shall be written with references. You are not really allowed to have your own opinion without having references.” Obviously, this student started to think of a strategy adopted from other assignments in the course and probably other educational experiences. For some students, their reasoning mirrored a simple equation of gaining knowledge, as Maggie enthusiastically expressed: "I had such limited previous knowledge. Through this it was really useful for me to see that I had learned a lot.” This student illustrated a knowledge dimension of fragments.

In line with the learning approach above, students' reasoning of assessment was from a perspective of right or wrong, such as looking for an answer in the course literature. As Cecilia complained, "I didn't have any feedback if I did right or wrong." However, there are reasons to believe that the course had a pedagogy that supported this approach, which Linda highlighted: "it was just one assignment among others ... we had a lot of small assignments to accomplish.”

\section{Teacher-Centred Teaching and Productive Learning}

As reflected in the second quadrant, the role of the teacher was visible in the instructions, where the teacher identified which learning outcome the students should reflect on. This delimiting purpose was not positive because it could decrease the students' engagement, as Klara reflected: "I am not interested in working with children ... I think that was why I didn't feel the interest to write.” However, Sara expressed an extended role in her writing: "When I reflect, I think I am the one who decides what I shall write and how I perceive the questions."

In the students' learning, the pedagogy of process-based assessment started to come to the fore. As Linda observed, "however, you thought it was some kind of work, but it was about my knowledge.” Doubts were expressed from the perspective of sifting and using references. Jennie was confused: "I thought: 'what shall I write?' I know roughly what I have as previous knowledge, but if I shall write everything I know about children with autism then it will be a novel.” All students expressed these kinds of difficulties in the first meeting where process-based assessment was in use. Jennie was aware of her previous and rich knowledge of a particular subject but expressed difficulties in delimiting and choosing the more important parts in relation to the learning outcomes for her story.

The students also understood the assessment differently. At the start of her writing, when she was not building her story on literature, Jennie thought, "Will the teachers think I'm stupid now when I have less knowledge in the learning outcomes?” Klara continued and argued with confidence that a student story can be developed differently and without one right answer: "Connected to these three learning outcomes there were instructions to reflect upon each assignment, but that can be done with different approaches.” 


\section{Learner-Centred Teaching and Reproductive Learning}

As reflected in the third quadrant, the students had space for interpreting the instructions, but conflicts arose from expectations based on other educational experiences. In fact, the teachers were not as visible in the instruction to the extent that the students desired.

The students were frequently comparing the new learning experience with other educational experiences. Jennie reflected that "I learned much more in the other parts when we had lectures and seminars, and assignments to work with.” For the process-based assessment task, this student noted an engagement for learning as "find[ing] as much as possible in these three learning outcomes." This created a feeling in several of the students' stories of learning, which were constituted of compilations of literature. One aspect that influenced students' actions and thinking was probably the course design, which Linda expressed dispassionately: "We had a dreadful amount of assignments, and this was one of many to accomplish." In moments of pressure the students adopted a strategy of accomplishing, promptly forgetting the experience, and continuing with the next task. Three students felt that they were "taking a chance" by sending the document to the teacher.

From the assessment perspective, in the reproductive approach to learning the students asked for judgments expressed as right or wrong. Again, the feedback from the teachers confirmed and summarised the students' efforts, but instead of asking for qualitative supervision Elisabeth argued that "the teacher must check that I am on the right track." A few students received constructive feedback, but the feedback had no requirement for them to make changes to their work. Klara took this decision: "I got a comment from the teacher on how I could write and develop the text, but I didn’t do it.”

\section{Learner-Centred Teaching and Productive Learning}

As reflected in the fourth quadrant, the students searched for the reflective moment that gave them support for further reflection. The role of the teacher highlighted an openness that supported students' interpretations and decision-making regarding the task.

As they approached the end of the course, the students began to take extended decisions in relation to the instructions. Klara asserted that "the text should be connected to the course literature and lectures but I didn’t think those had so much to give. Instead, the text was developed more from our practice.” Klara continued and reflected on the knowledge she gained from the process-based assessment in relation to the assignments in the course. She commented that "in other assignments, I gained new knowledge ... but the process documentation is only a reflection.” The student thought that there was something wrong when she had not developed (according to her understanding) new knowledge. Two students understood their knowledge as deeper. Klara observed how her previous knowledge had become more profound: "It (the text) felt as the text I wrote in my previous knowledge ... but here (in practice) I saw it was possible to accomplish and in which form, so it had become deeper." Linda continued and reflected, "My perspectives had become wider, because it was very much influenced by media before.” This 
moment of reflection and repetition was a positive activity for all students, as Cecilia noted: "There is nothing wrong with reflecting on your learning; it is positive."

When the purpose of assessment was for learning, the students received questions and reflections from the teacher to elaborate and reflect on. Only one student received feedback, which was used for elaborating the knowledge during a two-week training period as a school nurse. Jennie expressed satisfaction with this: "I thought about these comments when I was at the school practice.” However, the students were aware of the need for formative assessment. Jessica articulated her critique on the feedback:

Yes, [it is important] that the teacher not just makes summaries or that the teacher in fact not at all make summaries. Instead I want comments and perspectives on what I have written from the teachers' point of view. I do not want that feeling that I got something back which I wrote by myself, I ask for feedback from the teacher on what I have written.

Obviously, there was a gap between the students' and teachers’ expectations of each other.

\section{Discussion of the Findings}

This study aimed at gaining a better understanding of the student-teacher relationship in processbased assessment. The typology of the four categories of thinking and action that was developed illustrates the diverse aspects of the teacher's role in relation to the student's approach to the learning process and also the diverse aspects of the student's role in relation to teacher direction. The nature of the diversity relates to the fact that while students can be categorised strongly within one quadrant, there is considerable overlap. Furthermore, the ambiguity in the students' narratives made it necessary to conduct a very close analysis in order to derive the students' voices with regard to these four categories. The results did not clearly illustrate the extremes of teacher-centred teaching and reproductive learning and learner-centred teaching and productive learning from the starting point to the end of the process. Therefore, the students did not move from reproductive to productive learning in their learning process. Because of the diversity, the students' previous experiences played an important role in understanding process-based assessment. The data revealed two categories, with particular approaches arising from previous experiences of teaching, learning, and assessment in relation to this new experience.

In conducting this analysis, the theoretical perspective of Bernstein (2000) was used in order to interpret and discuss the results based on the concepts of strong and weak classification and framing. In the first category - a traditional approach to teaching and learning - the students argued for a mode of teaching and learning that they were familiar with. From the students' previous experiences, they knew very well how teaching and learning should be arranged, and they had clear ideas about what they wanted the teacher to do. This approach communicated a strong classification and framing in which the teachers and the students had clearly defined roles. These roles illuminate a power relationship in which the teacher monitors the students. The 
second category arises from a weakness in and a challenge to the traditional approach. This challenge most probably grew from entering into an approach of distance learning of this nature, in particular the reflective approach of process-based assessment. A starting point for this challenge is the students' previous experiences of gaining feedback, insights they gained from previous educational experiences such as upper secondary school. These insights became evident when the students started to enter a productive thinking phase on learning. However, this process became stronger once the students gained insight into the pedagogy of process-based assessment related to the feedback they received from the teacher. The weakening of the traditional approach resulted in a challenge to the students' previous beliefs about and reference points to teaching, learning, and assessment. This process can be seen as the cause of a state of confusion that was experienced by many of the students. The difficulty in moving on from this state of confusion was greater for some students than for others. In the second category, with an approach of process-based assessment, the students understood the learner-centred teaching. The locus of control changed accordingly because the students became more confident in their actions and thinking in relation to process-based assessment and probably distance learning as such. In the second approach, which involved weak classification and framing, the students were more aware of their own learning processes and their associated desires and claims.

The teachers' goal was to implement and develop process-based assessment in this distance education course. The role was understood from a perspective of what the teachers actually did or did not do in relation to the two categories. The students' approach to learning is a reflection of strong classification associated with teacher-centred teaching. The course design built on several assignments, which communicated a teacher-centred locus of control. Such design could be the root of the students' strategy towards learning, which was to "accomplish and forget." It is plausible to believe that the design of the template limited the findings. There is a high degree of structure with a teacher-centred approach in which the teachers control sequencing, organisation, timing, and pace (Bernstein, 2000) in students' learning. These teachers did their best given the preconditions and their own interest in bringing about change. The process of change would probably have been smoother if the teachers had been familiar with support and training in the pedagogy of process-based assessment and if they had developed the template themselves. With a learner-centred approach, process-based assessment provided opportunities for dialogue and interpretation (Moore, 2007), but the teachers' practices remained teacher-centred. Similarly, as the students entered their state of confusion, it seemed that the teachers themselves were trapped in the same space. This dilemma was illuminated in the process of assessment when the teachers provided feedback that did not challenge the students. It seems that the students moved more quickly towards a learner-centred approach to learning than the teachers moved towards a learner-centred approach to teaching.

The students were moving between strong and weak classification and framing in their learning. The strong classification in the students' learning was expressed through a comfort with the structured approach to learning, one in which they knew how to act and perform. This structured learning environment is something the students had grown up with and were familiar with. When classification became weaker, the students' educational awareness of the value in gaining feedback was heightened. This can be understood as contributing to a gap in terms of the 
development of a shared understanding in the student-teacher relationship. The pedagogy of process-based assessment involves weak classification and framing, arising from the nature of the learner-centred approach. Accordingly, the shift in the locus of control to the students gave them a stronger voice and more room for taking different decisions. However, the students acted in a counterproductive way in response to this opportunity; this was clear when they became satisfied with simply submitting the task and appeared uninterested in dialogue with the teacher. This counterproductive approach illuminates the power relationship between strong and weak classification, which also reflects the influence of the course design. Langer (2002) found that students have difficulties understanding this pedagogy, and, in a similar way, capturing the learning process was a complex task for the students in this study. These difficulties could be seen to be the result of the strong classification being an obstacle at the start due to the students' limited skills and prior experience with such an approach. The difficulty experienced in choosing content at the starting point of the process indicates their familiarity with a more reproductive strategy towards learning. When students are acclimatised to a traditional approach to teaching and learning, adjusting to the new approach is a big leap, especially when this is done without sufficient training. However, the productive approach to learning was visible in the students' reasoning and insights into their knowledge. The three learning outcomes were a channel for tacit communication and strong classification and framing in the student-teacher relationship (Moore, 2007).

In order to change this locus of control through weaker framing, it is probably necessary to strive towards shared responsibility by increasing the level of freedom and control the students have over the learning outcomes. Accordingly, individual productivity and creativity could be stimulated to a greater extent by offering students more and open choices to address their professional needs, thus enriching the distance learning experience. Students who were not asking for the possibility of choosing their learning outcomes probably had stronger arguments in favour of the teacher-centred approach. It can not be overlooked that the use of a pre-set template affected the results. This template provided a tacit voice of structure from the teachers (Moore, 2007), which had several "check points" by focusing on the individual development of each student. Some degree of structure is clearly needed, but the key question is how much.

Taras (2005, 2007a, 2007b) argues for assessment as one process through which the students receive a judgement. If the judgement comes from the teacher, it is a voice of strong classification. The students were asking for a summative assessment in its most simplified form (i.e., being right or wrong). This thinking was a strong belief that was reflected in the students' reasoning. When classification became weaker, the students gained insight into the fact that the answers could be diverse and did not necessarily follow a norm, particularly in a group with such diverse backgrounds. The students also had an awareness of what they wanted from assessment to support their learning. But when the students received constructive feedback, they did very little in response. This gap between awareness and action could be interpreted as arising from an unequal power relationship, associated with the traditional approach to teaching and learning and based on strong classification and framing. Thus, the students were satisfied if they could interpret or justify that their achievements were perceived as having been accomplished from the 
teacher's perspective. As a consequence, the process aspect in process-based assessment was moved to the background.

In summary, the key findings from this study lead to an increased understanding of the studentteacher relationship in the distance education context and, in particular, the ways in which the power relationship involves the teacher's role, the learning process, and the assessment process. A pedagogical issue for students in distance education was highlighted: professional experience meeting a new paradigm for learning. In terms of the teacher's role, the power relationship shows more openness than authoritarianism but also reveals greater demands on the student to take responsibility for his or her own learning. In terms of the student's learning process, the power relationship illuminates a shift in reasoning, decision-making, and actions with regard to the new experience of openness in process-based assessment in distance learning, in contrast to a traditional approach to learning. The assessment process plays an important role in the studentteacher relationship, which also influences the learning process and, in particular, has implications for the role that students expect their teachers to play. The next stage of the study will explore the impact of the teachers' beliefs about process-based assessment on this nursing education course. 


\section{References}

Bergström, P., \& Granberg, C. (2007). Process diaries: Formative and summative assessment in on-line courses. In N. Buzzetto-More (Ed.), Advanced principles of effective online teaching: A handbook for educators developing e-learning. Santa Rosa, California: Information Science Press.

Bernstein, B. (2000). Pedagogy, symbolic control and identity: Theory, research, critique (Rev. ed.). Lanham, Maryland: Rowman \& Littlefield Publishers, Inc.

Black, P., \& Wiliam, D. (1998). Inside the black box: Raising standards through classroom assessment. Phi Delta Kappan, 80(2), 139-148.

Boyatzis, R. (1998). Thematic analysis and code development: Transforming aualitative information. London and New Delhi: Sage.

Coffey, A., \& Atkinson, P. (1996). Making sense of qualitative data. London and New Delhi: Sage.

Garrison, D. R., \& Anderson, T. (2003). E-Learning in the 21st century: A framework for research and practice. London and New York: RoutledgeFalmer.

Garrison, D. R., \& Baynton, M. (1987). Beyond independence in distance education: The concept of control. The American Journal of Distance Education, 1(3), 3-15.

Harris, M. (2007). Scaffolding reflective journal writing - Negotiating power, play and position. Nurse Education Today, 28, 314-356.

Illeris, K. (2009). Transfer of learning in the learning society: How can the barriers between different learning spaces be surmounted, and how can the gap between learning inside and outside schools be bridged? International Journal of Lifelong Education, 25(2), 137148.

Langer, A. M. (2002). Reflecting on practice: Using learning journals in higher education and continuing education. Teaching in Higher Education, 7(3), 337-351.

Moore, M. G. (1980). Independent study. In R. Boyd \& J. Apps (Eds.), Redefining the discipline of adult education. San Francisco: Jossey-Bass.

Moore, M. G. (1991). Editorial: Distance education theory. The American Journal of Distance Education, 5(3), 1-6. 
Moore, M. G. (2007). The theory of transactional distance. In M. G. Moore (Ed.), Handbook of distance education ( $2^{\text {nd }}$ ed. pp. 89-105). New Jersey and London: Lawrence Erlbaum Associates.

SAOL (2009). Svenska Akademins ordlista 13:e upplagan [The Swedish language 13th edition, in Swedish]. Stockholm.

Säljö, R. (2000). Lärande i praktiken. Ett sociokulturellt perspektiv.[Learning in practice. A sociocultural perspective, in Swedish]. Stockholm: Prisma.

Taras, M. (2005). Assessment - summative and formative - some theoretical reflections. British Journal of Educational Studies, 55(4), 466-478.

Taras, M. (2007a). Assessment for learning: Understanding theory to improve practice. Journal for Further and Higher Education, 31(4), 363-371.

Taras, M. (2007b). Machinations of assessment: Metaphors, myths and realities. Pedagogy, Culture \& Society, 15(1), 55-69.

Thorpe, K. (2004). Reflective learning journals: From concept to practice. Reflective Practice, 5(3), 327-343.

The European Parliament and the Council of the European Union. (2006). Recommendation of the European Parliament and the Council on key competences for lifelong learning. Retrieved from http://eurlex.europa.eu/LexUriServ/site/sv/oj/2006/1_394/1_39420061230sv00100018.pdf

Swedish Research Council (2001). Ethical principles of research in humanistic and social science. Retrieved from http://www.vr.se

Wolcott, H. F. (2001). Writing up qualitative research ( ${ }^{\text {nd }}$ ed.). London and New Delhi: Sage.

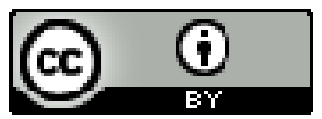




\title{
The Relationship between Academic Discipline and Dialogic Behavior in Open University Course Forums
}

\author{
Paul Gorsky, Avner Caspi, Avishai Antonovsky, Ina Blau, and Asmahan Mansur \\ Open University of Israel
}

\begin{abstract}
The objective of this study was to determine the relationship between disciplinary difference (exact and natural sciences versus humanities) and the dialogic behavior that occurred in Open University course forums. Dialogic behavior was measured in terms of students' and instructors' active participation in the forum (posting a message) as well as amounts and proportions of "teaching presence," "cognitive presence," and "social presence." We found that active participation in the science forums was much higher than in the humanities forums. We also found a ratio among the three presences that was constant across different academic disciplines, as well as across different group sizes and course types.
\end{abstract}

Keywords: Academic disciplines; disciplinary differences; asynchronous forums; dialogic behavior; community of inquiry model; virtual learning community

\section{Introduction}

The organization of knowledge into academic disciplines and the impact of these disciplines on educational objectives and curricula, on how subject matter is taught and learned, on how academic achievement is evaluated, and on how research is carried out has been extensively reported. The goal of our research is to investigate the impact of academic discipline on the dialogic behavior of participants in Open University course forums, that is, students' and instructors' active participation in the forum (i.e., posting a message) as well as amounts and proportions of "teaching presence," "cognitive presence," and "social presence." In order to study this relationship, we compared course forums from two broad disciplines whose differences greatly outweighed their similarities: exact and natural sciences versus humanities.

To place this study in a meaningful framework, we first discuss the nature of academic disciplines with special emphasis on the classic model proposed by Biglan (1973), who classified characteristics of subject matter in different academic areas. Second, we review research findings 
about educational objectives and how subject-matter is typically taught and learned in different disciplines. Finally, we present the research methodology and findings.

\section{The Nature of Academic Disciplines}

Discipline is defined by the Oxford English Dictionary as "a branch of learning or scholarly instruction." Given the diversity of academic disciplines that account for much of human knowledge, it is not surprising that significant similarities and differences exist among them. We now present a classic framework for classifying disciplines.

Biglan's research (1973) into the similarities and differences between subject matter across diverse disciplines (and the personal characteristics of those researchers who engaged in these disciplines) is considered a classic; since its publication, it has been cited extensively. Biglan found three dimensions along which disciplines may be classified:

1. Hard : Soft (the degree to which a paradigm exists),

2. Pure : Applied (the degree of concern with application),

3. Life : Non-life (the degree of concern with living systems).

Despite the statistical significance associated with the life : non-life dimension, it has been generally ignored. Left with a 2x2 matrix, Biglan (1973) classified disciplines into four categories. To each category, he associated disciplines and described the nature of their subjectmatter. Table 1 summarizes his classification.

Table 1

Biglan's (1973) Classification of Disciplines and their Subject-Matter Characteristics

\begin{tabular}{|c|c|c|}
\hline Disciplines & Disciplinary groups & Subject-matter characteristics \\
\hline $\begin{array}{l}\text { Hard : } \\
\text { Pure }\end{array}$ & $\begin{array}{l}\text { Exact and natural } \\
\text { sciences }\end{array}$ & $\begin{array}{l}\text { Cumulative, atomistic (crystalline/tree-like), concerned } \\
\text { with universals, quantities, simplification, resulting in } \\
\text { discovery/explanation. }\end{array}$ \\
\hline Soft : Pure & $\begin{array}{l}\text { Humanities and social } \\
\text { sciences }\end{array}$ & $\begin{array}{l}\text { Reiterative, holistic, organic, concerned with particulars, } \\
\text { qualities, complication, resulting in understanding/ } \\
\text { interpretation. }\end{array}$ \\
\hline $\begin{array}{l}\text { Hard : } \\
\text { Applied }\end{array}$ & $\begin{array}{l}\text { Science based } \\
\text { professions }\end{array}$ & $\begin{array}{l}\text { Pragmatic (know-how via hard knowledge), concerned } \\
\text { with mastery of physical environment, resulting in } \\
\text { products/techniques. }\end{array}$ \\
\hline $\begin{array}{l}\text { Soft : } \\
\text { Applied }\end{array}$ & $\begin{array}{l}\text { Social science based } \\
\text { professions }\end{array}$ & $\begin{array}{l}\text { Functional, utilitarian (know-how via soft knowledge), } \\
\text { concerned with enhancement of professional practice, } \\
\text { resulting in protocols/procedures. }\end{array}$ \\
\hline
\end{tabular}


Biglan (1973), and others who used this classification, clearly acknowledged that some disciplines (or particular sub-disciplines within a discipline) may straddle boundaries. For example, some fields within the discipline philosophy, say logic, tend toward hard-pure while others, say epistemology, tend toward soft-pure. Furthermore, disciplines, or sub-disciplines, may, over time, migrate towards one grouping from another; for example the movement of linguistics into the hard-pure area through the increased influence of computational research. Although these groupings were made decades ago, they still serve today as useful models for carrying out empirical research.

\section{Academic Disciplines: Goals}

To date, research has shown that disciplinary differences have a significant influence on the ways in which academic work is organized (Becher, 1990; 1994; Becher \& Trowler, 2001; Neumann, 2001). The formal academic goals of undergraduate programs commonly take the form either of a brief description of the subject matter or of a claim to high intellectual benefits. For example, a typical literature course (humanities, soft-pure) may cite as its goal: "to introduce students to the main tenets of literary criticism" or "students will appreciate the relevance of Shakespearean drama to the modern world." A typical mathematics course (exact science, hard-pure) may cite as its goal: "to introduce students to the fundamentals of calculus" or "students will acquire tools for analyzing partial differential equations." These formal goals are seemingly very similar; however, when operationalized, they differ in very significant ways from one knowledge field to another.

\section{Teaching across Disciplines}

The subject-matter characteristics of hard and soft disciplines described by Biglan (1973) in Table 1 generally correspond with particular instructional strategies. On the one hand, according to Biglan, hard subjects, both pure and applied, are generally grounded in an epistemological stance that is objective and absolute. Hard subjects are generally quantitative, based on precise measurements and widely accepted theories. Problem solving and practical skills are of high importance and priority. Hard subjects generally place a greater emphasis on mastery of content rather than on discussions. Teaching, therefore, is often didactic, based on lectures and workbooks.

On the other hand, according to Biglan (1973), soft subjects, both pure and applied, are generally grounded in an epistemological stance that is subjective and relative. They are generally qualitative and tend to place less emphasis on hierarchical knowledge foundations expressed mathematically. Discussion is a frequently employed instructional strategy.

\section{The Community of Inquiry Model}

Garrison, Anderson, and Archer (2000) developed the community of inquiry (CoI) model as an online learning research tool. The $\mathrm{CoI}$ model provides a comprehensive theoretical framework for research into both online learning and the practice of online instruction (Arbaugh, Bangert, \& 
Cleveland-Innes, 2010). The model emerged in the specific context of computer conferencing in higher education, that is, asynchronous, text-based group discussions (Garrison, Anderson, \& Archer, 2010). It remediated a lack of theoretical development in the field of online education and triggered a large amount of empirical studies (Akyol, Garrison, \& Ozden, 2009). During the years 2000-2008, 48 studies were carried out using the CoI model (Rourke \& Kanuka, 2009) and the body of research continues to grow rapidly suggesting important implications for the design of successful e-learning (Garrison, Anderson, \& Archer, 2010; Shea \& Bidjerano, 2009a).

The framework consists of three dimensions: cognitive presence, teaching presence, and social presence as well as categories and indicators to define each of the presences and to guide the coding of transcripts. Cognitive presence is defined by Garrison, Anderson, and Archer (2001) as the extent to which participants are able to construct meaning through sustained communication. Teaching presence includes subject matter expertise, the design and management of learning, and the facilitation of active learning (Anderson, Rourke, Garrison, \& Archer, 2001). Social presence is the perceived presence of others in mediated communication (Rourke, Garrison, Anderson \& Archer, 1999), which Garrison et al. (2000) contend supports both cognitive and teaching presence through its ability to instigate, to sustain, and to support interaction. It had its genesis in the work of John Dewey. This framework has provided significant insights and methodological solutions for studying online learning (Akyol et al., 2009; Garrison, Anderson, \& Archer, 2010; Garrison \& Archer, 2003; Garrison, Cleveland-Innes, Koole, \& Kappelman, 2006). The structure of the community of inquiry model has been confirmed through factor analysis (Arbaugh, 2008; Arbaugh \& Hwang, 2006; Garrison \& Arbaugh, 2007; Garrison, Cleveland-Innes, \& Fung, 2010; Shea \& Bidjerano, 2009b; Swan et al., 2008).

Social presence is described as the ability to project one's self and to establish personal and purposeful relationships (Rourke et al., 1999). The three main categories of social presence are affective communication, open communication, and group cohesion. Richardson and Swan (2003) explored perceptions of social presence in online courses and found that students' perceptions of social presence were highly correlated with perceived learning and satisfaction with their instructors (see also Steinweg, Trujillo, Jeffs, \& Hopfengardner-Warren, 2006). Picciano (2002) found relationships between student perceptions of social presence, learning, and interactions in the course discussions. The positive correlation between perceived social presence, seen according to the community of inquiry model as self projection, and most aspects of perceived learning may lead to the conclusion that social presence affords learning by setting a convenient climate (Caspi \& Blau, 2008). Garrison, Cleveland-Innes, and Fung (2010) argued recently that perceived social presence can be seen as a mediating variable between perceived teaching presence and cognitive presence. However, actual interaction in the course discussions in Picciano's (2002) study was not correlated with actual performance (their scores on a multiple choice exam and on a written assignment). Whether and how actual social interaction might or might not affect actual learning online remains unclear (Caspi \& Blau, 2008; Swan \& Shea, 2005).

Several studies investigated the shift of social presence over time in online course discussions. Swan (2002) reported that open communication indicators ("affective" and "interactive") of 
social presence increased over time, while cohesive indicators decreased. One possible explanation is that the use of such references became less necessary as a galvanized classroom community was formed. Another possible explanation addressed the fact that discussion was more exploratory than collaborative. Contrary to the nature of the shift in social presence reported by Swan (2002), Vaughan (2004) and Vaughan and Garrison (2006) found that the frequency of affective and open communication comments decreased, while group cohesion comments increased. It is important to note that the context of Vaughan's study (2004) was a blended professional development community. The interpretation was that affective and open communication was necessary to establish a sense of community. It was only after the social relationships were established and the group became more focused on purposeful activities that cohesive comments began to take precedence. Social presence online becomes somewhat transparent as the focus shifts to academic purposes and activities.

Teaching presence is defined as "the design, facilitation and direction of cognitive and social processes for the purpose of realizing [students'] personally meaningful and educationally worthwhile outcomes" (Anderson et al., 2001, p.5). Vygotsky's (1978) scaffolding analogies illustrate an assistive role for teachers in providing instructional support to students from their position of greater content knowledge. Although many authors recommend a "guide on the side" approach to moderating student discussions, a key feature of this social-cognition model is the adult, the expert, or the more skilled peer who scaffolds a novice's learning (Anderson et al., 2001). The community of inquiry model defines three categories of teaching presence: design and organization, facilitating discourse, and direct instruction. The categories of teacher presence have been tested by Anderson et al. (2001) in the analysis of the complete transcripts of two online courses and proved both reasonably reliable and useful in identifying differences in both the quantity and quality of the teaching presence projected by different online instructors. How these differences might relate to community has not yet been hypothesized, but the community of inquiry model might provide a starting point for such investigations (Swan \& Shea, 2005).

The body of evidence attesting to the importance of teaching presence for successful online learning is growing rapidly (Bliss \& Lawrence, 2009; Garrison \& Cleveland-Innes, 2005; Garrison, Cleveland-Innes, \& Fung (2010); Meyer, 2003; Murphy, 2004; Pawan, Paulus, Yalcin, \& Chang, 2003; Shea, Pickett, \& Pelz , 2004; Swan, 2002; Swan \& Shih, 2005; Varnhagen, Wilson, Krupa, Kasprzak, \& Hunting, 2005; Vaughan, 2004; Wu \& Hiltz, 2004). The consensus is that teaching presence is a significant determinate of perceived learning, student satisfaction, and sense of community. Perceived teaching presence had a strong direct effect on self-reported learning outcomes (LaPointe \& Gunawardena, 2004). Each category of a tutor's presence is vital to learning and the establishment of the learning community; their behavior must be such that they are seen to be "posting regularly, responding in a timely manner and modeling good online communication and interaction" (Palloff \& Pratt, 2003, p.118). Without an instructor's explicit guidance and "teaching presence," students were found to engage primarily in "serial monologues" (Pawan et al., 2003). Baker (2004) discovered that instructor immediacy, i.e., teaching presence (Rourke et al., 1999), was a more reliable predictor of effective cognitive learning than whether students felt "close to each other," i.e., social presence. 
Studies have demonstrated that instructor participation in threaded discussion is critical to the development of social presence (Shea, Li, Swan, \& Pickett, 2005; Swan \& Shih, 2005), and sometimes not fully appreciated by online faculty (Liu, Bonk, Magjuka, Lee, \& Su, 2005). Shea, $\mathrm{Li}$, and Pickett (2006) proposed that teaching presence - viewed as the core role of the online instructor - is a promising mechanism for developing learning community in online environments. The majority of students and instructors in Vesely, Bloom, and Sherlock's (2007) study identified the same elements for building online community, but students ranked instructor modeling as the most important element in building online community, while instructors ranked it fourth.

Cognitive presence is defined as the exploration, construction, resolution, and confirmation of understanding through collaboration and reflection in a community of inquiry (Garrison et al., 2001). Cognitive presence is grounded in the work of Dewey (1933) on reflective thinking (see Swan, Garrison, \& Richardson, 2009, for further discussion). Four categories (or phases) of cognitive presence are defined: triggering event, exploration, integration, and resolution. Garrison et al. (2001) argued that the third phase, integration, is the most difficult to detect from a teaching or research perspective. This phase requires active teaching presence to diagnose misconceptions, to provide probing questions, comments, and additional information in an effort to ensure continuing cognitive development, and to model the critical thinking process. Often students will be more comfortable remaining in a continuous exploration mode; therefore, teaching presence is essential in moving the process to more advanced stages of critical thinking and cognitive development.

\section{The Current Study: Rationale and Hypotheses}

Recently Garrison, Cleveland-Innes, and Fung (2010) suggested that the dynamic relationships among the presences across different academic disciplines be explored. This investigation does just that in the context of differences between academic disciplines. We used the quantitative content analysis technique and data logs to analyze three-week segments from 50 forums, half from exact sciences and half from humanities. Arbaugh, Bangert, and Cleveland-Innes (2010) also studied differences between academic disciplines. They found significant differences in perceptions of social, cognitive, and teaching presence between applied and pure academic disciplines. Their study was a survey based on perceptions of the CoI framework. In this study, the quantitative content analysis technique was used. Given the reliability and validity of this procedure and that all other relevant variables in the learning environment (course policy, content and difficulty, equivalent numbers of instructor assignments, group size, semi-random assignment to groups) were controlled, we expected to identify the impact of disciplinary difference on the dialogic behavior of the representative forums. We hypothesized that for forums in the exact sciences, active participation and levels of social presence, teaching presence, and cognitive presence would be significantly higher than for forums in the humanities. These hypotheses are based on empirical findings reported by Gorsky and Caspi (Caspi, Gorsky, \& Chajut, 2003; Gorsky, Caspi, \& Tuvi-Arad, 2004, Gorsky, Caspi, \& Trumper, 2004, 2006; Caspi \& Gorsky, 2006; Gorsky, Caspi, \& Smidt, 2007). 


\section{Methodology}

\section{Background}

The Open University of Israel is a distance education university that offers undergraduate and graduate studies to students throughout Israel. The learning environment is blended: The University offers a learning method based on printed textbooks, face-to-face tutorials, and an online learning content management system (LCMS) wherein each course has its own website. Course sites simplify organizational procedures and enrich students' learning opportunities and experiences. Website use is optional or non-mandatory so that equality among students is preserved. It does not replace textbooks or face-to-face tutorials, which are the pedagogical foundations of the Open University. The website provides forums for asynchronous instructorstudent and student-student interactions. Each course has a coordinator, who is responsible for all administrative and academic activities, and instructors, who lead tutorials. Instructors and coordinators are available for telephone consultations at specified days and times. Course coordinators define the number of forums made available and their purpose.

\section{Participants}

We analyzed findings from 50 forums, half from the exact sciences and half from the humanities. We created two composite forums that represented each of the disciplines. To create similar composites, the 50 individual forums were closely matched by group size and course level. Participation in all forums was non-obligatory; no grades or bonuses were linked to student participation. Distributions are shown in Tables 2 and 3.

Table 2

Distributions by Course Level

\begin{tabular}{|l|c|c|c|c|}
\hline \multirow{2}{*}{ Disciplines } & \multicolumn{3}{|c|}{ Course level } & \multirow{2}{*}{ Total } \\
\cline { 2 - 5 } & Introductory & Regular & Advanced & 25 \\
\hline Sciences (exact and natural) & 3 & 20 & 2 & 25 \\
\hline Humanities & 6 & 16 & 3 & 25 \\
\hline
\end{tabular}

Table 3

Distributions by Course Group Size - Number of Enrolled Students

\begin{tabular}{|l|c|c|c|c|}
\hline \multirow{2}{*}{ Disciplines } & \multicolumn{3}{|c|}{ Course size } & \multirow{2}{*}{ Total * } \\
\cline { 2 - 5 } & $<\mathbf{6 0}$ & $\mathbf{6 1 - 1 2 0}$ & $\mathbf{> 1 2 0}$ & Tences (exact and natural) \\
\hline Sciences & 7 & 9 & 8 & 24 \\
\hline Humanities & 7 & 11 & 6 & 24 \\
\hline
\end{tabular}

* Data were unavailable for 2 courses, one in each discipline 


\section{Instruments and Procedure}

Two instruments were employed for obtaining data: (1) the course log site that recorded the messages, and (2) the quantitative content analysis technique, which was used to code and analyze transcriptions from the 50 forums. This technique has been widely used; it is reliable and valid (Garrison, 2007). Its implementation, however, requires that several methodological issues be resolved (Garrison, Anderson, \& Archer, 2010).

One issue is the level of coding (e.g., indicator vs. category). Content analysis, as described by Rourke and Anderson (2004), is time-consuming, and coding at the indicator level is difficult, often yielding poor reliability (Murphy \& Ciszewska-Carr, 2005). In this study, we coded at the category level (Garrison et al., 2006).

A second issue is the unit of analysis. Rourke et al. (1999) identified five units of analysis used in computer conferencing research: proposition units, sentence units, paragraph units, thematic units, and message units (Garrison, Anderson, \& Archer, 2010). While there has been some discussion around this issue (Garrison et al., 2006; Fahy, 2001; Rourke, Anderson, Garrison, \& Archer, 2001), it remains a challenging decision influenced by research question and context. In the present study, we used the message unit, in accord with Anderson et al.'s (2001) study of teaching presence, Garrison et al.'s (2001) study of cognitive presence, Rourke et al.'s (1999) study of social presence, as well as Akyol, Garrison, and Ozden (2009), Gorsky and Blau (2009), and Shea et al.'s (2010) studies of all three presences.

A third issue is scoring: As in Gorsky and Blau (2009), we analyzed each message and scored each of the 10 categories as either present or not present ( 1 or 0$)$. In other words, if a category occurred more than once in a given message (say, two distinct occurrences of "open communication"), we recorded present only once. We did not count multiple recurrences of a category within the same message.

Other issues are objectivity, reliability, and replicability (Rourke et al., 2001). No established standards exist for inter-rater reliability (De Wever, Schellens, Valcke, \& Van Keer, 2006). There is no consensus for the percent agreement statistic. Often a cut-off figure of $0.75-0.80$ is used to determine reliability; others use 0.70 (Neuendorf, 2002; Rourke et al., 2001). To increase reliability and to control errors brought on by inexperience or misinterpretation, Garrison et al. (2006) suggest a negotiated coding approach: researchers code the transcripts and then actively discuss their respective codes with their fellow judges in order to achieve consensus or near consensus. Gros and Silva (2006) propose the use of a research methodology based on the intervention of the participants, especially course instructors, for analyzing computer-supported communication. In this study we used the traditional coding approach (without negotiation of disagreements or participant intervention): $25 \%$ of postings were randomly chosen and reestimated by a second rater; $92 \%$ agreement was achieved (Cohen's $\kappa=0.89$ ). 
From each course forum, three-week segments were analyzed. The trial period began one month after the start of the semester in order to insure that opening messages and initial enthusiasm had waned and that the final exam was still far distant.

\section{Findings}

Table 4 shows the percentage of students who participated in the composite science forum and the composite humanities forum by posting a message.

Table 4

Number and Percentage of Students who Posted Messages

\begin{tabular}{|l|c|c|}
\hline Students & Sciences & Humanities \\
\hline Number of students enrolled in the course & 2341 & 2562 \\
\hline Number of different students who posted & 301 & 158 \\
\hline Total participation & $12.86 \%$ & $6.17 \%$ \\
\hline
\end{tabular}

Student participation in the composite science forum was twice as high as student participation in the composite humanities forum. We also recorded the number of messages posted by instructors and students. Findings are shown in Table 5.

Table 5

Number of Messages Posted by Instructors and Students

\begin{tabular}{|l|c|c|c|c|c|}
\hline Postings & \multicolumn{2}{|c|}{ Sciences } & \multicolumn{2}{c|}{ Humanities } & Ratios \\
\hline Instructors & 410 & $31.51 \%$ & 191 & $38.82 \%$ & $\sim 2: 1$ \\
\hline Students & 891 & $68.49 \%$ & 301 & $61.18 \%$ & $\sim 3: 1$ \\
\hline
\end{tabular}

Students in the composite science forum wrote about three times as many messages as did their counterparts in the humanities. This finding, however, is surely related to the fact that twice as many students participated in the composite science forum as opposed to the composite humanities forum (Table 3). Instructors in the composite science forums wrote twice as many messages as did their counterparts in the humanities. We may assume that increased student participation accounts, at least in part, for the greater number of messages posted in the science forum, both by instructors and by the students themselves. In other words, if we factor out the twofold advantage of student participation in the science forum, we see that instructors in both disciplines posted a similar number of messages per student. In the same manner, if we factor out the twofold advantage in the number of science students, the adjusted ratio is $1.5: 1$. Science students wrote about $50 \%$ more messages than their counterparts in the humanities. A significant difference was found between the distributions of student and instructor postings in the two disciplines $\left[\chi^{2}(1)=306.1, p<.001\right]$. 
We next analyzed the forums in terms of the three dimensions that comprise the community of inquiry model. Findings are shown in Table 6. Table 6 (and tables henceforth) also show the adjusted ratios that take into account the 2.08:1 numerical advantage held by students in the science forums.

Table 6

Total Teaching, Social, and Cognitive Presence

\begin{tabular}{|c|c|c|c|c|c|c|}
\hline \multirow{2}{*}{ Presence } & \multicolumn{3}{|c|}{ Sciences } & \multicolumn{2}{c|}{ Humanities } & $\begin{array}{c}\text { Adjusted } \\
\text { ratios }\end{array}$ \\
\cline { 2 - 7 } & $\#$ & Adj. $\#$ & $\%$ & $\#$ & $\%$ & $\begin{array}{c}\text { Science : } \\
\text { humanities }\end{array}$ \\
\hline Teaching & 650 & 313 & $18.27 \%$ & 253 & $18.98 \%$ & $1.25: 1$ \\
\hline Social & 2050 & 986 & $57.63 \%$ & 878 & $65.87 \%$ & $1.12: 1$ \\
\hline Cognitive & 857 & 412 & $24.09 \%$ & 202 & $15.15 \%$ & $2.04: 1$ \\
\hline Totals & 3557 & $\mathbf{1 7 1 0}$ & $\mathbf{1 0 0} \%$ & $\mathbf{1 3 3 3}$ & $\mathbf{1 0 0 \%}$ & $\mathbf{1 . 2 8}: \mathbf{1}$ \\
\hline
\end{tabular}

Categories of all three presences were found to a greater extent in the composite science forum. Furthermore, a highly significant difference was found for distributions of teaching presence, cognitive presence, and social presence between the two composite forums, after adjusting for number of participants $\left[\chi^{2}(2) .=38.09 ; p<.0001\right]$. Social presence was more prevalent in the composite humanities forum, while cognitive presence was more prevalent in the composite science forum. We next analyzed the data at the level of category. Findings are shown in Table 7. 
Table 7

Teaching, Social, and Cognitive Presence by Categories: Instructors and Students

\begin{tabular}{|c|c|c|c|c|c|c|c|c|}
\hline \multirow[b]{2}{*}{ Presences } & \multirow{2}{*}{ Categories } & \multicolumn{3}{|c|}{ Sciences } & \multicolumn{2}{|c|}{ Humanities } & \multirow{2}{*}{$\begin{array}{c}\text { Adjusted } \\
\text { ratios } \\
\text { Science : } \\
\text { humanities }\end{array}$} & \multirow[t]{2}{*}{$\chi^{2}$} \\
\hline & & $\#$ & $\begin{array}{c}\text { Adj. } \\
\#\end{array}$ & $\%$ & \# & $\%$ & & \\
\hline \multirow{4}{*}{ Teaching } & Design & 195 & 94 & $30.0 \%$ & 71 & $28.06 \%$ & $1.32: 1$ & \multirow{3}{*}{$\begin{array}{c}\chi^{2}(2)=0.73 \\
p=.694\end{array}$} \\
\hline & Discourse & 65 & 31 & $10.0 \%$ & 22 & $8.70 \%$ & $1.41: 1$ & \\
\hline & Instruction & 390 & 186 & $60.0 \%$ & 160 & $63.24 \%$ & $1.16: 1$ & \\
\hline & Totals & 650 & 313 & $100 \%$ & 253 & $100 \%$ & $1.24: 1$ & \\
\hline \multirow{4}{*}{ Social } & Affective & 244 & 117 & $11.9 \%$ & 78 & $8.88 \%$ & $1.50: 1$ & \multirow{3}{*}{$\begin{array}{c}\chi^{2}(2)=34.68 \\
p<.001\end{array}$} \\
\hline & Open com. & 1282 & 616 & $62.5 \%$ & 465 & $52.96 \%$ & $1.32: 1$ & \\
\hline & Cohesion & 524 & 252 & $25.6 \%$ & 335 & $38.16 \%$ & $0.75: 1$ & \\
\hline & Totals & 2050 & 986 & $100 \%$ & 878 & $100 \%$ & $1.12: 1$ & \\
\hline \multirow{5}{*}{ Cognitive } & Trigger & 336 & 162 & $39.2 \%$ & 85 & $42.08 \%$ & $1.91: 1$ & \multirow{4}{*}{$\begin{array}{c}\chi^{2}(3)=1.79 \\
p=.61\end{array}$} \\
\hline & Exploration & 496 & 238 & $57.9 \%$ & 110 & $54.46 \%$ & $2.16: 1$ & \\
\hline & Integration & 22 & 11 & $2.6 \%$ & 7 & $3.46 \%$ & $1.57: 1$ & \\
\hline & Resolution & 3 & 2 & $0.4 \%$ & 0 & $0 \%$ & - & \\
\hline & Totals & 857 & 412 & $100 \%$ & 202 & $100 \%$ & $2.04: 1$ & \\
\hline $\begin{array}{l}\text { Grand } \\
\text { totals }\end{array}$ & & 3557 & 1710 & & 1333 & & $1.28: 1$ & \\
\hline
\end{tabular}

For each of the dimensions, and for all categories except cohesion, total amounts were greater in the composite science forum. No significant differences were found within the distributions of teaching presence and cognitive presence. For social presence, significant differences were found for the categories "open communication" (higher in the science forum) and "cohesion" (higher in the humanities forum).

We next analyzed amounts of teaching presence, cognitive presence, and social presence for instructors only. Table 8 presents these data. These ratios are also adjusted because instructor postings are related to the number of students who actively participated. 
Table 8

Teaching, Social, and Cognitive Presence by Categories: Instructors Only

\begin{tabular}{|c|c|c|c|c|c|c|c|c|}
\hline \multirow{2}{*}{ Presences } & \multirow{2}{*}{ Categories } & \multicolumn{3}{|c|}{ Sciences } & \multicolumn{2}{|c|}{ Humanities } & \multirow{2}{*}{$\begin{array}{c}\text { Adjusted } \\
\text { ratios }\end{array}$} & \multirow[t]{2}{*}{$\chi^{2}$} \\
\hline & & $\#$ & $\begin{array}{c}\text { Adj. } \\
\#\end{array}$ & $\%$ & \# & $\%$ & & \\
\hline \multirow{4}{*}{ Teaching } & Design & 94 & 45 & $20.98 \%$ & 56 & $23.93 \%$ & $0.80: 1$ & \multirow{3}{*}{$\begin{array}{c}\chi^{2}(2)=2.28 \\
p=.31\end{array}$} \\
\hline & Discourse & 27 & 13 & $6.03 \%$ & 21 & $8.97 \%$ & $0.62: 1$ & \\
\hline & Instruction & 327 & 157 & $72.99 \%$ & 157 & $67.09 \%$ & $1: 1$ & \\
\hline & Totals & 448 & 215 & $100 \%$ & 234 & $100 \%$ & $0.91: 1$ & \\
\hline \multirow{4}{*}{ Social } & Affective & 17 & 8 & $3.25 \%$ & 9 & $2.82 \%$ & $0.89: 1$ & \multirow{3}{*}{$\begin{array}{c}\chi^{2}(2)=32.74 \\
p<.001\end{array}$} \\
\hline & Open com. & 399 & 192 & $76.29 \%$ & 173 & $54.23 \%$ & $1.11: 1$ & \\
\hline & Cohesion & 107 & 51 & $20.46 \%$ & 137 & $42.95 \%$ & $0.37: 1$ & \\
\hline & Totals & 523 & 251 & $100 \%$ & 319 & $100 \%$ & $0.79: 1$ & \\
\hline \multirow{5}{*}{ Cognitive } & Trigger & 6 & 3 & $2.07 \%$ & 10 & $11.91 \%$ & $0.3: 1$ & \multirow{4}{*}{$\begin{array}{c}\chi^{2}(3)=11.37 \\
p=.001\end{array}$} \\
\hline & Exploration & 268 & 129 & $92.41 \%$ & 68 & $80.95 \%$ & $1.90: 1$ & \\
\hline & Integration & 13 & 6 & $4.48 \%$ & 6 & $7.14 \%$ & $1: 1$ & \\
\hline & Resolution & 3 & 2 & $1.04 \%$ & 0 & $0 \%$ & - & \\
\hline & Totals & 290 & 139 & $100 \%$ & 84 & $100 \%$ & $1.65: 1$ & \\
\hline $\begin{array}{l}\text { Grand } \\
\text { totals }\end{array}$ & & 1231 & 592 & & 637 & & $0.93: 1$ & \\
\hline
\end{tabular}

Adjusted ratios for teaching and social presence show that instructors in the composite humanities forum were equally or slightly more active than their counterparts in the humanities except for the category exploration. In this category, science instructors were more active. A significant difference was found within social presence for the category "cohesion" (higher in the humanities forum). In addition, significant differences were found in cognitive presence for the categories "trigger" (higher in the humanities forum) and "exploration" (higher in the science forum).

We next analyzed amounts of teaching presence, cognitive presence, and social presence for students only. Table 9 presents these data. Ratios are adjusted to account for the twofold participation of science students. 
Table 9

Teaching, Social, and Cognitive Presence by Categories: Students Only

\begin{tabular}{|c|c|c|c|c|c|c|c|c|}
\hline \multirow{2}{*}{ Presences } & \multirow{2}{*}{ Categories } & \multicolumn{3}{|c|}{ Sciences } & \multicolumn{2}{|c|}{ Humanities } & \multirow{2}{*}{$\begin{array}{c}\begin{array}{c}\text { Adjusted } \\
\text { ratios }\end{array} \\
\begin{array}{c}\text { Science : } \\
\text { humanities }\end{array} \\
\end{array}$} & \multirow[t]{2}{*}{$\chi^{2}$} \\
\hline & & \# & $\begin{array}{c}\text { Adj. } \\
\#\end{array}$ & $\%$ & \# & $\%$ & & \\
\hline \multirow{4}{*}{ Teaching } & Design & 101 & 49 & $50.00 \%$ & 15 & $78.95 \%$ & $3.27: 1$ & \multirow{3}{*}{$\begin{array}{c}\chi^{2}(2)=5.32 \\
p<.07\end{array}$} \\
\hline & Discourse & 38 & 18 & $18.81 \%$ & 1 & $5.26 \%$ & $18: 1$ & \\
\hline & Instruction & 63 & 30 & $31.19 \%$ & 3 & $15.79 \%$ & $10: 1$ & \\
\hline & Totals & 202 & 97 & $100 \%$ & 19 & $100 \%$ & $5.11: 1$ & \\
\hline \multirow{4}{*}{ Social } & Affective & 227 & 109 & $14.86 \%$ & 69 & $12.34 \%$ & $1.58: 1$ & \multirow{3}{*}{$\begin{array}{c}\chi^{2}(2)=9.93 \\
p=.01\end{array}$} \\
\hline & Open com. & 883 & 425 & $57.83 \%$ & 292 & $52.24 \%$ & $1.45: 1$ & \\
\hline & Cohesion & 417 & 201 & $27.31 \%$ & 198 & $35.42 \%$ & $\sim 1: 1$ & \\
\hline & Totals & 1527 & 734 & $100 \%$ & 559 & $100 \%$ & $1.31: 1$ & \\
\hline \multirow{5}{*}{ Cognitive } & Trigger & 330 & 159 & $58.20 \%$ & 75 & $63.56 \%$ & $2.12: 1$ & \multirow{4}{*}{$\begin{array}{c}\chi^{2}(2)=1.1 \\
p=.58\end{array}$} \\
\hline & Exploration & 228 & 110 & $40.21 \%$ & 42 & $35.59 \%$ & $2.62: 1$ & \\
\hline & Integration & 9 & 4 & $1.59 \%$ & 1 & $0.85 \%$ & $4: 1$ & \\
\hline & Resolution & 0 & 0 & $0 \%$ & 0 & $0 \%$ & - & \\
\hline & Totals & 567 & 273 & $100 \%$ & 118 & $100 \%$ & $2.31: 1$ & \\
\hline $\begin{array}{l}\text { Grand } \\
\text { totals }\end{array}$ & & 2296 & 1104 & & 696 & & $1.59: 1$ & \\
\hline
\end{tabular}

Students in the composite science forum were far more active than their counterparts in the humanities. This is especially conspicuous for all categories in teaching presence and for three of the four categories in cognitive presence (excluding "resolution"). Regarding the distributions of the categories, a significant difference was found for social presence.

\section{Toward a Population Parameter}

Given data from 50 forums, we carried out further calculations in order to estimate a population parameter that may characterize sample populations other than the one studied in this investigation. To begin, we calculated the average distribution of cognitive presence, teaching presence, and social presence across both disciplines. Table 10 shows the average distributions of the three presences for the entire sample. Even though there exists a highly significant difference between the distributions of the two forums, we tested for significant differences between each of 
the forums and the average distribution. No significant differences were found. In other words, assuming the possible existence of a distribution that characterizes the population (19.62:18.63: 61.75), neither forum differed from it significantly. Indeed, such findings may indicate the presence of a bimodal distribution.

Table 10

Differences between Observed Distributions by Disciplines and Proposed Population Parameter

\begin{tabular}{|l|c|c|c|c|c|c|c|}
\hline \multirow{2}{*}{ Discipline } & \multicolumn{2}{|c|}{$\begin{array}{c}\text { Cognitive } \\
\text { presence }\end{array}$} & \multicolumn{2}{c|}{$\begin{array}{c}\text { Teaching } \\
\text { presence }\end{array}$} & \multicolumn{2}{c|}{$\begin{array}{c}\text { Social } \\
\text { presence }\end{array}$} & \multirow{2}{*}{$\chi^{2}$} \\
\cline { 2 - 7 } & $\#$ & $\%$ & $\#$ & $\%$ & $\#$ & $\%$ & \\
\hline Exact sciences & 857 & $24.09 \%$ & 650 & $18.27 \%$ & 2050 & $57.63 \%$ & $\chi^{2}(2)=.052, p=.77$ \\
\hline Humanities & 202 & $15.15 \%$ & 253 & $18.98 \%$ & 878 & $65.87 \%$ & $\chi^{2}(2)=0.98, p=.61$ \\
\hline Average & $\mathbf{1 0 5 9}$ & $\mathbf{1 9 . 6 2 \%}$ & $\mathbf{9 0 3}$ & $\mathbf{1 8 . 6 3 \%}$ & $\mathbf{2 9 2 8}$ & $\mathbf{6 1 . 7 5 \%}$ & \\
\hline
\end{tabular}

If such a distribution of cognitive presence, teaching presence, and social presence is representative of the particular population investigated in this study, it must also manifest itself in a variety of situations, not just in disciplinary differences. To further test the robustness of the proposed population parameter, we calculated the distributions of the three presences across group size (see Table 3). Findings are shown in Table 11. The chi square column tests for significant differences between each of the distributions and the proposed parameter. No significant differences were found.

Table 11

Differences between Observed Distributions by Group Size and Proposed Population Parameter

\begin{tabular}{|l|l|l|l|l|l|l|c|}
\hline \multirow{2}{*}{$\begin{array}{l}\text { Group } \\
\text { size }\end{array}$} & \multicolumn{2}{|c|}{$\begin{array}{c}\text { Cognitive } \\
\text { presence }\end{array}$} & \multicolumn{2}{c|}{$\begin{array}{c}\text { Teaching } \\
\text { presence }\end{array}$} & \multicolumn{2}{c|}{$\begin{array}{c}\text { Social } \\
\text { Presence }\end{array}$} & \multirow{2}{*}{$\chi^{2}$} \\
\cline { 2 - 7 } & $\#$ & $\%$ & $\#$ & $\%$ & $\#$ & $\%$ & \\
\hline$<61$ & 212 & $24.28 \%$ & 148 & $16.95 \%$ & 513 & $58.76 \%$ & $\chi^{2}(2)=0.71, p=.70$ \\
\hline $61-120$ & 466 & $20.86 \%$ & 424 & $18.98 \%$ & 1344 & $60.16 \%$ & $\chi^{2}(2)=0.07, p=.97$ \\
\hline$>120$ & 391 & $21.81 \%$ & 331 & $18.46 \%$ & 1071 & $59.73 \%$ & $\chi^{2}(2)=0.15, p=.93$ \\
\hline
\end{tabular}

To even further test the robustness of the estimated parameter, we calculated the distributions of the three presences across course type: introductory, regular, and advanced. Findings are shown in Table 12. No significant differences were found between the proportions of the three presences and course type. 
Table 12

Differences between Observed Distributions by Course Type and Proposed Population Parameter

\begin{tabular}{|l|c|c|c|c|c|c|c|}
\hline \multirow{2}{*}{$\begin{array}{l}\text { Course } \\
\text { type }\end{array}$} & \multicolumn{2}{|c|}{$\begin{array}{c}\text { Cognitive } \\
\text { presence }\end{array}$} & \multicolumn{2}{c|}{$\begin{array}{c}\text { Teaching } \\
\text { presence }\end{array}$} & \multicolumn{2}{c|}{$\begin{array}{c}\text { Social } \\
\text { presence }\end{array}$} & \multirow{2}{*}{$\chi^{2}$} \\
\cline { 2 - 7 } & $\#$ & $\%$ & $\#$ & $\%$ & $\#$ & $\%$ & \\
\hline Introductory & 249 & $20.87 \%$ & 218 & $18.27 \%$ & 726 & $60.86 \%$ & $\chi^{2}(2)=0.11, p=.95$ \\
\hline Regular & 763 & $22.19 \%$ & 625 & $18.17 \%$ & 2050 & $59.61 \%$ & $\chi^{2}(2)=0.21, p=.90$ \\
\hline Advanced & 47 & $18.22 \%$ & 59 & $22.87 \%$ & 152 & $58.91 \%$ & $\chi^{2}(2)=0.29, p=.87$ \\
\hline
\end{tabular}

\section{Discussion}

\section{Disciplinary Differences}

Findings showed clearly the impact of academic discipline on the dialogic behavior of participants in Open University course forums. We hypothesized that for forums in the exact sciences, active participation and levels of social presence, teaching presence, and cognitive presence would be significantly higher than for forums in the humanities. Findings clearly support both hypotheses. We will frame the discussion in terms of answering three basic questions that emerge from the hypotheses:

1. What caused a twofold increase in student participation in the science forums and what caused science students to post, per capita, more messages than their counterparts in the humanities?

2. What caused instructors in each of the forums to behave as they did in terms of cognitive presence, teaching presence, and social presence?

3. What caused students in each of the forums to behave as they did in terms of cognitive presence, teaching presence, and social presence?

\section{Question 1.}

Increased student participation in the composite science forum may be associated with the nature of the discipline. Science courses have a relatively large number of tutor assignments based on problem-solving. Mandatory problems need to be solved and the forum is a useful resource for interpersonal student-instructor and student-student dialogue. Evaluation in humanities courses, at least among those found in the Open University of Israel, tend to have fewer tutor assignments (2-4) and these assignments are not based on solving problems.

Asynchronous forums are a resource that supports interpersonal dialogue (Gorsky \& Caspi, 2005; Gorsky, Caspi, \& Chajut, 2008). Regarding the utilization of this and similar resources for 
interpersonal dialogue (telephone, e-mail, etc.), it has been shown that students use such resources either when they experience difficulty in understanding subject-matter or when they are unable to solve problems (Caspi \& Gorsky, 2006; Gorsky, Caspi, \& Smidt, 2007; Gorsky, Caspi, \& Trumper, 2004; Gorsky, Caspi, \& Trumper, 2006; Gorsky, Caspi, \& Tuvi-Arad, 2004). Given subject-matter difficulty and tutor assignments based overwhelmingly on problem solving, it seems reasonable that students in the sciences utilized interpersonal dialogue to much higher extents than did their counterparts in the humanities.

\section{Question 2.}

We found significant differences between the categories of cognitive presence and social presence for instructors in the two disciplines. Within the dimension social presence, the category "open communication" was found to a much higher degree among instructors in the science forum. The centrality of problem solving may have been the catalyst that provoked such behavior since social presence includes such indicators as asking questions, referring to or quoting from others' messages, expressing agreement, and even simply continuing a thread rather than starting a new one. Also within the dimension social presence, the category "cohesion" was found to a much higher degree among instructors in the humanities forum. Given lackluster participation in the humanities forum, instructors may have tried to create a sense of group cohesion and to establish a more positive climate by addressing participants by name, using greetings and closures, and addressing the group as "we," "our," and "us," in order to encourage and to promote participation.

A highly significant disciplinary difference was noted for instructors' cognitive presence. On the one hand, adjusted ratios show (Table 7) that humanities instructors posted three times more messages associated with the category "trigger" than their counterparts in the sciences. This would indicate an attempt by humanities instructors to trigger and to encourage discussion in their forums. Indeed, a cursory review of the humanities forum showed that many questions posted by instructors remained unanswered. On the other hand, science instructors posted four times as many messages associated with the category "exploration" than their counterparts in the humanities. This may possibly indicate science instructors' increased participation in the problem solving process, alone or together with their students.

\section{Question 3.}

We found significant differences for all categories of cognitive presence, teaching presence, and social presence for students in the two disciplines. The most profound example is teaching presence, which may give a positive answer to the question recently posted by Garrison, Cleveland-Innes, and Fung (2010): Does teaching presence through design, facilitation, and direct instruction account for apparent disciplinary differences? Very high levels of teaching presence among the science students, however it manifested itself, were, for all practical intents and purposes, non-existent in the composite humanities forum. According to Vygotsky (1978), attempts to solve problems through social interaction and assistance from more competent peers promote students' learning abilities in their zones of proximal development (ZPD). Resulting 
from enhanced peer teaching presence, three of the four categories of cognitive presence were also more abundant in the composite science forum (a grand total of only three instances of "resolution" were recorded).

\section{Toward a Population Parameter}

Findings point to the intriguing possibility that the estimated population parameter for the distribution of cognitive presence, teaching presence, and social presence found in this study $(19.62: 18.63: 61.75)$ also exists for asynchronous communities of inquiry in wider contexts. Currently, these findings were obtained in undergraduate, asynchronous course forums at the Open University of Israel, analyzed by one of several possible analytic procedures using the community of inquiry model. This relationship may (or may not) exist in other sample populations and settings. Only further research will supply an answer. The data we found must be replicable in other communities of inquiry characterized by course idiosyncrasies, such as obligatory participation, in different universities, and in other cultures.

In order to begin the search for replicability, we referred to a previous study that utilized an identical analytic procedure (Gorsky \& Blau, 2009). We found the proportions of each presence in a graduate level education course (discipline: soft-applied, as opposed to soft-pure) over an entire semester. Table 13 displays these findings alongside those from this study.

Table 13

Comparing a Graduate Education Course with the Estimated Population Parameter and with the Composite Science and Humanities Forums

\begin{tabular}{|l|c|c|c|c|c|c|c|}
\hline \multirow{2}{*}{ Presence } & \multicolumn{2}{|c|}{$\begin{array}{c}\text { Forum1 } \\
\text { (Sciences) }\end{array}$} & \multicolumn{2}{c|}{$\begin{array}{c}\text { Forum2 } \\
\text { (Humanities) }\end{array}$} & \multicolumn{2}{c|}{$\begin{array}{c}\text { Forum 3 } \\
\text { (Grad. Education) }\end{array}$} & $\begin{array}{c}\text { Population } \\
\text { parameter }\end{array}$ \\
\cline { 2 - 8 } & $\#$ & $\%$ & $\#$ & $\%$ & $\#$ & $\%$ & $\%$ \\
\hline Teaching & 650 & $18.27 \%$ & 253 & $18.98 \%$ & 73 & $19.89 \%$ & 19.62 \\
\hline Social & 2050 & $57.63 \%$ & 878 & $65.87 \%$ & 236 & $64.30 \%$ & 61.75 \\
\hline Cognitive & 857 & $24.09 \%$ & 202 & $15.15 \%$ & 58 & $15.80 \%$ & 18.63 \\
\hline Totals & 3557 & $\mathbf{1 0 0} \%$ & $\mathbf{1 3 3 3}$ & $\mathbf{1 0 0 \%}$ & 367 & $\mathbf{1 0 0 \%}$ & $\mathbf{1 0 0 \%}$ \\
\hline
\end{tabular}

There is no significant difference between the distributions from the graduate level education course and the proposed population parameter $\left[\chi^{2}(2)=1.067, p=0.59\right]$. Furthermore, as it should be, this distribution is nearly identical to that of the typical humanities (discipline: softpure) forum $\left[\chi^{2}(2)=0.31, p=.85\right]$. Finally, assuming a bimodal distribution vis-à-vis disciplinary difference, it differs significantly from the composite science forum $\left[\chi^{2}(2)=12.82\right.$, $p<.001]$. 


\section{The population parameter and individual course forums.}

Assuming the existence of a population parameter $(19.62: 18.63: 61.75)$, we now investigate its relationship with the distributions obtained for each of the individual course forums; that is, to what extent did they correspond with the estimated parameter? Specifically, we calculated the standard deviation of the mean value for the magnitude of social presence in the composite science and humanities forums. Confidence intervals are shown in Table 14.

Table 14

Confidence Intervals for Expected Means for Social Presence

\begin{tabular}{|l|c|c|c|c|c|}
\hline Discipline & N & Mean & S.D. & S.E. & $\begin{array}{c}\text { 95\% confidence } \\
\text { intervals }\end{array}$ \\
\hline Humanities & 25 & 65.87 & 4.29 & 0.17 & $64.26-67.80$ \\
\hline Sciences & 25 & 57.63 & 8.96 & 0.36 & $53.43-60.83$ \\
\hline
\end{tabular}

Fourteen of the 25 forums in the humanities discipline lie with the $95 \%$ confidence interval; six of the 25 forums in the exact and natural science disciplines lie with the $95 \%$ confidence interval.

\section{Summary}

We have to remember that what we observe is not nature herself, but nature exposed to our method of questioning. (Heisenberg, 1958)

We reiterate that all findings from this study were obtained by using a particular scoring procedure (see Instruments and Procedure). Given the use of this procedure, we found highly significant relationships between academic discipline and dialogic behavior in Open University course forums. We also estimated a population parameter for the distribution of the three presences in asynchronous communities of inquiry. On the one hand, given the established reliability and validity of this particular procedure, these findings are more than mere artifacts. On the other hand, given the diversity of approaches to content analysis, these findings need further corroboration using different approaches and procedures. 


\section{References}

Akyol, Z., Arbaugh, J. B., Cleveland-Innes, M., Garrison, D. R., Ice, P., Richardson, J. C., \& Swan, K. (2009). A response to the review of the community of inquiry framework. Journal of Distance Education, 23, 123-136.

Akyol, Z., Garrison, D. R., \& Ozden, M. Y. (2009). Online and blended communities of inquiry: Exploring the developmental and perceptional differences. The International Review of Research in Open and Distance Learning, 10, 65-83.

Anderson, T., Rourke, L., Garrison, D. R., \& Archer, W. (2001). Assessing teaching presence in a computer conferencing context. Journal of Asynchronous Learning Networks, 5. Retrieved from http://sloan-c.org/publications/jaln/v5n2/pdf/v5n2 anderson.pdf

Arbaugh, J. B. (2008). Does the community of inquiry framework predict outcomes in online MBA courses? The International Review of Research in Open and Distance Learning, 9, 1-12. Retrieved from http://www.irrodl.org/index.php/irrodl/article/view/490/1048

Arbaugh, J. B., Bangert, A., \& Cleveland-Innes, M. (2010). Subject matter effects and the community of inquiry $(\mathrm{CoI})$ framework: An exploratory study. The Internet and Higher Education, 13, 37-44.

Arbaugh, J. B., \& Hwang, A. (2006). Does "teaching presence" exist in online MBA courses? The Internet and Higher Education 9, 9-21.

Becher, T. (1990). Academic tribes and territories. Milton Keynes: Open University Press.

Becher, T. (1994). The significance of disciplinary differences, Studies in Higher Education, 19, 151-61.

Becher, T., \& Trowler, P. R. (2001). Academic tribes and territories: Intellectual enquiry and the cultures of disciplines ( $2^{\text {nd }}$ ed.). Buckingham, UK: Open University Press.

Biglan, A. (1973). The characteristics of subject matter in different academic areas. Journal of Applied Psychology, 57, 195-203.

Bliss, C. A., \& Lawrence, B. (2009). From posts to patterns: A metric to characterize discussion board activity in online courses. JALN, 13. 1-18. Retrieved from http://www.cems.uvm.edu/ cbliss/Discussion_Paper_Bliss-Lawrence-2008.pdf

Caspi, A., \& Blau, I. (2008). Online discussion groups: The relationship between social presence and perceived learning. Social Psychology of Education, 11, 323-346. 
Caspi, A., \& Gorsky, P. (2006). Open university students' use of dialogue. Studies in Higher Education, 31, 735-752.

Caspi, A., Gorsky P., \& Chajut, E. (2003). The influence of group size on non-mandatory asynchronous instructional discussion groups. The Internet and Higher Education, 6, 227-240.

De Wever, B., Schellens, T., Valcke, M., \& Van Keer, H. (2006). Content analysis schemes to analyze transcripts of online asynchronous discussion groups: A review. Computers \& Education, 46, 6-28.

Dewey, J. (1933). How we think (Rev. ed.). Boston: D.C. Heath.

Fahy, P. J. (2001). Addressing some common problems in transcript analysis. International Review of Research in Open and Distance Learning, 1. Retrieved from http://www.irrodl.org/index.php/irrodl/article/view/321/530

Garrison, D. R., Anderson, T., \& Archer, W. (2000). Critical inquiry in a text-based environment: Computer conferencing in higher education. The Internet and Higher Education 2, 87105 .

Garrison, D. R., Anderson, T., \& Archer, W. (2001). Critical thinking and computer conferencing: A model and tool to assess cognitive presence. American Journal of Distance Education, 15, 7-23.

Garrison, D. R., Anderson, T., \& Archer, W. (2010). The first decade of the community of inquiry framework: A retrospective. The Internet and Higher Education, 13, 5-9.

Garrison, D.R., \& Arbaugh, J.B. (2007). Researching the community of inquiry framework: Review, issues, and future directions. Internet and Higher Education, 10, 157-172.

Garrison, D. R., \& Archer, W. (2003). A community of inquiry framework for online learning. In M. Moore (Ed.), Handbook of distance education. New York: Erlbaum.

Garrison, D. R., \& Cleveland-Innes, M. (2005). Facilitating cognitive presence in online learning: Interaction is not enough. American Journal of Distance Education 19, 133148 .

Garrison, D. R., Cleveland-Innes, M., Koole, M., \& Kappelman, J. (2006). Revisiting methodological issues in the analysis of transcripts: Negotiated coding and reliability. The Internet and Higher Education, 9, 1-8. 
Garrison, D. R., Cleveland-Innes, M., \& Fung, T. S. (2010). Exploring causal relationships among teaching, cognitive and social presence: Student perceptions of the community of inquiry framework. The Internet and Higher Education, 13, 31-36.

Gorsky, P., \& Blau, I. (2009). Online teaching effectiveness: A tale of two instructors. International Review of Research on Distance Learning, 10, 1-27.

Gorsky, P., Caspi, A., \& Tuvi-Arad I. (2004). Use of instructional dialogue by university students in a distance education chemistry course. Journal of Distance Education, 19, 1-19.

Gorsky, P., Caspi, A., \& Trumper, R. (2004). Dialogue in a distance education physics course. Open Learning: The Journal of Open and Distance Learning, 19, 265-277.

Gorsky, P., Caspi, A., \& Trumper, R. (2006). Campus-based university students' use of dialogue. Studies in Higher Education, 31, 71-87.

Gorsky, P., Caspi, A., \& Smidt, S. (2007). Use of instructional dialogue by university students in a difficult distance education physics course. Journal of Distance Education, 22, 1-22.

Gros, B., \& Silva, J. (2006). El problema del análisis de las discusiones asincrónicas en el aprendizaje colaborativo mediado. Revista de Educación a Distancia- RED, 16. Retrieved from http://www.um.es/ead/red/16/gros.pdf

Heisenberg, W. (1958). Physics and philosophy: The revolution in modern science. Lectures delivered at University of St. Andrews, Scotland, Winter, 1955-56. NY: Harper and Row.

LaPointe, D. K., \& Gunawardena, C. N. (2004). Developing, testing and refining of a model to understand the relationship between peer interaction and learning outcomes in computermediated conferencing. Distance Education, 25, 83-106.

Liu, X., Bonk, C. J., Magjuka, R. C., Lee, S., \& Su, B. (2005). Exploring four dimensions of online instructor roles: A program level case study. Journal of Asynchronous Learning Networks, 9, 29-48.

Meyer, K. A. (2003). Face-to-face versus threaded discussions: The role of time and higher-order thinking. Journal of Asynchronous Learning Networks, 7, 55-65.

Murphy, E. (2004). Recognizing and promoting collaboration in an online asynchronous discussion. British Journal of Educational Technology, 35, 421-431.

Murphy, E., \& Ciszewska-Carr, J. (2005). Sources of difference in reliability: Identifying sources of difference in reliability in content analysis of online asynchronous discussions. International Review of Research in Open and Distance Learning, 6. Retrieved from http://www.irrodl.org/index.php/irrodl/article/view/233/855 
Neuendorf, K. A. (2002). The content analysis guidebook. Thousand Oaks, CA: Sage Publications.

Neumann, R. (2001). Disciplinary differences and university teaching, Studies in Higher Education, 26, 135-146.

Palloff, R., \& Pratt, K. (2003). The virtual student: A profile and guide to working with online learners. San Francisco, CA: Jossey-Bass Inc.

Pawan, F. T., Paulus, M., Yalcin, S., \& Chang, C. (2003). Online learning: Patterns of engagement and interaction among in-service teachers. Language Learning \& Technology, 7, 119-140.

Picciano, A.G. (2002). Beyond student perceptions: Issues of interaction, presence, and performance in an online course. Journal of Asynchronous Learning Networks, 6. Retrieved from http://www.aln.org/publications/jaln/v6n1/pdf/v6n1_picciano.pdf

Richardson, J.C., \& Swan, K. (2003). Examining social presence in online courses in relation to students' perceived learning and satisfaction. Journal of Asynchronous Learning Networks, 7. Retrieved from http://www.aln.org/publications/jaln/v7n1/pdf/v7n1_richardson.pdf

Rourke, L., \& Anderson, T. (2004). Validity issues in quantitative computer conference transcript analysis. Educational Technology Research and Development, 52, 5-18.

Rourke, L., Anderson, T., Garrison, D. R., \& Archer, W. (1999). Assessing social presence in asynchronous test-based computer conferencing. Journal of Distance Education 14, 5071. Available at http://www.jofde.ca/index.php/jde/article/viewArticle/153/341

Rourke, L., Anderson, T., Garrison, D. R., \& Archer, W. (2001). Methodological issues in the content analysis of computer conference transcripts. International Journal of Artificial Intelligence in Education 12, 8-22.

Rourke, L., \& Kanuka, H. (2009). Learning in communities of inquiry: A review of the literature. Journal of Distance Education, 23, 19-48.

Shea, P., \& Bidjerano, T. (2009a). Cognitive presence and online learner engagement: A cluster analysis of the community of inquiry framework. Journal of Computing in Higher Education, 21, 199-217.

Shea, P., \& Bidjerano, T. (2009b). Community of inquiry as a theoretical framework to foster "epostemic engagement" and "cognitive presence" in online education. Computers \& Education, 52, 543-553. 
Shea, P., Hayes, S., Vickers, J., Gozza-Cohen, M., Uzuner, S., Mehta, R., Valchova, A., \& Rangan, P. (2010). A re-examination of the community of inquiry framework: Social network and content analysis. The Internet and Higher Education, 13, 10-21.

Shea, P., Li, C. S., \& Pickett, A. M. (2006). A study of teaching presence and student sense of learning community in fully online and web-enhanced college courses. The Internet and Higher Education, 9, 175-190.

Shea, P., Li, C. S., Swan, K., \& Pickett, A. M. (2005). Developing learning community in online asynchronous college courses: the role of teaching presence. Journal of Asynchronous Learning Networks, 9. Retrieved from http://www.sloan-org/publications/jaln/v9n4/pdf/v9n4_shea.pdf

Shea, P. J., Pickett, A. M., \& Pelz, W. E. (2004). Enhancing student satisfaction through faculty development: The importance of teaching presence. In J. Bourne \& J. C. Moore (Eds.), Elements of quality online education: Into the mainstream, Volume 5 (pp.39-59). Needham, MA: Sloan-C.

Steinweg, S. B., Trujillo, L., Jeffs, T., \& Hopfengardner-Warren, S. (2006). Maintaining the personal touch in a growing program: Strategies for establishing social presence in online classes. Journal of the Research Center for Educational Technology, 2. Retrieved from http://www.rcetj.org/?type $=$ art\&id $=79598 \&$

Swan, K. (2002). Building communities in online courses: The importance of interaction. Education, Communication and Information, 2, 23-49.

Swan, K., Garrison, D.R., \& Richardson, J. (2009). A constructivist approach to online learning: The community of inquiry framework. In C.R. Payne (Ed.), Information technology and constructivism in higher education: Progressive learning frameworks. Hershey, PA: IGI Global.

Swan, K., \& Shea, P. (2005). The development of virtual learning communities. In S.R. Hiltz \& R. Goldman (Eds.), Asynchronous learning networks: The research frontier (pp. 239260). New York: Hampton Press.

Swan, K., Shea, P., Richardson, J., Ice, P., Garrison, D. R., Cleveland-Innes, M., \& Arbaugh, J. B. (2008). Validating a measurement tool of presence in online communities of inquiry. E-Mentor, 2, 1-12.

Swan, K, \& Shih, L. F. (2005). On the nature and development of social presence in online course discussions. Journal of Asynchronous Learning Networks 9. Retrieved from http://www.sloan-c.org/publications/JALN/v9n3/v9n3 swan.asp 
Varnhagen, S., Wilson, D., Krupa, E., Kasprzak, S., \& Hunting, V. (2005). Comparison of student experiences with different online graduate courses in health promotion. Canadian Journal of Learning and Technology, 31, 99-117.

Vaughan, N. (2004). Investigating how a blended learning approach can support an inquiry process within a faculty learning community (Doctoral dissertation). University of Calgary. Retrieved from http://www.ucalgary.ca/ nvaughan/norm/nvaughandissertation.pdf

Vaughan, N., \& Garrison, D. R. (2006). How blended learning can support a faculty development community of inquiry. Journal of Asynchronous Learning Networks 10. Retrieved from http://www.sloan-c.org/publications/JALN/v10n4/v10n4_vaughan.asp

Vesely, P., Bloom, L., \& Sherlock, J. (2007). Key elements of building online community: Comparing faculty and student perceptions. MERLOT Journal of Online Learning and Teaching, 3. Retrieved from http://jolt.merlot.org/vol3no3/vesely.pdf

Vygotsky, L. (1978). Mind in society: The development of higher psychological processes. Cambridge MA: Harvard University Press.

Wu, D., \& Hiltz, S. R. (2004). Predicting learning from asynchronous online discussions. Journal of Asynchronous Learning Networks, 8, 139-152. 


\title{
Length of Online Course and Student Satisfaction, Perceived Learning, and Academic Performance
}

\author{
Janet M. Ferguson \\ Canisius College, USA
}

\author{
Amy E. DeFelice \\ City University of New York (CUNY) Graduate Center, USA
}

\begin{abstract}
This research presents findings from a two-part study. In the first part, graduate students taking online courses were given a course evaluation form. Student responses from online abbreviated summer sessions were compared to student responses from online full-semester courses.

Both the intensive and full-semester courses were taught by the same professor and both had identical requirements in terms of assignments and exams. The independent variable was the length of time taken to complete the requirements, with the dependent variables being satisfaction with the course, perceived learning, and academic performance. A statistical analysis of the data found significant differences in a number of areas.
\end{abstract}

Keywords: Online learning; course format; graduate school; course satisfaction; communication; academic performance; five-week intensive course; full-semester course; massed vs. distributed learning; equivalency theory

\section{Introduction}

Online education continues to grow and the expansion has touched all areas of education, from grade school to graduate school. Online learning has become a mainstream tool in education (Harden, 2002). In surveying more than 1,000 colleges and universities, The Sloan Consortium found that increasing numbers of postsecondary institutions consider online learning as part of their long-term strategy. According to the Consortium report, $56 \%$ of institutions included online learning in their strategic plans in 2005, as compared to $49 \%$ in 2003 . Enrollment in online courses and programs continues to increase. In 2005, online course/program enrollment grew by 18.2\%. This exceeds overall higher education course enrollment growth and also exceeds - by 10 times - the online course enrollment growth projected by the National Center for Education 
Statistics (Allen \& Seaman, 2005). According to some educators, online learning is one of the most important and significant new instructional approaches available for improving teaching and learning in schools today (Blomeyer, 2002). Seok (2007) claims that "elearning” is the pedagogy for new learning in the $21^{\text {st }}$ century. Improved technology has enabled instructors to design and implement online courses, using advanced techniques that are now available. However, not all online courses are designed the same way; thus, it is difficult to characterize a typical online program (Rovai \& Barum, 2003). An online program can be based on traditional lecture courses, or be self-paced, with limited or extensive interactions. Or, as in this study, the course format could be a traditional full semester or an intensive five-week summer session. Many graduate-level teacher education programs are providing students with the option of a "fast-track" to certification by offering condensed five-week courses during the summer. Seamon (2004) says "as education researchers seek to increase the body of knowledge about effective teaching and learning, it is important not to neglect a critical variable in the instructional equation: course format.”

According to some researchers, student satisfaction with the type of course delivery is determined by the degree of structure in the course (Stein, 2004). According to Stein, all of the components defining structure, such as clearly defined objectives, assignments, and deadlines, need to be present in order to increase student satisfaction.

In another study, Drennan, Kennedy, and Pisarski (2005) found that student satisfaction is influenced by positive perceptions towards technology and by an autonomous learning mode. They also found that the personality characteristics that the student brings to the course, such as an internal locus of control, can have a direct effect on satisfaction with the course.

According to Watson and Rutledge (2005), the most often cited reason for students enrolling in an online course was a "time frame most suitable for their own circumstance," (i.e., convenience). Coursework could be completed at home, after work, or after caring for a family. Travel expenses, a growing concern because of increasing gasoline prices, are eliminated, and so is time spent travelling. Accordingly, the convenience of an online course impacted student satisfaction levels with the course.

Car (2000) offers another viewpoint and suggests that not all online courses are equally effective because of differences in course design. Student satisfaction, as reflected in course completion rates, is heavily influenced by interaction between instructor-student and between student-student. Frederickson et al. (2006) reported that interaction with the teacher is the most significant contributor to perceived learning and that students who feel they have not had adequate access to their instructors are also less satisfied with the course. The study done by Watson and Rutledge (2005) found that $30 \%$ of the students disagreed with the statement, "I felt as much a part of my online class as a regular class,” indicating a degree of dissatisfaction with the interactions. This may mean that there was a certain feeling of apartness or disconnection in the online class.

Jung, Choi, Lim, and Leem (2002), when researching different types of online interactions and their effect on satisfaction with the course, found that the learners' satisfaction was more strongly 
related to the amount of student-student interaction than to the interaction with the instructor. They found that the students who collaborated with each other (i.e., to problem solve on a discussion board) expressed the highest level of satisfaction. A more recent study by Nummenmaa (2008) found that visible collaborative activities in a web-based learning environment impacted students' reaction to the course. They maintained that "lurkers," or those who did not actively participate in the course, had more negative emotional experiences with the course than those who interacted collaboratively. All of these studies indicate that connectedness to the course, either by participating collaboratively with other students or by interacting with the professor, will likely impact student satisfaction and that online courses offer the additional challenges and opportunities associated with not being physically connected to the class.

According to equivalency theory (Simonson, Scholosser, \& Hanson, 1999), course learning experiences should be constant regardless of delivery method. The basic premise of equivalency theory is that learning experiences for both local, or face-to-face learners, and distant, or online learners, should be designed in order to provide equivalent learning for both groups of students. The research of Lapsley, Moody, and Arbaugh (2008) supports equivalency theory in terms of online and face-to-face instruction. They found that online and face-to-face instruction provides equivalent learning opportunities for students. Although equivalency theory is used to determine equivalent value of the experiences of face-to-face and online learners, in this study equivalency theory was used to determine if equivalency was met for students in five-week online courses compared to students in fifteen-week online courses. This study examined whether there were differences in online student satisfaction, perceived learning, and performance when course content and teaching pedagogy remained the same but the two courses differed in length: one was a five-week, intensive online course and the other was a fifteen-week, full-semester online course.

Many studies involving distance education have focused on comparing the academic performance and effectiveness of an online course to the academic performance and effectiveness of a traditional, face-to-face course. Some studies have compared student satisfaction with an online course versus student satisfaction with a traditional course. The authors were unable to locate any study that researched student satisfaction with a full-semester online course compared to student satisfaction with an intensive, five-week online course.

Studies on the benefits of distributed versus massed learning go back to as early as 1885 to the work on memory by German psychologist Hermann Ebbinghaus. Distributed learning is learning that occurs in smaller pieces over a longer period of time. Massed learning is learning that is condensed into one time period, such as "cramming” for a test. Distributed learning is more effective for long-term memory. In the 1980's, there was considerable research done on massed versus distributed learning in a face-to-face, traditional classroom setting. Seamon (2004) found that students in a shortened, intense, face-to-face course academically outperformed students in a full-semester, face-to-face course. He conducted a study that examined the long-term effects of different instructional formats and found that students' performance in an intensive course, meaning a course that was shorter than a full semester, was superior initially, but in post-testing three years later the full-semester students outperformed the intensive course students. Anastasi (2007) found that academic performance was similar in summer face-to-face and full-semester 
face-to-face courses. According to Anastasi, studies of face-to-face courses suggest that, contrary to previous research, students tend to perform as well in abbreviated courses, and the belief that shortened courses are somehow inferior to full-semester courses is unfounded. Earlier research by Bohlin and Hunt (1995) found that student attitudes in a face-to-face traditional format course were more positive than student attitudes in an intensive shortened face-to-face format.

The pedagogical issues associated with a shortened format versus a full-length format include the effect of different strategic approaches. The attitude of the instructor was found to be crucial to the success of intensive courses (Brett, 1996). This has been confirmed in more recent studies, which have found that a lively, engaging teaching strategy is necessary to keep the intensive course students focused (Scott, 2003). In addition, some early studies found that intensive course instructors were more likely to use class discussion instead of lectures, as well as different textbooks, tests, quizzes, and term papers (Allen et al., 1982). Allen maintained that the differences in teaching strategies would likely have an effect on the success of an intensive course.

If the metaphor is correct that education is the delivery of information, then the Internet may be the most efficient method for delivering information in terms of speed and convenience (Gordon, 2000). One may also conclude that a five-week course is a more efficient delivery format than a fifteen-week course. Another metaphor, mentioned by Gordon, is that the student is a consumer; from this perspective, students will be attracted to a program (or format) that will accomplish what they need in the shortest amount of time. If our current pedagogy is largely a product of pragmatic constraints, such as time, class size, and linear textbooks, then the pedagogy of a fiveweek course might need to be considerably different than a fifteen-week course simply because of the time factor. This raises the question of whether students are learning the content to the same degree in the different formats. In this study, the authors found that students learned the same content in the five-week and fifteen-week courses; thus, equivalency theory was supported.

All of the existing research has focused on intensive versus semester length courses in a traditional classroom setting. There is no current research on the impact of the format (i.e., shortened vs. full-term) of online courses on student satisfaction or academic performance.

\section{Purpose of the Study}

The first part of this study will compare the shortened and full-length course formats based on students' satisfaction with the interaction in the course and their intention to take online courses in the future. The second part of the study will compare students' academic performance in an intensive online course to students' academic performance in a full-semester online course. 
The research questions are as follows:

1. Is there a difference in students' satisfaction with communication between a five-week online course and a full-semester online course?

2. Will students in a five-week online course be more or less likely than students in a fullsemester online course to take another online course?

3. Is there a difference in students' perceived learning between a five-week online course and a full-semester online course?

4. Do graduate students enrolled in a five-week online course show similar student learning when compared to graduate students in a full-semester online course, as demonstrated by academic performance?

\section{Methodology}

At this medium-sized, liberal arts institution, most graduate students enroll in five-week summer sessions to complete their master's degree in one year. The five-week intensive courses are only offered during the summer. Many of these students want to take at least one course online because of the convenience.

Graduate students enrolled in the online course for pre-service teachers, Test, Measurement and Statistics, were asked to complete an online course evaluation survey at the end of the course. The platform used to teach the web-based course was the Blackboard learning management system, which allowed interaction through discussion boards, email, and chat rooms. The discussion board and email were the prime means of communication for the courses being studied.

A total of 75 students from four consecutive semesters completed the 15-question Likert scale survey, which also allowed individual comments. One of the courses was taught as an intensive five-week session and three of the courses were taught as full fifteen-week sessions. The same instructor taught all the courses, and the course requirements, including tests and assignments, were identical. The teaching strategy was identical for the two formats. The instructor attempted the same pedagogical approach in all of the courses in order to compare student satisfaction within the context of the course format.

The survey consisted of a 4-point rating scale, ranging from 1 (strongly disagree), 2 (disagree), 3 (agree), and 4 (strongly agree). The survey was designed as a 4-point scale to eliminate a neutral, or fence-sitting, option. The reliability of the survey was determined to be .77, using Cronbach's Alpha, which indicates an acceptable degree of internal consistency for this instrument.

In the second part of the study, final grades from a total of 114 students were analyzed from three summer sessions and four full-semester sessions. A compilation of students' grades from two tests and three assignments were used to compare academic performance. The assignments and the tests were weighted equally at $20 \%$ each. For the first assignment, students used SPSS (Statistical Package for the Social Sciences) to analyze two sets of test scores and they wrote a 
paper interpreting the results. For the second assignment, the students made up a test in their content area and grade level, including all of the different types of test questions and a scoring guide. The last assignment required students to select a standardized test in their content area, to critique the test's validity and reliability, using BMMY (Buro’s Mental Measurement Yearbook), and to state whether they would use it to evaluate their students. All of the assignments were sent electronically to a digital drop box. The tests consisted of a midterm test and a final test. Both were given online on a specific day, with a two-hour time limit. The final test required an understanding of previously learned material, but it was not cumulative.

\section{Hypotheses}

1. Students in an intensive five-week online course will have different satisfaction with course communication and interaction than students in a full-semester online course.

2. Students in an intensive five-week online course will have different satisfaction levels than students in a full-semester online course, as indicated by their intention to take online courses in the future.

3. Students' perceived learning will be different in the intensive five-week online course than in the full-semester course.

4. There will be differences in students' academic performance levels in the intensive five-week online course versus the full-semester course.

\section{Results}

SPSS was used to analyze the data. Table 1 summarizes the findings of individual scales according to course format and semester. 
Table 1

Mean Scores for Both Regular and Intensive Online Courses

\begin{tabular}{|l|c|c|c|c|c|c|c|c|}
\hline & \multicolumn{2}{|c|}{$\begin{array}{c}\text { Summer } \\
\text { five-week }\end{array}$} & \multicolumn{2}{c|}{$\begin{array}{c}\text { Spring } \\
\text { full-semester }\end{array}$} & \multicolumn{2}{c|}{$\begin{array}{c}\text { Fall } \\
\text { full-semester }\end{array}$} & \multicolumn{2}{c|}{$\begin{array}{c}\text { Spring } \\
\text { full-semester }\end{array}$} \\
\cline { 2 - 10 } & \multicolumn{2}{|c|}{$\mathbf{n = 2 9}$} & \multicolumn{2}{c|}{$n=\mathbf{1 4}$} & \multicolumn{2}{c|}{$\mathbf{n = 1 2}$} & \multicolumn{2}{c|}{$\mathbf{n = 2 0}$} \\
\cline { 2 - 10 } & MEAN & $S D$ & MEAN & SD & MEAN & SD & MEAN & $S D$ \\
\hline $\begin{array}{l}\text { Communicated } \\
\text { with classmates }\end{array}$ & 3.00 & 1.02 & 2.85 & .555 & 2.92 & .515 & 2.90 & .788 \\
\hline $\begin{array}{l}\text { Communicated } \\
\text { with professor }\end{array}$ & 2.6 & 1.07 & 3.21 & .893 & 3.17 & .389 & 3.40 & .754 \\
\hline Would take again & 3.4 & .884 & 3.14 & 1.03 & 3.17 & .937 & 3.75 & .444 \\
\hline $\begin{array}{l}\text { Perceived } \\
\text { learning }\end{array}$ & 3.2 & .608 & 3.21 & .579 & 3.17 & .577 & 3.55 & .686 \\
\hline
\end{tabular}

A $t$ test was used to determine whether there were significant differences in student satisfaction with communication and interaction between the five-week session and the full-semester session. It was found that students in the intensive five-week course showed higher satisfaction with student-student communication than students in the full-semester courses $(t=4.09, p=.026)$. Interestingly, the students in the full-semester session showed higher satisfaction with studentprofessor communication $(t=6.79, p=.007)$. See Table 2 .

Table 2

Students' Satisfaction and Perceived Learning

\begin{tabular}{|l|c|c|c|}
\hline & $\boldsymbol{t}$ & $\boldsymbol{d} \boldsymbol{f}$ & Significance \\
\hline $\begin{array}{l}\text { Communicated with } \\
\text { classmates }\end{array}$ & 4.09 & 112 & .026 \\
\hline $\begin{array}{l}\text { Communicated with } \\
\text { professor }\end{array}$ & 6.79 & 112 & .007 \\
\hline $\begin{array}{l}\text { Would take another } \\
\text { online course }\end{array}$ & -.150 & 112 & .890 \\
\hline Perceived learning & .542 & 112 & .625 \\
\hline
\end{tabular}

There were no significant differences between the full-semester students and the five-week students in terms of their intention to take another online course in the future. Perceived learning was higher overall in the full-semester courses than in the intensive five-week course; however, the differences were not found to be significant. 
Using the $t$ test for equality of means the overall mean final grade for the students in the fiveweek courses was found to be significantly higher than the mean final grade for the students in the full-semester courses $(t=2.35, p=.02)$. See Table 3 .

Table 3

Student Performance

\begin{tabular}{|l|l|l|l|l|l|c|}
\hline & $\boldsymbol{N}$ & Mean & $\boldsymbol{S D}$ & $\boldsymbol{t}$ & $\boldsymbol{d f}$ & Significance \\
\hline $\begin{array}{l}\text { Full } \\
\text { semester }\end{array}$ & 76 & 87.32 & 6.4 & & & \\
\hline \multicolumn{2}{|l}{} & & & -2.35 & 112 & .021 \\
\hline $\begin{array}{l}\text { Summer } \\
\text { semester }\end{array}$ & 38 & 90.01 & 4.14 & & & \\
\hline
\end{tabular}

\section{Discussion}

In terms of student satisfaction with the intensive versus the full-semester format, the findings showed two differences, both involving satisfaction with communication. Students in the intensive course were less satisfied with their communications with the instructor than the fullsemester students were. However, students in the intensive course were more satisfied with communications with other students than the full-semester students were. This aligned with hypothesis one.

In a five-week session, the burden on the professor to keep track of every email and to respond to every discussion board entry is, from experience, much more intense and demanding than if the communications were spread out over a whole semester. This might in part explain the significant difference between students' satisfaction with communications with their professor in a five-week course versus a full-semester course. In a five-week course, the professor might be overwhelmed and overburdened with a constant barrage of emails and questions, and oversights might occur unintentionally. Students may have relied on each other to a greater degree in the intensive course using the discussion board and/or email. According to Keller (2010), and his model of motivational design, satisfaction is an important component for promoting and sustaining motivation in the learning process. Keller maintains that providing feedback and reinforcement is important to motivation and thus to satisfaction. The five-week online course in which students were less satisfied with communications with the professor fits the model of motivational design in that less feedback and reinforcement were being provided by the professor in the shortened course.

There are some pedagogical advantages of online education. According to Gordon (2000), the time constraints of a traditional classroom prevent full participation of all the students, especially if the class is very large. In an online class, participation is not limited and everyone can join in a discussion at any time. If, as Gordon states, the quantity of communication in an online course is 
greater, then one wonders if the quantity of communication in a full-semester online course would be greater than in a five-week course because there is more time to interact. This could, in part, explain the greater satisfaction with communication with the professor in a full-semester course.

It was hypothesized that students in an intensive five-week course would indicate different levels of perceived learning and different satisfaction levels than the full-semester online students. Perceived learning was lower for students in the five-week session, but not significantly so. Thus, hypothesis three was not supported. Also, there were no significant differences in satisfaction levels as indicated by intent to take future online courses. Thus, hypothesis two was not supported. However, significant differences were found in academic performance, with students in the five-week session showing stronger academic performance than the full-semester students, thus supporting hypothesis four. This could be explained, in part, by the intense nature of a condensed course, where students must be focused and "on-task" continuously, with no breaks. The learned material would be fresh in the students' minds with perhaps better recollection during testing.

This study offers several useful findings, with implications for teaching in both formats. First, effective communication between students and instructors is vital to a successful online course. The teaching strategies of the online instructor need to include a variety of ways to allow this communication to occur, especially in the five-week intensive course, where the student must remain continuously focused. A pedagogical shift is needed in the five-week course to emphasize interaction with the professor. Live chat rooms, threaded discussions, and the use of blogs, combined with prompt responses to all email inquiries, are strategies that would provide opportunities for increased interaction. Other techniques to help with the intense workload would be to use recorded podcasts and Frequently Asked Questions (FAQs). These techniques could be used in the full-semester course as well, but an emphasis on instant responses would not be as critical. In an intensive course, the professor needs to be available to respond promptly to online inquiries. Another possible pedagogical change could be to make attendance in the chats and participation in the discussions mandatory, as well as to grade the quality of participation, which would motivate students to be actively involved. Participation was not graded in either the fullsemester or the five-week course; however, an assumption is made that this strategy would help the students in the full-semester course to feel more connected to their classmates.

This research has broken new ground in the study of online learning in that it is the first to explore how different formats (full-semester versus five-week shortened courses) influence student attitudes and academic performance. As online course offerings expand, the more we know about concentrated online courses, the better we can address student learning. This research may have implications for an institution's policies for determining the length of online courses.

A limitation of this study involves the type of student. The summer session student may be different from a full-semester student, for example full-time versus part-time, older versus younger, higher or lower GPA, personality characteristics, and general expectations from the 
course. These variables were not explored in this study and raise questions for future research. The findings from this study are also limited by the fact that certain factors could not be controlled and this was not a random sample. Students' personalities and predispositions could affect responses, as well as their familiarity with technology and their background in the subject being studied. One suggestion to ensure familiarity with the technology would be to require all students to complete an online informational workshop that explains how to use drop boxes, chat rooms, etc. This study should be repeated with a larger number of students in the sample.

Another question that needs to be addressed includes a study of the number of students in the online course, or class size, and how this effects satisfaction, perceived learning, and actual academic performance. Students' level of participation in the discussion boards and chat rooms on Blackboard could also be compared to their satisfaction with their connection to the professor and to other students. Additionally, future research should include studies comparing retention of learning between intensive and full-semester students.

Some of the findings from this study support equivalency theory in that perceived learning and overall satisfaction were not significantly different for the five-week intensive course and the fullsemester course. This indicates that students had equivalency of perceived learning experiences in both the intensive and the full-semester courses. In addition, this study found that students' satisfaction with a five-week session when compared to a full-semester session, in a number of areas, was similar but that effective, meaningful communication both student-to-student and student-to-professor is key to a successful online course, regardless of format. Significant differences in satisfaction with student-student and student-professor communications between the five-week session and full-semester session suggests that different pedagogical approaches must be considered. Although different pedagogical considerations must be made for the different course formats, equivalent learning is possible. Benefits of this study include informing professors who are teaching five-week online summer session courses that their pedagogical approach should be different than the approach they use for a full-semester online course. 


\section{References}

Allen, I., \& Seamon, J. (2005). Growing by degrees: Online education in the United States. Needham, MA: The Sloan Consortium.

Allen, J.L., Miller, T.A., Fisher, B.L., \& Moriarty, D.D. (1982). A survey of January interim psychology courses. Teaching of Psychology, 9(4), 230-321.

Anastasi, J.S. (2007). Full semester and abbreviated summer courses: An evaluation of student performance. Teaching of Psychology, 34(1), 19-22.

Blomeyer, R. (2005). Virtual school and e-learning in K-12 environments: Emerging policy and practice. North Central Regional Educational Laboratory, Policy Issues, 11, 1-12.

Bohlin, R.M., \& Hunt, N.P. (1995). Course structure effects on students' computer anxiety, confidence and attitudes. Journal of Educational Computing Research, 13(3), 263-270.

Brett, M. (1996). Teaching extended class periods. Social Education, 60(2), 77-79.

Carr, S. (2000). As distance education comes of age, the challenge is keeping the students. Chronicle of Higher Education, 46(23), A39-A41.

Drennan, J., Dennedy, J., \& Pisarski, A. (2005). Factors affecting student attitudes toward flexible online learning in management education. The Journal of Educational Research, 98(6), 331-338.

Ebbinghaus, H. (1885/1962). Memory: A contribution to experimental psychology. New York: Dover.

Fredericksen, E., Pickett, A., \& Shea, P. (2006). Student satisfaction and perceived learning with on-line courses: Principles and examples from the SUNY learning network. Journal of Asynchronous Learning Networks, 4(2), 2-31.

Gordon, O.E., (2000). Pedagogical issues in internet education. Southern Utah University. http://aabss.org/journal2000/f10Gordon.jmm.html.

Harden, R.M. (2002). Myths and e-learning. Medical Teacher, 24(5), 469-472.

Jung, Il, Choi, S., Lim, C., \& Leem, J. (2002). Effects of different types of interaction on learning achievement, satisfaction and participation in web-based instruction. Innovations in Education and Teaching International, 39(2), 153-162.

Keller, J. (2010). ARCS model of motivational design. Retrieved from http://www.learning-theories.com/kellers-arcs-model-of-motivational-design.html. 
Lapsley, R., Kulik, B., Moody, R., \& Arbaugh, J.B. (2008). Is identical really identical? An investigation of equivalency theory and online learning. The Journal of Educators Online, 5(1).

Nummenmaa, M., \& Nummenmaa, L. (2008). University students emotions, interest and activities an a web-based learning environment. British Psychological Society, 78(1), 163-178.

Rovai, A.P., \& Barnum, K.T. (2003). On-line course effectiveness: An analysis of student interactions and perceptions of learning. Journal of Distance Education, 18, 57-73.

Scott, P.A. (2003). Attributes of high-quality intensive courses. New Directions for Adult and Continuing Education, 97, 29-38.

Seamon, M. (2004). Short and long-term differences in instructional effectiveness between intensive and semester-length courses. Teachers College Record, 106(4), 852-874.

Seok, S. (2007). eTeacher's role and pedagogical issues in elearning. World Conference on EDMEDIA, 2627-2630, Chesapeake, VA.

Simonson, M., Schlosser, C., \& Hanson, D. (1999). Theory and distance education: A new discussion. American Journal of Distance Education, 13, 60-75.

Stein, D. (2004). Student satisfaction depends on course structure. Online Classroom, 4-5.

Watson, S.W., \& Rutledge, V.C. (2005). Online course delivery and student satisfaction. ERIC document ED490363.

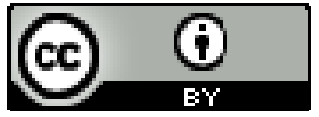




\title{
The Challenges of Implementing Distance Education in Uganda: A Case Study
}

\section{Gudula Naiga Basaza}

Uganda Martyrs University, Uganda

\section{Natalie B. Milman}

The George Washington University, USA

\author{
Clayton R. Wright \\ Canada
}

\begin{abstract}
This brief case study provides a pithy introduction to Uganda and outlines key factors that affect the implementation of distance education in the nation: poor infrastructure, the high cost of an education, an outdated curriculum, inadequate expertise in distance education, and poor attitudes towards distance learning. These factors are also evident in other African countries.
\end{abstract}

Keywords: Distance education; Uganda

\begin{abstract}
About Uganda
The Republic of Uganda is a developing East African country with a population of 31 million people, 85\% of whom live in rural areas (World Bank, 2009). It possesses the following characteristics, as reported by the World Bank and UNICEF in 2009:

- a youthful population with children below 15 constituting more than half of the population;

- a ranking of 157 out of 182 countries on the human development index;

- a ranking of 91 out of 135 countries on the human poverty index;

- a high mortality rate due to poor sanitary conditions and a lack of funding to improve health services;

- a rate of $38 \%$ of the population living below the national poverty line; and

- an adult literacy rate of $74 \%$ (86\% for urban areas and $66 \%$ for rural areas).
\end{abstract}


Demographic surveys conducted by the Uganda Health Services reveal that increasing education levels in Uganda are proportional to improvements in key health indicators (Uganda Demographic and Health Services survey, 2006). Thus, the provision of accessible and quality education is essential for the health of the people. In addition, education is important for the economic growth of the country.

The government of Uganda gives priority to education as evidenced by increased budget allocations and by the introduction of free primary education in 1997. Primary level enrolment has increased from 2.6 million in 1995 to 7.4 million in 2008 (Uganda Bureau of Statistics, 2009). Universal secondary education was introduced in order to absorb the increasing number of students who completed primary education. Now, institutions of higher learning are unable to accept all of the secondary school graduates who qualify and who want to enroll. Between 9,000 and 12,000 students qualify for postsecondary education, but only $25 \%$ of them are accepted into college or university (Experience Africa, 2009). The enrolments in tertiary institutions have increased $90 \%$ during the last 10 years, but the number of tertiary institutions has increased by only 1.8\% during the same period (MyUganda, 2010).

In order to meet the needs of those seeking postsecondary education, but who are denied entry, and in order to improve the health of the citizens and the economy of the country, Uganda must provide additional access to higher education. Distance education (DE) could provide this access.

\section{The Challenges}

Higher education could accelerate development within Uganda. However, there are several major challenges that must be addressed. Each is outlined below.

\section{Infrastructure for Higher Education}

Uganda currently lacks the physical and human infrastructure to cope with the demand for postsecondary education. Further, accessibility to postsecondary education is affected by the distribution of institutions throughout the country. Most of the 31 registered universities are located in the central or urban region of the country, yet the majority of the population lives in rural areas. The distribution of institutions affects the cost of access. Most of the students are not able to commute from their homes to institutions located in urban areas; thus, they must live near the institution and thereby incur additional costs.

The surface area of Uganda is small, allowing people to move from one border to another in a day - a very long day over sub-standard roads. The sole means of transport is by road, using buses and minibuses as few Ugandans own vehicles. The roads, even those with asphalt, are in poor condition and are not lighted. Due to poor road conditions, the poor mechanical conditions of the vehicles, and speeding, at least 2,000 people die annually from road accidents and about 10,000 are injured (Naturinda, Bagala, \& Mugaga, 2009). Thus, transportation is a limiting factor to educational access. Distance education addresses this barrier. 
The building of educational facilities has not kept pace with postsecondary student enrolment, which grew from 5,000 in the 1970s to 124,314 in 2005 (Kasozi, 2006). Consequently, most postsecondary institutions have enrolments that exceed the available space in lecture halls and in libraries. Students are often seen sitting outside the lecture room as classes are conducted. In addition, the current number of students overwhelms available resources, such as books, Internet access, and study space. Digital resources, which a number of universities subscribe to, are available, but due to low Internet bandwidth, impatient students give up before they can access the material they want. In some institutions, the ratio of students to computers is so high that the scramble to access a computer becomes an obstacle to peaceful learning and research. Distance education, may, in part, address the enrolment and space pressures occurring at face-to-face institutions, but distance students will also need access to technological resources.

The National Council of Higher Education in Uganda sets standards for teaching and learning in postsecondary institutions. The Council recommends the number of doctoral and master's degree holders that should be employed by each institution. These percentages are not met, especially by new and rural universities. The number of qualified lecturers is limited by the lack of affordable opportunities for further study within Uganda. Thus, if they can afford it and/or if they receive bursaries, students are likely to obtain further education outside of the country. Due to poor pay, about US\$400 per month, lecturers teach in a number of institutions to make ends meet. This situation compromises the time allocated to (and thus the quality) of teaching and student support because lecturers are constantly moving from one institution to another. Distance learning that utilizes technology should minimize the movement of lecturers between institutions that share instructors. But the widespread implementation of educational technology cannot occur until challenges with the electrical and telecommunications infrastructure are addressed.

Globally, distance learning makes use of information and communication technologies (ICTs) to deliver learning opportunities as well as to provide access to resources and to facilitate interactivity. However, distance learning in Uganda is dependent on printed modules with supplementation by face-to-face sessions (Basaza, 2006). If technology is used to deliver or to enhance distance learning, a reliable electrical grid must be accessible. Unfortunately, electricity is not always available 24 hours per day, 7 days per week in Uganda. As Uganda is a land-locked country, obtaining diesel fuel for electric generators can be expensive. Further, connectivity to the electrical grid declined O.4\% in 2008 (Uganda Bureau of Statistics, 2009), while elsewhere in Africa connectivity increased.

\section{The Cost of Higher Education}

The comparatively high cost of postsecondary education is a barrier to those who want to enroll. On average, a postsecondary student in Uganda requires US\$2,000 per year for tuition and upkeep. Access to tuition loan systems is minimal; thus, potential students and their parents have limited access to extra funds. Even the government institutions admit students predominately on private sponsorship. Tuition fees, books, educational supplies, and living expenses must be paid by parents and students. Note, however, that only about $5 \%$ of the working population has permanent paid employment (Uganda Bureau of Statistics, 2009). The median monthly wage is 
US\$18 (US\$24 for male and US\$10 for female employees) (Uganda Bureau of Statistics, 2009). Consequently, it is easier for Ugandan families to save US\$500 for one year of distance education than to save US\$2,000 for one year of traditional, on-campus instruction.

\section{The Relevance of the Curriculum}

The education system in Uganda is being challenged to produce job creators rather than job seekers. The curriculum has not been adapted to suit contemporary needs (Kasozi, 2006). Current teaching promotes rote learning rather than application, problem-solving, and entrepreneurial skills. Kagoda (2009) decried the process of curriculum reform: "We need the input of the private sector, Federation of Uganda Employers, parents, experienced educationists, retired teachers and any other stakeholders. If half-baked graduates affect us all, then why can't we be consulted on something as important as curriculum?” Rubanju (2008) recommends a fundamental restructuring of the ways in which teaching and learning are delivered, including regular curriculum reviews and the use of ICTs. Rubanju notes that in the traditional lecture hall or classroom, theory and applications are not linked. Studying via distance learning will allow students to apply theories to their own settings and to observe the effect on their environment. The results of these activities could inform curriculum reform and spur the introduction of educational theories and practices that are suitable for the current context in Uganda.

\section{Inadequate Expertise in Distance Education}

Most of the university lecturers do not have a background in education or in instructional and learning methodology. Instead, they have degrees in various subjects and are hired by universities on that basis. Some have obtained guidance about how to teach in a face-to-face setting from colleagues, but very few have experience with distance education instruction and learning strategies. Their inadequacy is reflected in the lack of quality instruction, the lack of quality distance learning materials, and the lack of student support. Students are frustrated with this lack of support, but they are also challenged by the mode of delivery - print! The Ugandan culture tends to be a verbal, or talking, culture; thus, students feel pressure when they are expected to read and write for extended periods of time.

\section{Poor Attitudes towards Distance Learning}

The majority of distance learners in Uganda are employed or involved in subsistence farming and fishing. They enroll in distance education in order to obtain a qualification and/or a promotion. They want to update their knowledge and skills. Some enroll in distance education courses with the attitude that distance education is easy because they can learn at their own pace; however, distance learning requires self-discipline and self-management. Unfortunately, some students drop out or do not graduate. Also, some lecturers believe that once you choose to study at a distance, you do not need extra support. Sensitization and exposure to distance education methods will help students and lecturers to alter their attitudes towards distance education in a land that prizes face-to-face interactions and on-campus instruction. 


\section{Interventions for Enhancing Distance Education in Uganda}

In order to address the lack of resources in the educational system, institutions must collaborate among themselves and with business to provide an infrastructure that will support distance learning. Institutions that offer distance learning are making minimal efforts to establish resource centres in various regions of the country due to prohibitive costs. However, if institutions combine their resources, they could establish state-of-the-art resource centres for use by all of their students.

Distance learning offers business opportunities for investors. For example, distance institutions could reach a memorandum of understanding with an investor to establish a modern resource centre, and payment could be made over time. The business school at Makerere University, Uganda's oldest and largest university, used this approach to establish a computer laboratory. Students were levied a small annual fee to cover the construction and equipment costs of the centre.

When an institution offers education, it does so on behalf of the state, regardless of whether it is sponsored privately or by the government. Thus, within its mandate, the government should prioritize educational infrastructure, including the construction of educational buildings. Priority should be given to establishing a reliable electrical grid, increasing access to the grid, providing Internet broadband connectivity, and facilitating the import of telecommunications equipment, such as computers. The government is not a limitless resource and cannot fully subsidize the education and ICT sectors, but these sectors are drivers of human and economic development.

The poor attitudes students may have towards distance education could be addressed through sensitization, orientation, and the provision of tool kits that help users to study at a distance. Prospective students must be informed that distance education is not easy; rather, it requires selfdiscipline. The public-at-large could be informed about the benefits of distance education: It is not only cost-effective but also enables people to study where they live and to contribute to their families and communities as they study.

Lecturers must receive training in on-campus and distance instructional methods and learning strategies. These sessions can be offered at their current institutions as a job requirement. Teaching will not be recognized as a profession until it is treated as such and individuals who lecture are required to obtain training and to receive some form of certification.

When the quality of distance education is improved as a result of updated curricula, improved instructor training, the provision of modern resource centres, and access to broadband Internet services and reliable power, the attitudes towards distance education will change. At the same time, it must be recognized that distance education is compared to traditional face-to-face instruction in Uganda; however, it is unclear whether the tendency to use rote learning on-campus is a better alternative to instruction delivered via a distance format. 


\section{Conclusion}

Uganda, like many other developing countries, is benefiting, and will continue to benefit from, the implementation of distance education. DE provides flexibility for students, reduces the need for educational buildings, reduces transportation costs incurred by students, allows students to remain with their families and communities, and enables tuition fees to be set relatively low when compared to on-campus tuition fees. In Uganda, however, the success of distance education is inhibited by poor infrastructure, the relatively high cost of an education, an irrelevant curriculum, inadequate expertise in distance education, and poor attitudes towards distance learning. Globally, the use of educational technologies is increasing because the technologies can help bridge the distance between the learners and their learning environment. The increased use of educational technology in Uganda will only exacerbate existing challenges, which must be addressed. Distance learning is unlikely to succeed without collaboration involving the government, the educational institutions, and the business community. 


\section{References}

Basaza, N. G. (2006). Distance education and realistic teacher education pedagogy in Uganda: Impact of an ICT-based learning environment (Unpublished doctoral thesis). University of Ghent, Belgium.

Experience Africa (2009). Information about primary and secondary schools in Uganda. Retrieved from http://www.experienceafrica.co.uk/J1.htm.

Kagoda, M. (2009). Consult widely before curriculum review. Retrieved from http://www.newvision.co.ug/D/9/35/697700.

Kasozi, A. B. K. (2006). A proposed quality assurance framework for institutions of higher learning in Uganda. Paper presented at the seminar on Quality Assurance in Tertiary Education, Servres, France.

MyUganda (2010). Education in Uganda. Retrieved from http://www.myuganda.co.ug/edu/.

Naturinda, S., Bagala, A., \& Mugaga, H. (2009). Road accident claims life of Budiope legislator. Retrieved from http://allafrica.com/stories/200912010546.html.

Rubanju, A. C. G. (2008). Quality challenges in higher education institutions in Uganda. M.Phil Higher Education (HE), Faculty of Education, Institute for Educational Research. University of Oslo. Retrieved from http://www.uv.uio.no/studentliv/isne/assets/docs/Unit\%201\%20paper\%20assignment.doc

Uganda Bureau of Statistics (2009). Statistical abstract. Retrieved from http://www.ubos.org/onlinefiles/uploads/ubos/pdf\%20documents/2009Statistical_\%20Ab stract.pdf.

Uganda Bureau of Statistics (2006). Uganda demographic and health survey. Retrieved from http://www.measuredhs.com/pubs/pdf/FR194/FR194.pdf.

UNICEF (2009). Uganda statistics. Retrieved from http://www.unicef.org/infobycountry/uganda_statistics.html.

World Bank (2009). Uganda. Retrieved from http://ddpext.worldbank.org/ext/ddpreports/ViewSharedReport?\&CF=\&REPORT_ID=91 47\&REQUEST_TYPE=VIEWADVANCED.

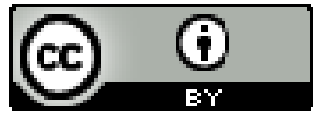




\title{
Book Review
}

\section{Learning Cultures in Online Education}

\author{
Editors: Robin Goodfellow and Marie-Noëlle Lamy (2009). Learning Cultures in Online \\ Education. New York: Continuum Studies in Education. 248 pages. ISBN: 978-18470-60624-4
}

\section{Reviewer: Nataly Tcherepashenets, SUNY, Empire State College, USA}

I felt lucky to come across Learning Cultures in Online Education, edited by Robin Goodfellow and Marie-Noëlle Lamy from the Open University, UK. This insightful book, which successfully blends empirical studies and theoretical underpinnings, responds to my professional interest in the place of foreign language education within the scholarship on online learning. The editors, both of whom are engaged in the dynamic fields of distance language learning and e-literacy, suggest viewing online language learning as a practice that vividly exemplifies learning cultures as they emerge in distance education across disciplines. The title of the book alludes to this connection, which according to the authors is promising because in their opinion the process of learning about cultures, where the development of linguistic competency, arguably, plays a central role, is related intrinsically to the emergence of "learning cultures."

In the informative introduction, Goodfellow and Lamy celebrate a polysemous concept of culture, which resists the boundaries of a single definition. In addition, the editors outline four major areas of inquiry associated with cultural contact. They are (1) transnational and cross-border education; (2) the take-up of computer-mediated interaction by previously marginalized groups; (3) the growth of new forms of knowledge production, which overlap the issues of identity and media; and (4) the spread of social networking phenomena and their use in education.

Offering a useful frame for the chapters, the editors suggest viewing cultural issues as inseparable from educational, linguistic, and technological ones. Cultural perspectives incorporate such areas as curriculum, interaction, collaboration, pedagogy, language, and assessment, as well as issues of cultural identity, which are frequently raised in research literature but are not often addressed satisfactorily. They note such factors as the growth of multiculturalism and the widening participation policies in national systems of higher education, which face the constraints of low IT literacy and lack of familiarity with online systems and pedagogies, the rapid expansion of transnational e-learning, and the spread of new media communication practices (i.e., Internet community, socializing, and informal learning practices), which are becoming increasingly influential for the learning process and indicate the necessity to further problematize "learning 
cultures.” This necessity becomes more evident in subsequent chapters, where researchers bring international contexts to bear upon such areas of inquiry as "cultural learning styles," (i.e., the preferences of individuals), "cultures of learning," (i.e., the norms and values associated with learning in specific institutions), and finally "learning cultures," (i.e., the area of emergent innovative collective approaches to learning in conditions that are wholly characterized by remote communication).

In the first chapter, Charles Ess, the founder of the Cultural Attitudes to Technology and Communication conference (CATAC), who has written widely on topics of culture, education, and technology, argues that cultural identity is a hybrid, which has many more dimensions than nationality or mother tongue. He views online scenarios as themselves culturally coded spaces, which invite the formation of "third cultures" based on the combination of elements from different cultural traditions in which individuals socialize to form their own identity. Recognizing diverse aspects of culture and the lack of theories "to do justice to the multiple dimensions of 'culture”” (10), Ess challenges the very possibility of conceptualizing "learning cultures.”

In the second chapter, "Identity, Gender and Language in Synchronous Cybercultures: A CrossCultural Study,” Charlotte N. Gunawardena, Ahmed Idrissi Alami, Gayathri Jayatilleke, and Fadwa Bouchrine further investigate the topic of online cultural hybridity by drawing on the empirical research they conducted in Morocco and Sri Lanka. Their findings demonstrate the possibility of hybrid cultural identities emerging from local systems of activity, such as an Internet chat. These authors pay special attention to the discussion of the ways that participants' identities, for example their gender and religion, are enacted and/or concealed as part of the process of negotiating norms of communication online.

In chapter three, "Entering the World of Online Foreign Language Education: Challenging and Developing Teacher Identity,” Robert O’Dowd discusses the influence of the implementation of online learning on the identities of faculty members. While recognizing that the Internet and virtual learning platforms have become an integral part of education in Western society and have helped to shape the expectations and hopes that teachers and students now bring to formal education, O'Dowd points out that transitional processes from face-to-face to online teaching/learning and new institutional e-learning policies may take different shapes. Analyzing a case study of foreign language and linguistics classrooms on a Spanish campus, he suggests that the impact of online learning and teaching is intrinsically related to the general culture of learning and teaching that exists in each school. O'Dowd suggests that it is important not to underestimate the impact of a university's socio-institutional context, which includes the minds and behavior of the teachers, on online learning practice.

Whereas the focus of chapter three is on instructors, Christine Develotte considers the same transition but emphasizes the identities of students in chapter four, "From Face-to-Face to Distance Learning: The Online Learner's Emerging Identity.” Her case study examines an online course, Teaching French as a Foreign Language, offered at a French university. Considering the experience of online textual activity as socially demanding, she analyses the "discursive space" and learning cultures that emerge in the online learning environment, represented by the learners, 
and tracks their emotional and cognitive adaptation to the role of online learner. Drawing a comparison between on-site and online instruction, Develotte concludes that the learning culture that is constructed in the process of online instruction is more convivial and less competitive, and it leads to more connections among students and between students and instructors than the more familiar but less dynamic, in her opinion, on-site condition.

The textuality of online learning environments is also a point of departure for Leah Macfadyen's chapter five, "Being and Learning in the Online Classroom: Linguistic Practices and Ritual Text Acts." She discusses learning cultures as communities, "in which the 'rules of engagement' have to be constructed." According to Macfadyen, significant learning needs physical embodiment, which can be achieved via online "textual rituals," during which self-identity is necessarily constructed through the interactions between participants. Macfadyen analyses in depth a course in global citizenship, where some participants reconstruct themselves as global citizens.

Anne Hewling further explores "textualized interactions" in chapter six, "Technology as a 'Cultural Player' in Online Learning Environments," but from a different angle. She focuses on the analysis of virtual learning environments and criticizes the functional efficiency of the systems in practice. Hewling is particularly interested in the exploration of the role of technology in the negotiation of culture. In her view, technology can function autonomously; as well, it can replace the authority of the institution. As Hewling suggests, technology appears to behave as a cultural factor, and its unpredictable functioning in combination with the unfamiliar pedagogy can create cultural challenges even for students whose cultural background is the same as that of the host institution.

In chapter seven, "Trouble and Autoethnography in Assessment Genre: A Case for Postnational Design in Online Internationalized Pedagogy,” Catherine Doherty focuses on the 'troubling' assessment procedures in a context of postnational pedagogy, which online internationalized learning exemplifies. Drawing on a case study of an MBA core unit offered by an Australian university, this author argues that in postnational learning cultures all students should be positioned as international, regardless of their national identity or place of residence. Therefore, in order to prevent the dominant influence of local practices and learning cultures that operate within the host institution, it is necessary to examine traditional "assessment genres." Ironically, as Doherty observes, to avoid privileging any local frame of assessment "by default," it is an imperative to closely analyze local assessment approaches, especially in their interactions with transnational environments and identities. She views this "autoethnographic move" as one of the characteristics of post-national pedagogy and suggests that internationalized online learning offers unique opportunities for its further exploration.

Jay Lemke and Caspar van Helden in chapter eight, "New Learning Cultures: Identities, Media and Networks," provide a further critique of traditional schooling and point out how students learn through popular culture media and personal social networking, including online communities. These authors suggest that further research on how people learn outside the school and the curriculum will be instrumental for improving online learning practice and education in 
general. They call for special attention to be given to such factors as the roles of passion and emotion in learning as well as to learners' motivation.

After acknowledging that significant research has been done on the responsiveness of instructional design to the cultural peculiarities of learners from different national, religious, and linguistic backgrounds, the editors state their intention to move the existing debate on online cultures in a "somewhat different direction" through the exploration of six major themes. They are (1) the nature of identity online; (2) the continuing importance of embodiment; (3) the negotiation of cultures and the limitations of essentialist approaches to cultural difference; (4) the centrality of language(s) and textuality; (5) the under-acknowledged importance of the affective dimension, including resistance and creativity; and (6) the increasingly unpredictable behavior of technologies. There is no doubt that these themes allow contributors to draw readers' attention to the rapidly changing face of "culture" in online education and to the active role that institutions, faculty, designers, and learners play in this process. The editors successfully bring these themes together to outline two key areas of interest, which, in their opinion, are productive directions for future research. They are (1) studies of the processes by which institutions and corporations develop hegemonies over pedagogies of global online education, and (2) an investigation of the cultural dimensions of communication in online learning communities and the processes of negotiation of identities by their participants.

In their discussion of institutional cultural hegemony over pedagogy, the editors ask a plausible question about the possibilities of developing alternative models to the dominant Western/Anglo model of online learning. They suggest that an understanding of the cultural nature of Western/Anglo online pedagogy and its relation to the discourses of cultural differences is a promising area of future research, which would allow the promotion of non-Anglo-hegemonic models of online learning. A critical awareness of culture is integral to the development of nonhegemonic models of online learning, which are shaped largely by "hybridized identities." Such identities result from the process of negotiating cultural identity, which, arguably, occurs mainly via (in) linguistic interaction.

Research on second language learning and intercultural studies therefore can serve as a basis for research on online learning cultures. The editors draw a parallel between the most recent developments in the research on language learning and the potential areas of study in multicultural online learning research. As in applied linguistics, the inquiry moves away from the evidence of language learning towards the socio-cultural conditions for language learning; in the research on learning cultures, the conditions in which multicultural online language learning takes place should be analyzed as well. Lamy and Goodfellow also note that issues of power are at the center of research on socio-cultural language learning theory, where most often the focus is on immigrants' language development and heritage language research. Power issues are also of primary importance in intercultural exchange research, where power has been constructed in psychological terms as a facilitator or as an inhibitor of comfort in online groups.

In the spirit of promoting multiculturalism as an intrinsic feature of learning cultures in online environments, the book ends by suggesting the consideration of open education resources 
(OERs), created by diverse groups of scholars, as a promising focus for research on online learning cultures.

In summary, this book will be of interest to a growing audience of researchers and practitioners who are interested in both the creation of and the immersion in learning cultures, particularly as they develop in online environments and as they challenge our approaches to education.

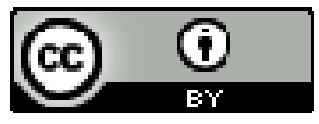

Athabasca

University 


\section{Book Review}

\section{Perspectives on Distance Education: Open Schooling in the 21st Century}

Editors: D. A. M. X. Abrioux and F. Ferreira (2009). Perspectives on Distance Education: Open Schooling in the 21st Century. Vancouver: Commonwealth of Learning. ISBN: 978-1-89497533-9.

Reviewer: Ramesh Sharma, Indira Gandhi National Open University, India

There is no denying the fact that primary school education is the most important building block of an educational system. If the foundation is strong, the future will be secured. Numerous commissions, forums, and governments have advocated greater attention and resource allocation to primary education. Open schooling (OS) has become one of the mechanisms to achieve that goal. This book deals with different dimensions of open schooling, such as the formulation of policies that foster the growth of open schools, the use of ICT, and the cost structures. To bring home the point, case studies from six Commonwealth countries are described to provide a diverse picture of the status and future of OS across the globe. These cases provide a picture of different governance models and levels of autonomy, different degrees of openness, different stages of establishment, and a wide range of enrolments, jurisdictions, student success, adoptability of ICT, instructional design, human support etc. The book draws a picture of the spectrum of OS systems.

The book's 11 chapters are distributed in four parts. Part I: Introduction contains one chapter by Dominique Abrioux. Part II: Themes offers three chapters. Part III: Case Studies presents case studies from sub-Saharan Africa (Botswana and Namibia), Oceania (Australia \& Papua New Guinea), South Asia (India) and North America (Canada). Part IV: Conclusion contains the final chapter by the second editor, Frances Ferreira.

In his preface, Sir John Daniel categorically emphasizes that, following the success of postsecondary education through open and distance learning (ODL), it is now time for OS to flourish. Having restated the significance of Education for All in 1990 at Jomtien and in 2000 at Dakar, different governments have paid serious attention to Universal Primary Education (UPE), one of the goals declared at the Dakar Forum. To help developing countries to achieve UPE and gender equality, the Fast-Track Initiative (FTI) was introduced, and it boosted efforts to achieve higher literacy levels. Through carefully designed programs and the lifelong learning and flexible 
mechanisms of OS, many issues yet to be addressed for UPE can be sorted out. Additionally, private providers are now beginning to pay attention to OS.

In the introductory chapter, "Special Issues and Practices in Open Schooling," Abrioux discusses such core issues as the need to increase the breadth, equality, and openness of access, the relevance of curricula to the needs of stakeholders, the quality of the teaching and learning, and the maximizing of the cost-effectiveness, cost-efficiency, and sustainability of educational systems. These challenges in developing countries are particularly serious. He suggests the establishment of an OS model with mechanisms to overcome barriers and to enable access to open learning. There is a need to clarify whether OS is to complement or to serve as an alternative to the conventional schooling system. This chapter also touches upon three additional themes: policy for OS, use of ICT in OS to increase accessibility, and the quality and costeffectiveness of OS.

The second chapter discusses policies that enable the development of OS. All six institutions examined in this book have different procedures, protocols, rules, and regulations that are affected by the state or provincial and national roles they play in relation to different levels of government. Some governments have taken OS quite seriously; for others, it is a low priority. This chapter poses a question as to why governments should formulate policies for OS. Emerging from the discussion is the conclusion that due to their different cost structures, both ODL and OS need specific policies irrespective of government's commitment so that they are not subjected to changes in government or funding priorities. Identification and analysis of issues followed by setting a specific agenda can set the stage for the selection of a range of specific policy options. Policy documents should include the following: background of OS, definition of terms, statement of principles, application and scope, date of commencement, responsibilities of different units, and sources of funding, etc. The chapter presents useful tips to formulate effective approaches, such as consideration of the paramount importance of the beneficiaries, the cautious use of technology (recognizing it is only a mechanism), careful investment, integration of OS with existing educational systems, and a caution that OS not be treated as a one-fix solution to educational problems.

In the chapter on ICT for OS, the author points out that OS allows educational access to large populations, offers a platform to people with disabilities, young mothers, and street children, etc. who cannot participate in traditional educational systems, and caters to the need for lifelong learning. Increased access to high quality resources can increase learner involvement and motivation by allowing greater interaction among learners. OS institutions use various ICT tools to make intervention successful. Appropriate planning frameworks can resolve such infrastructure issues as availability of resources, funding requirements, and maintenance. Adoption of ICT must be in tune with learning models and the way ICT may be used to establish repositories of instructional lessons, self tests, quizzes, and program orientations. The authors of this chapter also discuss human resource issues, such as capacity building and the languages staff and students should use in their respective OS systems. 
Chapter four pertains to the costs of open schooling and describes different approaches to calculate ODL systems, types of costs, factors affecting costs as well as costs related to ICT implementation. As suggested by the author, through careful design OS can deliver education that is at the same level of quality as that offered in traditional schools. Part III consists of six case studies originating in different Commonwealth countries. These case studies provide the following information about the OS systems: background, national context, legal and regulatory framework, governance, organizational model, institutional culture, funding mechanisms, student success rates, curriculum framework, degree of openness, student support services, student assessment practices, use of ICT, quality control, and cost-effectiveness mechanisms.

The final chapter presents a picture of the bright but challenging future of open schooling. The author asserts that open schools can be a solution for enhancing access to quality secondary schooling; on the other hand, there is a paucity of documented evidence to support this assertion, which is needed to advance the OS agenda and to remove the misconceptions about OS amongst policy makers and key stakeholders. Citing relevant practices of institutions described in previous chapters, the author of this chapter emphasizes the factors that address the issues of equality of access and outreach, relevance of curricula to societal needs, improvement of the quality of teaching and learning, and achievement of cost-effectiveness and cost-efficiency.

This book's critique of the existing practices, policies, rules, and regulations of open schools and its recommendations for creating new and successful OS models will appeal to distance education practitioners, policy makers, educational technologists, government officers, and researchers. The book deepens our understanding of the infrastructure, policy framing, ICT, and costing issues relative to the governance and operation of successful OS institutions. I strongly recommend it for all those who may have an interest in OS or who are concerned about planning its advancement, wherever they happen to be.
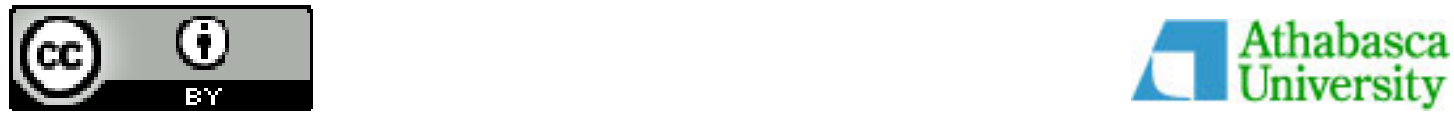


\title{
69. Thirty Years of Distance Education: Personal Reflections
}

\author{
Terralyn McKee \\ Athabasca University, Canada
}

\begin{abstract}
This paper reflects on the evolving experience of modern distance education (DE) as a field of practice for professionals and as a medium for student access to education and training. The writer's 30 years in the field, as both teacher and student, has coincided with the five-stage evolution of DE delivery defined by Taylor (1995-2010). The author considers the perceived identity crisis and diverse theoretical frameworks of the field since the 1980s as well as the need for new levels of change management to enable the tools, technologies, and emerging systems of $\mathrm{DE}$ in order to create the flexibility, responsiveness, and networking that students require and that teachers need to learn.
\end{abstract}

Keywords: Distance education delivery; correspondence; multimedia; telelearning; flexible learning; intelligent flexible learning

\section{Introduction}

I have started this paper numerous times only to walk away in frustration. I had wished to record my personal journey through 30 years of distance education (DE) and its technologies for some time and thought the task would be easy. Ultimately, it has been like trying to hit a moving target. The field appears to have a constant identity crisis, defined by a developmental deluge of pedagogies and technologies depending on the favoured course delivery methods of the day. Moore (1985) summed up this situation in stating that most published DE research is descriptive and not generalisable, is only marginally based in theory, and is deficient in disciplined research under controlled conditions.

The rate of technology's development and integration in education since then has added to this confusion. Advances in the digital architecture of the Internet and Worldwide Web have presented a dazzling array of new possibilities for professional and social relationships. In the evolving dissonance of mediated environments, I have struggled to articulate my personal unease with the pedagogical applications of technology during my 30 years of distributed teaching and 
learning. I have experienced education face-to-face, by postal correspondence, by correspondence with telephone support, by correspondence augmented with audio and then videotape, broadcast, computer-mediated, blended in-class teaching and learning, and now by digital education on the Web. The constant deluge of data and technologies, combined with the pace at which learning environments continue to change, have left me more than confused as a student, and almost terrified as a teacher in my concern to keep up!

\section{Five Generations of Distance Learning}

DE technologies and practices have undergone radical transformations during the past 50 years and are considered by many to be the leading edge of academic opportunity for postsecondary institutions. Seeking a structure for my personal reflections, I finally found it in the analysis of the ongoing iterations of DE technologies by Taylor $(1995,2001)$. Taylor describes the evolution of technological innovation in DE in a way that mirrors my own DE experiences (Table 1). The transformation process I have been forced through has been volatile and evanescent. Having experienced all five of Taylor's evolutionary stages in one capacity or another, I will use his five generations of DE technology as an organisational guide for this paper.

Table 1

Generations of Distance Education (Taylor, 2001)

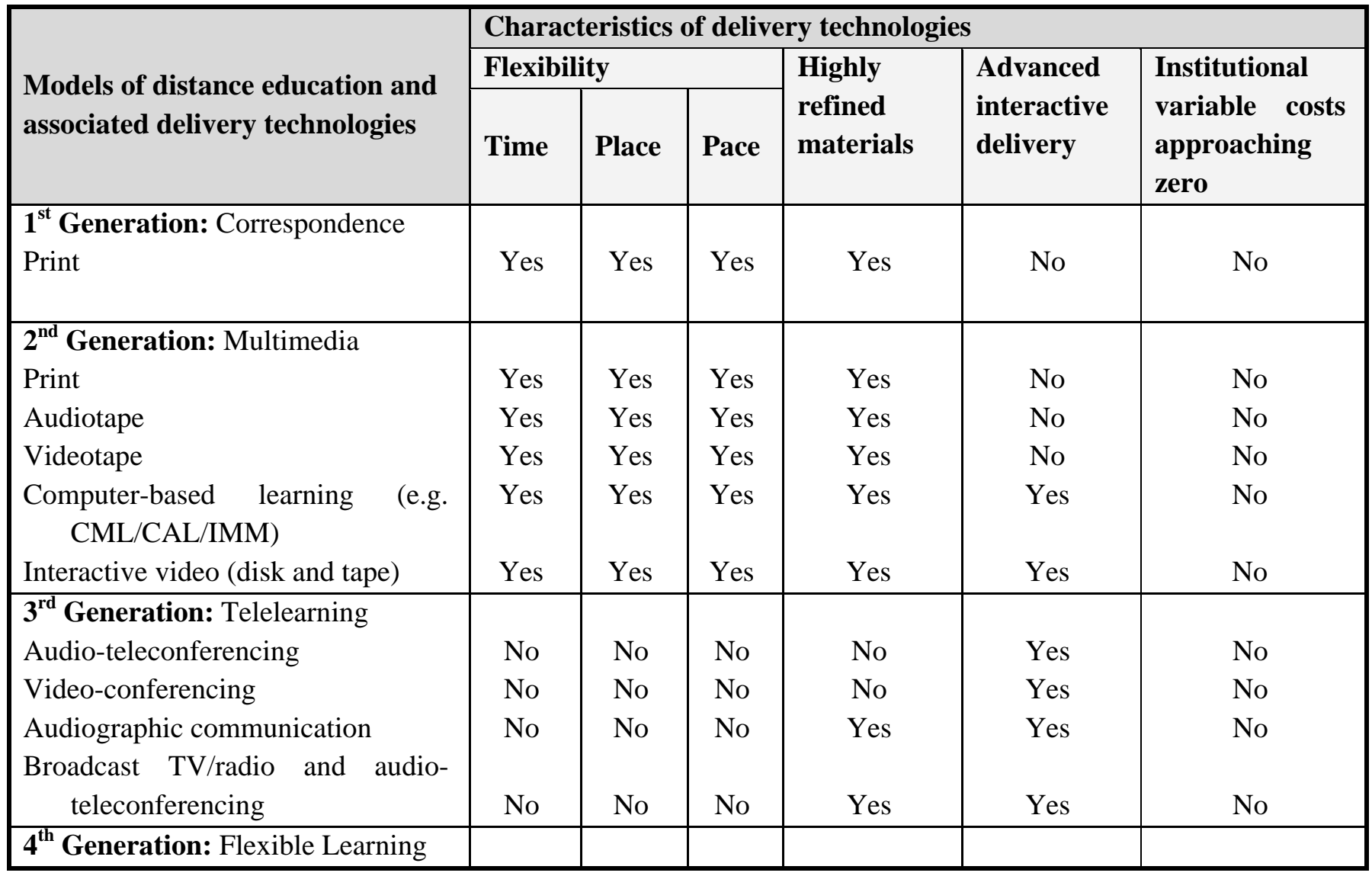




\begin{tabular}{|c|c|c|c|c|c|c|}
\hline $\begin{array}{l}\text { Interactive multimedia (IMM) } \\
\text { online } \\
\text { Internet-based access to WWW } \\
\text { resources } \\
\text { Computer-mediated communication }\end{array}$ & $\begin{array}{l}\text { Yes } \\
\text { Yes } \\
\text { Yes }\end{array}$ & $\begin{array}{l}\text { Yes } \\
\text { Yes }\end{array}$ & $\begin{array}{l}\text { Yes } \\
\text { Yes } \\
\text { Yes }\end{array}$ & $\begin{array}{l}\text { Yes } \\
\text { Yes } \\
\text { Yes }\end{array}$ & $\begin{array}{l}\text { Yes } \\
\text { Yes }\end{array}$ & $\begin{array}{l}\text { Yes } \\
\text { No }\end{array}$ \\
\hline $\begin{array}{l}5^{\text {th }} \text { Generation: } \\
\text { Intelligent Flexible Learning } \\
\text { Interactive multimedia (IMM) } \\
\text { online }\end{array}$ & Yes & Yes & Yes & Yes & Yes & Yes \\
\hline $\begin{array}{l}\text { Internet-based access to WWW } \\
\text { resources }\end{array}$ & Yes & Yes & Yes & Yes & Yes & Yes \\
\hline $\begin{array}{l}\text { Computer mediated } \\
\text { communication, using automated } \\
\text { response systems } \\
\text { Campus portal access to } \\
\text { institutional processes and resources }\end{array}$ & Yes & Yes & Yes & Yes & Yes & Yes \\
\hline
\end{tabular}

\section{Correspondence Education (First Generation)}

\section{Print.}

The experience of correspondence education is dependent upon the literacy skills of the learner and upon the course design expertise of the teacher and institution. My own experiences with correspondence education support the suggestion by Bourdeau and Bates (1996) and MorteraGutiérrez (2006) that the delivery method is less critical than the design and management process. I believe I have experienced the gamut of DE correspondence courses, from the exceptional to the poor, disorganised, and incoherent. The chief component in my assessments is the quality of dialogue that the materials have afforded me as a learner. Moore's theory of transactional distance (1997) explored how the DE dialogue, even conducted by remote participants, can provide an unique form of communication between teacher and student. Print materials have the capacity to provoke dialogue and to reduce the emotional and cognitive distance between these two participants.

In fact, Moore went as far as to describe the student's experience of print materials as "a form of learner-instructor dialogue because the learner (has) an internal or silent interaction with the person who in some distant place and time organized a set of ideas or information for transmission.” To describe the student's relationship with printed content as in any way an actual interaction might be interpreted as devaluing human interaction in education. A recent metaanalysis of online study, however, has indicated that learning is predicted more by the quality of Moore's "student-content interaction" than by "student-student" or even "student-instructor interaction" (Bernard et al., 2009). Indeed, the aspects of correspondence-type course delivery that I have appreciated the most, both as a student and a teacher, are the permanence and ease-ofuse of print materials, the relatively inexpensive construction process of learning packages, the 
limited technology knowledge required for interaction with the materials, and the ability to match the learning to my schedule and place of study. Experience tells me that the most effective correspondence courses adhere to prescribed design formats that are intuitive, sequential, complete, and organized, and that support both the learner and the content.

The disadvantage of the print-based method is the limited interaction possible with teachers and classmates. The ability to interact with the materials is also limited to the strength of the dialogue created by the materials and the teacher. It is hard to remain motivated by static content and to personalise or extend its learning opportunities. For a teacher, the process is equally difficult because of the partial assumptions that are possible about the students' prior knowledge and experience of the course content. In addition, the evaluation process for this type of learning can miss the richness and insight of the teacher-student relationship and may not accurately measure the true educational effects. Personally, I do not "test" well and have been frustrated by the summative approaches of many correspondence course evaluations. Summative evaluations left to the end of a course, the point of no return, miss the opportunity to identify and to deal with areas of misunderstanding regarding key concepts. This problem is especially serious when the course relies upon postal service alone,

Moore (1997) summarised this situation as follows: "It is the separation of learners and teachers that profoundly affects both teaching and learning. With separation there is a psychological and communications space to be crossed, a space of potential misunderstanding between the inputs of teacher and those of the learner."

\section{Mixed Media Delivery (Second Generation)}

\section{Print, audiotape, videotape, computer-based learning, interactive video (disk and tape).}

I tend to think of second-generation distance education as correspondence courses on steroids, good, bad, or downright ugly. The innovations with respect to audio/visual tools expanded learning opportunities in distance education by enriching the delivery options. The content could now sing and dance and offered new options for teacher-student interaction. The "tyranny of proximity,” as Taylor (1995) called it, was diminishing. As with any emerging new system, however, these tools have frequently been used to less than full effect.

- The Ugly: I once received a distance course about religious philosophy from a reputable university, in a set of 10 audio cassettes, a textbook, and a print syllabus. By the seventh hour of the audio cassettes, I felt desperate. They were taped during course lectures, the quality of the sound was awful, and the organisation of the materials followed the whim of the in-class discussion, which was never audible and in which questions were not reframed for the benefit of the distance learner. Overall, the impact of these aids in the course, for me, was negative and counter-productive. 
- The Good: In contrast, I had the pleasure of taking an education course for secondary school counseling, which was the epitome of instructional design. The course was conducted in the same institution as the ugly course, but with a different teacher. The materials arrived with several audiotapes produced by the professor in a quiet area, which supported key content areas, a videotape demonstrating effective counseling techniques, two textbooks, and an expertly produced learning guide, which prefaced the learning objectives, was sequential, informative, and graphically appealing, used frequent reinforcing self-quizzes, and provided optional activities for assignments. I remained highly motivated throughout this course because it catered to my preferred learning style and reduced transactional distance by providing a visceral connection to the materials and to the teacher.

\section{Telelearning (Third Generation)}

\section{Audio-teleconferencing, video-conferencing, audiographic communication, and broadcast TV/radio.}

Audio- and video-conferencing addressed transactional distance issues by adding the synchronous element to learning that only face-to-face education had afforded previously. Despite the awkwardness of the communication media (e.g., protocols for turn-taking and the ability to share thoughts), the capacity to transmit and participate through a technology that allowed synchronous sharing of voice, data, and graphic images was critical to my further commitment to distance learning. With all the benefits of the new technologies came the inevitable glitches and access issues as well as the endless learning curve required to keep pace with the new technologies. But the content now had the ability to sing and dance, and I was able to interact with it as a teacher as well as a student and to construct my experience in way that I found engaging and motivating. As an added bonus, the experience gave me the urge to understand how my Apple IIe worked and to find ways of making that information useful to my own students in the classroom.

Although I am not greatly in favour of direct education as a primary teaching model, I do have respect for the wide range of approaches it provides for knowledge and skills acquisition. I appreciate the information modeling and guided practice which provides as much repetition as the student needs to master information before moving on to higher-order thinking skills (Hunter, 1994). Without a solid foundation in the terminologies, processes, and conceptual frameworks of a topic, the higher-order issues are less meaningful. Computer-mediated direct instruction allows skill-and-drill processes that many teachers tire of after a few iterations, and it allows the individual student to monitor his or her own progress and to plan further iterations as needed. 


\section{Flexible Learning (Fourth Generation)}

\section{Interactive multimedia (IMM) online, Internet-based access to WWW resources, computer-mediated communication.}

If, as I described earlier, the second-generation mixed-media approach to DE is correspondence courses on steroids, the fourth generation takes things to a new level and begins to resemble the science-fiction film, The Matrix. Distance educators and designers are presented with completely new challenges - to understand and define innovative philosophy, epistemology, codes of ethics, aesthetics, politics, culture, and practice. In this respect, DE is living up to its reputation described by Christensen (1997) as a disruptive innovation - dynamic, radical, and unpredictable in terms of its evolution and use. Current DE is experiencing growing pains at the most basic levels and is prompting reflection across the educational field as a whole. The technologies are creating opportunities for students and educators to view educational processes, goals, definitions, and environments (face-to-face and distance) in exciting new lights and as ripe with possibility. Access to the Worldwide Web has forever changed how I learn as a student, grow as a professional, and teach in my classroom. One-size-fits-all education is giving way to customisation in content, learning styles, methodology, and practice. Information can be personalised to create knowledge that is unique and boundless through connection to the power of co-creation with peers. I enjoy the opportunity to connect with peers online to discuss course assignments and practical and theoretical applications of new information. Sharing and actually co-editing presentations synchronously has generated insights into learner-directed approaches, which are so valuable in the current global economy. I have sought actively to incorporate the approaches I have learned from DE in my face-to-face classes, capitalising on the best technological methods of both approaches.

The types of tools and technology that I have used in my personal journey through DE generations 1 to 4 are listed in Table 2. As may be apparent from this paper so far, however, the process for me has been less about technology per se and more about the process of integrating innovation into coherent teaching and learning practices.

Table 2

The Author's Journey with Different DE Tools and Technologies

\begin{tabular}{|l|l|}
\hline Text & $\begin{array}{l}\text { IRC (Internet relay chat - mIRC, ICQ, etc), Microsoft } \\
\text { Outlook (email), MSN Messenger, bulletin boards, } \\
\text { threaded discussion boards, Google Groups, wikis, } \\
\text { WebBoard, blogs }\end{array}$ \\
\hline Audio-conferencing & $\begin{array}{l}\text { Speakerphone, polycom, operator-assisted conferencing } \\
\text { (most reliable), Flash }\end{array}$ \\
\hline $\begin{array}{l}\text { Audio/video (i.e., all of the programs } \\
\text { listed under audio-conferencing, with } \\
\text { the added feature of visual engagement) }\end{array}$ & $\begin{array}{l}\text { GoTo Meeting, Desire2Learn, WebCT (too complicated), } \\
\text { Moodle (most intuitive), Powerpoint, SlideShare, Skype, } \\
\text { Flickr, YouTube }\end{array}$ \\
\hline
\end{tabular}




\section{Intelligent Flexible Learning (Fifth Generation)}

\section{Interactive multimedia (IMM) online, Internet-based access to WWW resources, computer-mediated communication, using automated response systems, campus portal access to institutional processes and resources.}

How is the fifth generation different from the fourth? Taylor (2001) identified it as a "derivation" that provides the fluidity, flexibility, and speed needed to drive the next iteration of educational technology in an age where knowledge and information are the chief currencies. The current iterations seem boundless, and Taylor (2010) now identifies three separate fifth-generation levels, involving various blended learning approaches. While the emerging innovations may be difficult to predict, the need driving them is not. The learner in the digital age (digital native) is immersed in a technological environment with little separation between formal learning, social networks, recreation, and employment. An emerging theory that addresses this learning construct is connectivism (Siemens, 2006), and it is a current driving force behind my personal philosophical orientation in DE. The traits exhibited by learners today, as demonstrated by Siemens in Figure 1 , most accurately depict my own processes and preferred styles, regardless of the educational media used online or in class.

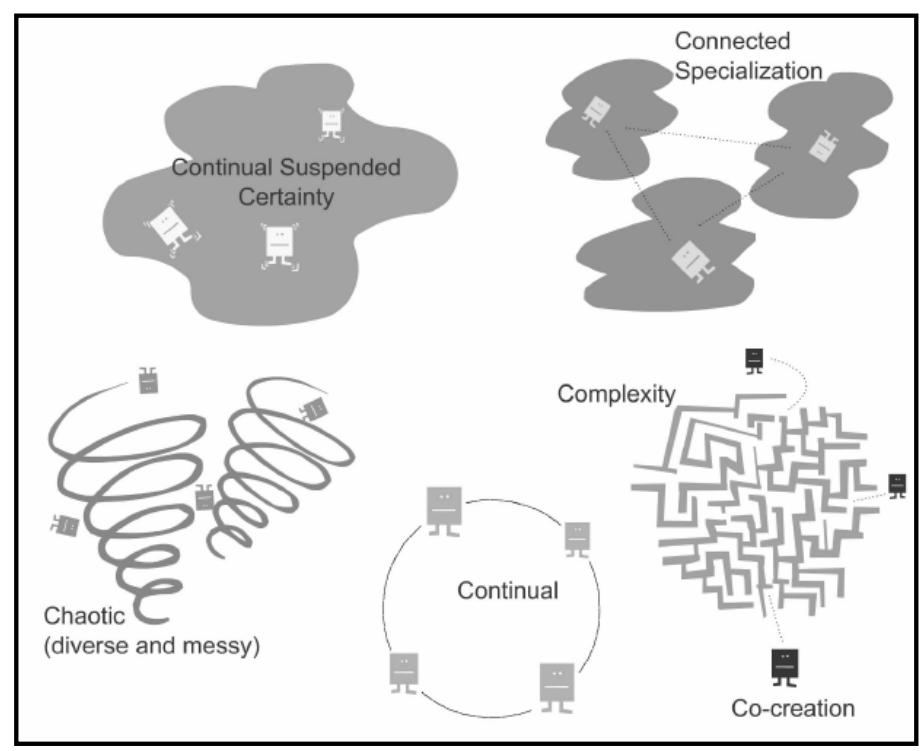

Figure 1. Traits of Learning Today (Siemens, 2006).

The boundary between online and in-class situations in the connectivist approach is more theoretical than actual, as blended approaches are rapidly becoming the norm. Taylor (2001) defined the fifth-generation type of $\mathrm{DE}$ as an "intelligent flexible learning model” seamlessly integrating all aspects of the educational system, including administration, enrolment, commerce, publishing, and distribution. The skill sets and knowledge requirements of future generations will 
look quite different from those required today. Meeting this challenge with appropriate systems, tools, and processes will be a daunting task given the current rate of technological change.

The DE system has struggled to make effective use of the early Web 1.0 methods. With the development of the new interactive Web, popularly known as Web 2.0 (O’Reilly, 2005), distance educators are attempting to capitalise on an even wider range of technologies, although my perception is that they have not yet glimpsed the full paradigm shift that is emerging in knowledge construction and management in this new technological environment. Web 2.0 methods have introduced interactive networking concepts that enliven educational activities with greater personalised meaning and socialised connectivity. Still, however, many educators resist collaborative learner-directed approaches that shift power and control away from the institutions and individuals and towards a more personally connected web of educational experience. On the cusp of a "Web 3.0 (r)evolution" (Agarwal, 2009), DE continues to flounder in this perplexing technological world without a consistent identity or commitment to its organisation and development.

\section{Conclusions}

In my ideal distance education delivery system, the process of change management in innovation is more important than tools, technologies, and systems. These change, evolve, and are often abandoned as the cycle of change folds back upon itself. My own ideal distance-based delivery system is changeable based on context and environment; flexible and responsive to the demands of the content, connections, and tools; connected in a vast ocean of academic and social networks, allowing construction of individual and shared ideologies and knowledge frameworks; and sufficiently intuitive to acknowledge my prior experiences and knowledge in building a system appropriate to my level of understanding, interest, and commitment. My personal journey through 30 years of this evolutionary process has left me dizzied by the pace of change, but ultimately optimistic for the generations to come. 


\section{References}

Agarwal, A. (2009). Web 3.0 concepts explained in plain English. Retrieved from http://www.labnol.org/Internet/web-3-concepts-explained/8908/

Bernard, R., Abrami, P., Wade, A., Borokhovski, E., Tamim, R., Surkes, M., \& Bethel, E. (2009). A meta-analysis of three interaction treatments in distance education. Review of Educational Research, 79(3), 1243-1289.

Bourdeau, J., \& Bates, A. (1996). Instructional design for distance learning. Journal of Science Education \& Technology, 5(4), 267-283.

Christensen, C. (2000). The innovator's dilemma: The revolutionary book that will change the way you do business. New York: Harper Business.

Hunter, M. (1994). Enhancing teaching. Upper Saddle River, NJ: Pearson Education.

Moore, M. (1997). Theory of transactional distance. In D. Keegan (Ed.), Theoretical principles of distance education (pp. 22-38). London: Routledge. Retrieved from: http://www.aged.tamu.edu/research/readings/Distance/1997MooreTransDistance.pdf

Moore, M. (1985). Some observations on current research in distance education. Epistolodidaktika, 1, 35-62.

Mortera-Gutiérrez, F. (2006). Faculty best practices using blended learning in e-learning and face-to-face instruction. International Journal on E-Learning, 5(3), 313-337.

O’Reilly, T. (2005). What is web 2.0? Design patterns and business models for the next generation of software. Retrieved from http://oreilly.com/web2/archive/what-is-web20.html.

Siemens, G. (2006). Knowing knowledge. Vancouver: Lulu Press. Retrieved from http://www.elearnspace.org/KnowingKnowledge LowRes.pdf.

Taylor, J. (1995). Distance education technologies: The fourth generation. Australian Journal of Educational Technology, 11(2), 1-7. Retrieved from http://www.ascilite.org.au/ajet/ajet11/taylor.html.

Taylor, J. (2001). Fifth generation distance education. e-Journal of Instructional Science \& Technology, 4(1), 1-14. Retrieved from http://eprints.usq.edu.au/136/.

Taylor, J. (2010). Sustainable higher education learning futures. Keynote address, AACE conference: Global Learn Asia Pacific, Penang. 


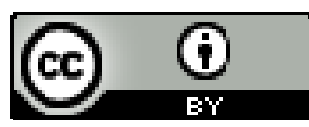

Athabasca University 


\title{
70. Universal Instructional Design Principles for Moodle
}

\section{Tanya Elias}

Athabasca University, Canada

\begin{abstract}
This paper identifies a set of universal instructional design (UID) principles appropriate to distance education (DE) and tailored to the needs of instructional designers and instructors teaching online. These principles are then used to assess the accessibility level of a sample online course and the availability of options in its LMS platform (Moodle ${ }^{\mathrm{TM}}$ ) to increase course accessibility. Numerous accessibility-sensitive plug-in modules are found to be available to Moodle users, though relatively few features were included in the sample course analysed. This may be because they have not been made available to instructors at the institutional level. The paper offers a series of recommendations to improve the accessibility of online DE to learners with diverse abilities, disabilities, and needs.
\end{abstract}

Keywords: Universal instructional design; distance education; learning management systems; Moodle

\section{Universal Instructional Design Principles and Distance Education}

DE students may face a variety of physical, learning, psychological, visual, and hearing challenges (Moisey, 2004). As well, the nature of contemporary online DE presents other unique types of diversity challenges. Students studying at a distance are often in diverse geographic locations, physically isolated from one another, the institution, and their instructors. Students also demonstrate diversity in their study schedules, timelines, and work and family commitments, all of which affect their availability to study. Moreover, differences exist in their technical skills and levels of online connectivity. Universal instructional design (UID) principles have been developed in order to generate products and services appropriate to the widest range of diversity (Burgstahler, 2001; Council for Exceptional Children, 2005), and it is instructive to examine the extent to which standard online learning management systems (LMS) have made use of these principles. 
Burgstahler (2007) describes UID as:

...the design of instructional materials and activities that make the learning goals achievable by individuals with wide differences in their abilities to see, hear, speak, move, read, write, understand English, attend, organise, engage, and remember. Universal design for learning is achieved by means of flexible curricular abilities. These alternatives are built into the instructional design and operating systems of educational materials - they are not added on after-the-fact. (p. 1)

Thus, when online learning is designed using these principles, the resulting products and environments meet the needs of potential users with a wide variety of characteristics. In a graduate course text forum attended by this writer, Baggaley explained,

The ultimate acid test of online software is its ability to cater to users with disabilities. Software which effectively serves their needs could just be the best software for all users. A case in point is iVocalize, an audio-conferencing software designed by a disabled designer for others with similar hurdles, which is quite simply the most user-friendly audio-conferencing software I have encountered. (Personal communication, October 8, 2009)

UID features make learning more accessible to learners with disabilities, and these can be useful to diverse learners. In the case of open source learning management systems, these features are openly available for customisation.

Based on the existing principles of UID (Connell et al., 1997; Scott et al., 2002), the current study identified a set of eight UID principles tailored to DE. Only one of the original UID principles (size and space for approach and use) was removed from this list. Otherwise, the existing UID principles and their accompanying definitions required only minor revisions to reflect the types of diversity found among online distance learners.

\section{Eight UID Principles Tailored to Distance Education}

1. Equitable use. The design is useful and accessible for people with diverse abilities and in diverse locations. The same means of use should be provided for all students, identically whenever possible or in an equivalent form when not.

2. Flexible use. The learning design accommodates a wide range of individual abilities, preferences, schedules, and levels of connectivity. Provide the learners with choice in methods of use. 
3. Simple and intuitive. The course interface design is easy to understand, regardless of the user's experience, knowledge, language skills, technical skills, or current concentration level. Eliminate unnecessary complexity.

4. Perceptible information. The design communicates necessary information effectively to the user, regardless of ambient conditions or the student's sensory abilities.

5. Tolerance for error. The design minimises hazards and adverse consequences of accidental or unintended actions.

6. Low physical and technical effort. The design can be used efficiently and comfortably and with minimal physical and mental fatigue.

7. Community of learners and support. The learning environment promotes interaction and communication among students and between students, faculty, and administrative services.

8. Instructional climate. Instructor comments and feedback are welcoming and inclusive. High expectations are espoused for all students.

In developing this list of DE-related UID principles, two prime questions arose:

1) What strategies and tools are currently available to implement the principles?

2) Are available tools and strategies being used currently to enhance efficient accessibility?

\section{Methodology}

The above principles and a review of accessibility-related product lists and literature (Adaptive Technology Resource Centre, 2010; Special Needs Ontario Window, 2010; Resource Support Centre, n.d.; Council for Exceptional Children, 2005) generated 40 categories of online course accessibility for the study (see Table 1).

Table 1

Universal Instructional Design Principles and Categories of Online Course Accessibility

\begin{tabular}{|l|l|}
\hline UID principle & \multicolumn{1}{|}{$\begin{array}{l}\text { Categories of online course } \\
\text { accessiblity }\end{array}$} \\
\hline Equitable use & 1) All content online \\
& 2) “Anywhere Anytime” \\
& 3) Translator \\
\hline Flexible use & 4) Mind maps/diagram displays \\
& 5) Conferencing tools \\
\hline
\end{tabular}




\begin{tabular}{|c|c|}
\hline & $\begin{array}{l}\text { 6) Video/audio presentation tools } \\
\text { 7) Slide presentation tools } \\
\text { 8) Video/audio assignment tools } \\
\text { 9) Links to additional information } \\
\text { 10) Choice of study topics/ assignments }\end{array}$ \\
\hline Simple and intuitive use & $\begin{array}{l}\text { 11) Resume course } \\
\text { 12) Simple interface } \\
\text { 13) Direct link to new posts } \\
\text { 14) Easy-to-navigate menus } \\
\text { 15) Books } \\
\text { 16) Searchable forums } \\
\text { 17) Searchable content } \\
\text { 18) Mobile interface } \\
\text { 19) Text-only interface } \\
\text { 20) Offline resources }\end{array}$ \\
\hline Perceptible information & $\begin{array}{l}\text { 21) Screen preferences, font size, masking, } \\
\text { colours } \\
\text { 22) Screen/document readers } \\
\text { 23) Text-to-speech } \\
\text { 24) Screen/cursor magnifiers } \\
\text { 25) Transcription } \\
\text { 26) Captions }\end{array}$ \\
\hline Tolerance for user error & $\begin{array}{l}\text { 27) Ability to edit after posting } \\
\text { 28) Confirmation before sending } \\
\text { assignments } \\
\text { 29) Warnings when leaving course site }\end{array}$ \\
\hline Technical and physical effort & $\begin{array}{l}\text { 30) Voice recognition } \\
\text { 31) Word prediction } \\
\text { 32) Built-in assistive technologies } \\
\text { 33) Limited use of external links } \\
\text { 34) Embedded multimedia/ assistive } \\
\text { technologies } \\
\text { 35) Browser capability checker }\end{array}$ \\
\hline Learner community and support & $\begin{array}{l}\text { 36) Study group } \\
\text { 37) Links to support services }\end{array}$ \\
\hline Instructional climate & $\begin{array}{l}\text { 38) Involvement in discussion forums } \\
\text { 39) Regular email contact with students } \\
\text { 40) Availability for one-on-one } \\
\text { consultation }\end{array}$ \\
\hline
\end{tabular}


A sample online course was then examined in relation to its current level of accessibility in these categories. The course was Introduction to Educational Technology, an online graduate course at Athabasca University (AU) in Canada, delivered using the popular open source LMS, Moodle ${ }^{\mathrm{TM}}$. The student population of the sample course was comprised of adult learners with diverse abilities, learning styles, schedules, and geographic locations. This study reviewed the course site and its learning materials and included interviews with students and the course teacher during the fall 2009 semester. Analysis of the course website's features was encouraged by the instructor in the interests of improving the site via formative evaluation. At the time of the analysis, version 1.92 of Moodle was being used at AU; since then, it has been upgraded to version 1.97.

Using the same accessibility categories, the wider range of features available in Moodle, though not necessarily used at AU, was considered. The Moodle.org website indicates that there are currently over 49,000 registered Moodle sites in 210 countries with over 34 million users (Moodle, 2010). As an open source product, Moodle is flexible in its customisations, and its use is limited by the knowledge, learning, resources, and innovative spirit of its users rather than by the proprietary rights of vendors (Weber, 2003). Batpurev et al. (2009), in a study of Moodle’s use in Mongolia, found that its feature-richness was one of Moodle's best attributes. In April 2010, the Moodle.org community site offered 632 modules and 131 themes for customising various facets of the learning environment. The current analysis assigned each module to an accessibility category based on a reading of the summaries of each module and theme. It is emphasised that the quality of the modules was not assessed. Moreover, the Moodle (2010) site carries the following disclaimer:

WARNING: Please be aware that some of these items have not been reviewed, and the quality and/or suitability for your Moodle site has not been checked. The modules here may have security problems, data-loss problems, interface problems or just plain not work. Please think carefully about maintenance before relying on contributed code in your production site, as some of this code may not work with future versions of Moodle.

Therefore, the current analysis does not attempt to assess the actual quality of the Moodle modules or to encourage the use of specific modules or themes. It provides instead an overall impression of the types and number of available modules in order to illustrate the potential for improving access to online course platforms generally.

\section{Formative Evaluation Results and Recommendations}

A substantial number of assistive technologies and multimedia options have been integrated into Moodle modules. It was determined that a series of standard product features (v. 1.7 and above), as well as 121 modules and themes, have the potential to enhance the accessibility of online courses. The features and modules were identified as meeting $79 \%$ of the UID accessibility 
criteria relevant to online learning. Relatively few accessibility-related Moodle modules were integrated into the sample online course, which demonstrated implementation of only $26 \%$ of the accessibility categories. This was due to the limited availability of these modules in the default Moodle platform made available to instructors institutionally (Baggeley, personal communication). Most of the categories represented in the sample course related to the application of pedagogical strategies using standard Moodle features.

Based on these findings, a series of recommendations for supporting the implementation of the UID principles for DE has been developed, relating to the customisation and use of LMS technologies. The recommendations emphasise the integration of pedagogical strategies and technical tools in online education in order to meet the diverse abilities, disabilities, and needs of online learners more efficiently.

\section{Equitable Use}

According to the UID principles for DE, course design should facilitate equitable use. The design must be useful to and accessible by people with diverse abilities and in diverse locations (Table 2).

Table 2

Availability of Moodle Modules Serving the Equitable Use Principle

\begin{tabular}{|lccc|}
\hline Equitable use & $\begin{array}{c}\text { Available in } \\
\text { Moodle? }\end{array}$ & $\begin{array}{c}\text { Used in sample } \\
\text { course? }\end{array}$ & Number of modules \\
\hline All content online & $\mathrm{Y}$ & $\mathrm{Y}$ & Standard feature \\
\hline “Anywhere Anytime” & $\mathrm{Y}$ & $\mathrm{Y}$ & Standard feature \\
\hline Translator & $\mathrm{Y}$ & $\mathrm{N}$ & 4 \\
\hline
\end{tabular}

\section{Recommendations.}

- Put content online. Online files should be directly accessible by screen reader, text-tospeech, and screen preferences programs, which make content more accessible, and eliminate the need to adapt textbooks.

- Provide translation. Language barriers present a problem for many learners. The incorporation of translation modules can help learners for whom English is a foreign language. Four Moodle modules incorporating Google translation features were identified. 


\section{Flexible Use}

UID principles relevant to DE also prescribe flexible use. Course design should accommodate a wide range of individual abilities, preferences, schedules, levels of connectivity, and choices in methods of use (Table 3).

Table 3

Availability of Moodle Modules Serving the Flexible Use Principle

\begin{tabular}{|lcccc|}
\hline Flexible use & $\begin{array}{l}\text { Available } \\
\text { Moodle? }\end{array}$ & $\begin{array}{c}\text { in } \\
\text { Used in sample } \\
\text { course? }\end{array}$ & Number of modules \\
\hline Links to additional information & $\mathrm{Y}$ & $\mathrm{Y}$ & Standard feature \\
\hline Choice of topics/ assignments & $\mathrm{Y}$ & $\mathrm{Y}$ & Standard feature \\
\hline Conferencing tools & $\mathrm{Y}$ & Text only & 22 \\
\hline Audio/video presentation tools & $\mathrm{Y}$ & External only & 15 \\
\hline Slide presentation tools & $\mathrm{Y}$ & External only & 4 \\
\hline Audio/video assignment tools & $\mathrm{Y}$ & $\mathrm{N}$ & 8 \\
\hline Mind maps/ diagram displays & $\mathrm{Y}$ & $\mathrm{N}$ & 5 \\
\hline
\end{tabular}

\section{Recommendations.}

- Make synchronous sessions optional. Asynchronous delivery allows students the flexibility to set diverse study schedules. Synchronous activities can be offered as options, or scheduled in small groups to meet scheduling needs. In addition, recordings of synchronous sessions can be made available to students who cannot attend live sessions. Students can also be given choice with respect to the content studied.

- Present content and accept assignments in multiple formats. Multimedia tools can be used to present content and assignments in multiple forms, providing the learner with flexibility and choice. Graphical representation of concepts using mind maps and diagrams increases the flexibility in use and is an excellent and available method to increase content accessibility. Learners with sensory disabilities, learning disabilities, and diverse learning styles can all benefit from content presented in redundant forms. These tools, however, should be integrated directly into the LMS (an issue revisited under the tolerance for error principle). Thirty-two Moodle modules are available currently to enable a variety of multimedia presentations.

- Offer choice and additional information. Offering links to additional information and choices of assignments and topics of study allows learners to be more active participants in the process. It also allows them to meet course requirements in a way that is best suited to their individual abilities, disabilities, and needs. 


\section{Simple and Intuitive Use}

In accordance with UID principles for DE, unnecessary complexity should be eliminated and course design should be simple and intuitive. The sample course demonstrated a typical weakness of the Moodle interface, the need to scroll through long lists to reach current information, such as new discussion posts. (Table 4).

Table 4

Availability of Moodle Modules Serving the Simple and Intuitive Principle

\begin{tabular}{|lccc|}
\hline Simple \& intuitive & $\begin{array}{c}\text { Available in } \\
\text { Moodle? }\end{array}$ & $\begin{array}{c}\text { Used in sample } \\
\text { course? }\end{array}$ & $\begin{array}{c}\text { Number of } \\
\text { modules }\end{array}$ \\
\hline Searchable forums & $\mathrm{Y}$ & $\mathrm{Y}$ & Standard feature \\
\hline Books & $\mathrm{Y}$ & $\mathrm{Y}$ & 3 \\
\hline Searchable content & $\mathrm{Y}$ & $\mathrm{N}$ & 2 \\
\hline Easy-to-navigate menus & $\mathrm{Y}$ & $\mathrm{N}$ & 19 \\
\hline Simple interface & $\mathrm{Y}$ & $\mathrm{N}$ & 8 \\
\hline Direct link to new posts & $\mathrm{Y}$ & $\mathrm{N}$ & 6 \\
\hline Resume at log-off place & $\mathrm{Y}$ & $\mathrm{N}$ & 3 \\
\hline Mobile interface & $\mathrm{Y}$ & $\mathrm{N}$ & 3 \\
\hline Offline resources & $\mathrm{Y}$ & $\mathrm{N}$ & 2 \\
\hline Text-only interface & $\mathrm{N}$ & $\mathrm{N}$ & 0 \\
\hline
\end{tabular}

\section{Recommendations.}

- Simplify the interface. The Moodle interface could be simplified by offering a series of buttons that link learners directly to the following: 1) the current week of study, 2) new discussion posts, and 3) the last log-off place. No scrolling would be required. From this simple interface, students could quickly and easily navigate course sites using organisational options in available Moodle modules to simplify access to content via collapsible menus and tabs. Finding information in course sites could also be improved by using enhanced search features. Although searchable discussion forums are a standard feature in Moodle, searchable course content is not comprehensive. Such improvements would be beneficial to those with sensory disabilities and attention and memory problems, as well as to distracted, busy adult learners generally.

- Offer text-only, mobile, and offline options. The current Moodle interface and other course resources are effective for online learners with fast Internet connections. In areas that lack high-bandwidth connections, however, Moodle’s loading speed creates a barrier to access. Some Canadian learners, such as those in the sample course and millions of potential learners in developing countries with low-bandwidth conditions, are restricted to dial-up Internet service (Baggaley, 2007; Batpurev et al., 2009). Simplified and 
mobile interfaces are currently available in Moodle. Although a text-only interface was not located among the modules and themes of the Moodle website, open source software (e.g., WebbIE) is available to translate websites into text-only interfaces. The existence of these open source products demonstrates the ability to increase accessibility by simplifying and improving the intuitiveness of course sites. Learners struggling with low levels of Internet connectivity might also benefit from course materials in offline formats (Batpurev et al., 2009).

\section{Perceptible Information}

Screen and font preferences, text-to-speech, screen readers, captions, and screen/cursor magnifiers can ensure that all learners have access to perceptible information (Table 5).

Table 5

Availability of Moodle Modules Serving the Perceptible Information Principles

\begin{tabular}{|lccc|}
\hline Perceptible information & $\begin{array}{c}\text { Available in } \\
\text { Moodle? }\end{array}$ & $\begin{array}{c}\text { Used in sample } \\
\text { course? }\end{array}$ & $\begin{array}{c}\text { Number of } \\
\text { modules }\end{array}$ \\
\hline $\begin{array}{l}\text { Screen preferences, font size, masking, } \\
\text { colours }\end{array}$ & $\mathrm{Y}$ & Limited & 3 \\
\hline Captions & $\mathrm{Y}$ & $\mathrm{N}$ & 3 \\
Text-to-speech & $\mathrm{Y}$ & $\mathrm{N}$ & 1 \\
\hline Screen/document readers & $\mathrm{N}$ & $\mathrm{N}$ & 0 \\
\hline Screen/cursor magnifiers & $\mathrm{N}$ & $\mathrm{N}$ & 0 \\
\hline Transcription & $\mathrm{N}$ & $\mathrm{N}$ & 0 \\
\hline
\end{tabular}

\section{Recommendations.}

- Incorporate assistive technologies. Although external assistive technologies can be used in conjunction with online course materials, these tools should be integrated into the LMS itself, according to the principles of UID (Council for Exceptional Children, 2005). Many of these features already exist in multiple Moodle modules and themes.

- Add captions, descriptors, and transcriptions. Video- and audio-conferencing can present a significant obstacle to accessibility. Moisey (personal communication, November 20, 2009) indicates: "You can go over the recording afterward if you need to....and you can boost the volume, but other than that, there is really no way of making it more accessible" for students who are hearing impaired. Poor connections and language barriers can be exacerbated by LMS features. A conferencing system with transcriptions would help to make conference recordings more searchable for all users. Captions and transcription, for which no existing modules were located in Moodle during this analysis, are available in 
other open source software (Resource Support Centre, 2010) and should be considered in order to improve the accessibility of online course platforms generally.

\section{Tolerance for User Error}

UID principles also minimise hazards and adverse consequences of errors in software operation by designing learning environments with a tolerance for error (Table 6).

Table 6

Availability of Moodle Modules Serving the Tolerance for User Error Principle

\begin{tabular}{|lccc|}
\hline Tolerance for error & $\begin{array}{c}\text { Available in } \\
\text { Moodle? }\end{array}$ & $\begin{array}{c}\text { Used in sample } \\
\text { course? }\end{array}$ & $\begin{array}{c}\text { Number of } \\
\text { modules }\end{array}$ \\
\hline Ability to edit after posting & $\mathrm{Y}$ & $\mathrm{Y}$ & Standard feature \\
\hline $\begin{array}{l}\text { Confirmation before sending } \\
\text { assignments }\end{array}$ & $\mathrm{N}$ & Text only & 0 \\
\hline Warnings when leaving course site & $\mathrm{N}$ & Text only & 0 \\
\hline
\end{tabular}

\section{Recommendations.}

- Allow students to edit their posts. Incomplete and incorrect discussion posts can be accidently uploaded by students. If they have been composed outside the Moodle site, their appearance can change after being uploaded. Allowing learners to correct such mistakes is essential because it supports learner confidence in the use of the technology.

- Issue warnings using text and sound. Resources used by users outside the course website might not be as benign as those within the course site. Notes in the course materials should identify and warn students about potential risks. Leaving the course website without logging out, for example, can expose users to security risks, especially if they are required to enter personal information to access the online software. Students who are less technologically aware can be vulnerable to identity theft, phishing, unwanted marketing, and computer viruses. Text-only warnings about such risks and critical announcements about assignments can be overlooked by students, and their importance could be stressed by the use of images and sound. A pop-up window and "ping" sound to warn students that they are about to leave the course site, for example, would make the site more error-tolerant. 


\section{Technical and Physical Effort}

Ideally, online learning should require a low level of technical and physical effort compared with on-campus learning. Issues related to physical effort, however, should still be considered when designing online learning (Table 7).

Table 7

Availability of Moodle Modules Serving the Low Technical and Physical Effort Principle

\begin{tabular}{|lccc|}
\hline Low technical \& physical effort & $\begin{array}{c}\text { Available in } \\
\text { Moodle? }\end{array}$ & $\begin{array}{c}\text { Used in sample } \\
\text { course? }\end{array}$ & $\begin{array}{c}\text { Number of } \\
\text { modules }\end{array}$ \\
\hline Built-in assistive technologies & $\mathrm{Y}$ & $\mathrm{N}$ & Many \\
\hline Limited use of external links & $\mathrm{Y}$ & $\mathrm{N}$ & Many \\
\hline $\begin{array}{l}\text { Embedded multimedia/ assistive } \\
\text { technologies }\end{array}$ & $\mathrm{Y}$ & $\mathrm{N}$ & Many \\
\hline Browser capability checker & $\mathrm{Y}$ & $\mathrm{N}$ & 1 \\
\hline Voice recognition & $\mathrm{N}$ & $\mathrm{N}$ & 0 \\
\hline Word prediction & $\mathrm{N}$ & $\mathrm{N}$ & 0 \\
\hline
\end{tabular}

\section{Recommendations.}

- Consider issues of physical effort. Long periods of typing can create physical discomfort and reduce hand mobility. Assistive technologies, including voice recognition and word prediction, would help to meet the diverse needs of students, including those who are not normally disabled.

- Incorporate assistive technologies and multimedia, and embed links. Although online course materials can be accessed using external assistive technologies, their use is likely to lead to higher levels of mental fatigue if they are not integrated into the course platform. For example, if the text size in a discussion forum reply box cannot be increased, a visually impaired student may have to 1) increase the size of the text, 2) copy it into external word-processing software, and 3) return to the Moodle site to paste it in the box for uploading. Extensive use of external links and external programs in this way increases the technical effort required by all users. Integrating available Moodle modules to enable the use of sound and video and other assistive technologies built directly into the course site can help to reduce the physical and mental fatigue of online learners.

- Include a way to check browser capabilities. A useful optional Moodle module is a browser capability checker. At the beginning of a course, the students can be given a list of required and optional plug-ins and other software to access course materials. The checker then indicates the products correctly installed with a green check mark. Helping 
students to identify technological requirements at the beginning of a course could save them from technical frustration later on.

\section{Learner Community and Support}

The use of discussion forums in LMS-mediated online courses results in a sense for learners of community and support (Table 8).

Table 8

Availability of Moodle Modules Serving the Community of Learners and Support Principle

\begin{tabular}{|lccc|}
\hline $\begin{array}{l}\text { Community of learners \& } \\
\text { support }\end{array}$ & $\begin{array}{c}\text { Available in } \\
\text { Moodle? }\end{array}$ & $\begin{array}{c}\text { Used in sample } \\
\text { course? }\end{array}$ & $\begin{array}{c}\text { Number of } \\
\text { modules }\end{array}$ \\
\hline Links to support services & $\mathrm{Y}$ & Small font & Standard feature \\
\hline Study group & $\mathrm{Y}$ & Limited & 2 \\
\hline
\end{tabular}

\section{Recommendations.}

- Provide study groups and tools. The development of a sense of community outside the online class environment, however, can often be limited. Several available Moodle modules enable students to study together and to share marked-up text with one another. Such features can help to develop a sense of purpose and cohesiveness among small groups and can enable learners with diverse needs and disabilities to feel like less of a burden to the group. Developing stronger ties among learners in this way could also create a peer support network for solving technical problems, for example, when no other assistance is available.

- Provide easy-to-find links to support services. Links for students to services, including administration, library, and other supportive services, need to be accessible to online students directly from the LMS in a way not necessary on-campus. Links to these services should be prominently and consistently placed on every course page. Therefore, when considering a simplified interface, course developers should also consider the font size and placement of these links.

\section{Instructional Climate}

The UID principle instructional climate concentrates specifically on the impact of the instructor delivering a course as opposed to the course design (Table 9). 
Table 9

Availability of Moodle Modules Serving the Instructional Climate Principle

\begin{tabular}{|lccc|}
\hline Instructional climate & $\begin{array}{c}\text { Available in } \\
\text { Moodle? }\end{array}$ & $\begin{array}{c}\text { Used in sample } \\
\text { course? }\end{array}$ & $\begin{array}{c}\text { Number of } \\
\text { modules }\end{array}$ \\
\hline $\begin{array}{l}\text { Involvement in discussion } \\
\text { forums }\end{array}$ & $\mathrm{Y}$ & $\mathrm{Y}$ & Standard feature \\
\hline $\begin{array}{l}\text { Availability for one-on- } \\
\text { one consultation }\end{array}$ & $\mathrm{Y}$ & $\mathrm{Y}$ & Standard feature \\
\hline $\begin{array}{l}\text { Regular email contact with } \\
\text { students }\end{array}$ & $\mathrm{Y}$ & $\mathrm{Y}$ & 7 \\
\hline
\end{tabular}

\section{Recommendations.}

- Encourage instructors to make contact and stay involved. Course instructors must be highly engaged in the discussion forums, and they must make posts that clarify, ask questions, and focus the discussion on important topics in a way that fosters learning and creates high expectations for all learners in an atmosphere of inclusivity. The instructor in the sample course also sent private email announcements to students on a regular basis. Regular contact through the use of group emails, one-on-one email, Skype, and telephone can help to ensure student success and to enhance an online course. Instructor accessibility is an essential component of course accessibility. Clear expectations in terms of comments, feedback, and inclusivity should be set for all course instructors to help them help their learners.

\section{Conclusions}

"Inclusive education values diversity. As such, learning materials are designed so that all learners are included - the best way to do so is to avoid erecting barriers" (Moisey, personal communication, November 17, 2009). A wide range of features to reduce barriers and increase accessibility is available for the popular Moodle learning management system. If these are not adequately used in the Moodle platforms provided by educational institutions, an incorrect impression may be gained that Moodle does not provide comprehensive and accessible options. By way of illustration, relatively few of the features fulfilling UID and accessibility goals had been made available for the sample online course examined in this study; and it remains to be seen whether UID principles are being widely implemented in other online courses. Institutions interested in addressing accessibility issues should evaluate and exploit the potential of the LMS products available to them and should invest in training and support for their course designers and instructors on the benefits of implementing UID strategies. Research is required to consider how assistive technologies and solid pedagogical approaches can remove barriers to educational diversity and disability. 


\section{References}

Adaptive Technology Resource Centre (2010). Accessibility and usability testing [online resource]. Retrieved from http://atrc.utoronto.ca/index.php?option=com content\&task=blogcategory\&id=26\&Itemi $\underline{\mathrm{d}=109}$

Baggaley, J. (2007). Distance education technologies: An Asian perspective. Distance Education, 28(2), 125-131.

Batpurev, B., Hewagamage, K., Peiris, K., \& Weerakoon, W. (2010). Open-source software for learning management. In J. Baggaley \& T. Belawati (Eds.), Distance education technology in Asia. New Delhi: Sage India. Retrieved from http://www.pandoraasia.org/downloads/Book-2/PANdora-book2_v6-Chap8.pdf

Burgstahler, S. (2001). Equal access: Universal design of instruction methods. Seattle, WA: Do-IT, University of Washington. Retrieved from http://www.washington.edu/doit/Brochures/PDF/equal_access_udi.pdf

Burgstahler, S. (2007). Universal design of instruction: Definition, principles, and examples.

University of Washington. Retrieved from

http://www.washington.edu/doit/Brochures/Academics/instruction.html

Connell, B., Jones, M., Mace, R., Mueller, J., Mullick, A., \& Ostroff, E. (1997). The principles of universal design. Retrieved from http://www.design.ncsu.edu/cud/about_ud/udprincipleshtmlformat.html

Council for Exceptional Children (2005). Universal design for learning: A guide for teachers and education professionals. Arlington, VA: Pearson Education.

Moisey, S. (2004). Students with disabilities in distance education: Characteristics, course enrollment and completion, and support services. Journal of Distance Education, 19(1), 73-91. Retrieved from http://www.jofde.ca/index.php/jde/article/view/106

Moodle (2010). About Moodle. Retrieved from http://Moodle.org/about/

Regional Support Centre. (2010. The assessor's guide to freeware and open source software alternatives. JISC Regional Support Centre, Scotland North \& East.

Scott, S., McGuire, J., \& Shaw, S. (2003). Universal design for instruction: A new paradigm for adult instruction in postsecondary education. Remedial \& Special Education, 24(6), 369379 . 
Special Needs Ontario Window (2010). Adaptive technology products. Retrieved from http://snow.utoronto.ca/index.php?option=com_content\&task=view\&id=178\&Itemid=12 $\underline{9}$

WebbIE (2010). The free browser for people with little or no sight. Retrieved from http://www.webbie.org.uk

Weber, S. (2002). Open source software in developing economies. California: Berkeley.

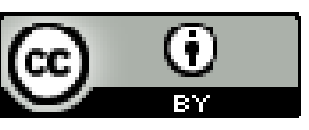

